\title{
Energy
}

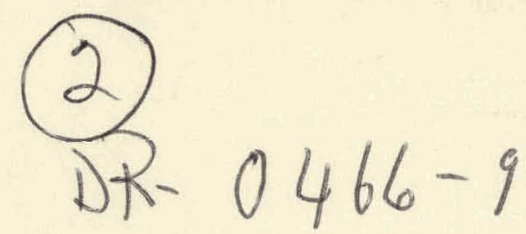

PULSED-FLOW AIR CLASSIFICATION FOR WASTE TO

\section{ENERGY PRODUCTION}

Final Report

By

J. Jeffrey Peirce

P. Aarne Vesilind

September 30, 1983

Work Performed Under Contract No. AC05-79CS20544

Duke University

Durham, North Carolina

Technical Information Center

Office of Scientific and Technical Information United States Department of Energy 


\section{DISCLAIMER}

This report was prepared as an account of work sponsored by an agency of the United States Government. Neither the United States Government nor any agency Thereof, nor any of their employees, makes any warranty, express or implied, or assumes any legal liability or responsibility for the accuracy, completeness, or usefulness of any information, apparatus, product, or process disclosed, or represents that its use would not infringe privately owned rights. Reference herein to any specific commercial product, process, or service by trade name, trademark, manufacturer, or otherwise does not necessarily constitute or imply its endorsement, recommendation, or favoring by the United States Government or any agency thereof. The views and opinions of authors expressed herein do not necessarily state or reflect those of the United States Government or any agency thereof. 


\section{DISCLAIMER}

Portions of this document may be illegible in electronic image products. Images are produced from the best available original document. 


\title{
DISCLAIMER
}

\begin{abstract}
This report was prepared as an account of work sponsored by an agency of the United States Government. Neither the United States Government nor any agency thereof, nor any of their employees, makes any warranty, express or implied, or assumes any legal liability or responsibility for the accuracy, completeness, or usefulness of any information, apparatus, product, or process disclosed, or represents that its use would not infringe privately owned rights. Reference herein to any specific commercial product, process, or service by trade name, trademark, manufacturer, or otherwise dnes not necessarily constitute or imply its endorsement, recommendation, or favoring by the United States Government or any agency thereof. The views and opinions of authors expressed herein do not necessarily state or reflect those of the United States Government or any agency thereof.
\end{abstract}

This report has been reproduced directly from the best available copy.

Available from the National Technical Information Service, U. S. Department of Commerce, Springfield, Virginia 22161.

Price: Printed Copy A08

Microfiche A01

Codes are used for pricing all publications. The code is determined by the numbcr of pages in the publication. Information pertaining to the pricing codes can be found in the current issues of the following publications, which are generally available in must librarics: Energy Research Abstrasts (ERA); Government Reports Announcements and Index (GRA and I); Scientific and Technical Abstract Reports (STAR); and publication NTIS-PR-360 available from NTIS at the above address. 
FINAL REPORT

by :

J. Jeffrey Peirce, Ph.D.
P. Aarne Vesilind, Ph.D.

September 30,1983

Submitted to: Municipal Waste Division

U. S. Department of Energy

Forrestal Building: Room CE 323

1000 Independence Avenue, S.W.

Washingtori, D. C. 20585

ATTENTION: Mr. Donald $\mathrm{K}$. Walter

Center for Environmental Engineering

Department of Civil and Environmental Engineering Duke University

Durham, North Carolina 27706 
TABLE OF CONTENTS

Page

Acknowledgements

i i

Absledet

i i i

List of Exhibits

1

1. Chapter I: Executive Summary

34

2. Chapter II: Literature Search

49

3. Chapter III: Theory of Pulsed-Flow Classification

4. Chapter IV: Laboratory Analysis

83

5. Chapter V: Conclusions

Appendix 1: Notations

Appendix 2: Program Listing 


\section{ACKNOWLEDGEMENTS}

This project evolved with the support of Mr. Donald Walter of the Municipal Waste Division of the U. S. Department of Energy in Washington, D. C. Mr. John Mayberry monitored the project with frequent visits from the offices of EG \& G Idaho. The assistance and encouragement of these individuals is gratefully acknowledged.

The research tasks and final report are the result of a team effort. The results and analysis were obtained with the assistance of our graduate students: Mr. Richard Stessel and Ms. Barbara Wolf.

The manuscripts of the monthly reports, task reports and this final report were typed by Ms. Judith Edwards. All drafting is the art of Mr. Fred Avent. 


\section{ABSTRACT}

The development and testing of of pulsed-flow air classification for waste-to-energy production are discussed. Air classifiers, a potentially valuable unit operation in waste-to-energy production facilities, currently do not meet expectations in field applications. Standard designs generally permit large amounts of combustible material to escape as reject while producing a fuel that is high in metal and glass contaminants. pulsed-flow classification is presented as a concept which can avoid both pitfalls.

Municipal solid waste (MSW) is composed of particles which can be cataloged as combustible and non-combustible fractions by defining a density split between aluminum arid plastic: generally all other non-combustibles are more dense than aluminum, while all other combustibles are less dense than plastic. However, current designs for classifiers tend to separate complex MSW by aerodynamic characteristics which do not always produce the desired split based on density alone. Pulsed-flow classifiers are seen to offer a unique. solution to this puzzle. Compared to straight wall and zigzag classifiers, a more efficient pulsed-flow classifier, is seen to operate under laboratory conditions over a wider range of air flows.

In this report; each aspect of theory and laboratory testing is summarized:

- Particle characteristics

- Theory of pulsed-flow classification

- Laboratory testing

- Pulsed-flow air classification for waste-to-energy production

Conclusions from the research are summarized in the final section of this Final Report. 


\section{LIST OF EXHIBITS}

$\underline{\text { EXHIBIT }}$

TITLE

Page

Executive, 1

Municipal Solid Waste Particles

4 in Free-Fall

Executive 2

Particle and Parameter List:

8

Velocities of Particles from

First Eight Seconds Fal1

Executive 3

Theoretical Particle Velocities

and Accelerations in Free Fall

Executive 4

Particle Accelerations Referenced

10

to Time when Terminal Velocity

is Attained

Executive .5

Log of Accelerations of Falling

Particles at Times Before

Attaining Terminal Velocity 
Executive 6

Executive 7

Executive 8

Executive $y$

Executive 10

- Executivè 11

Executive 12

Executive 13

1

2

$$
\text { MSW }
$$

Thousands of Tons, as

Generated
17

Classifier

Separation Efficiency for Feed 1:

18

Aluminum and Plastic Plates

Separation Efficiency for Feed 2:

19

Shredded Aluminum and Plastic

Separation Efficiency for Feed 3:

20

Shredded Simulated Municipal Solid

Waste

Zag-Zag Velocity Grid

22

Stacked Triangle Velocity Grid́

23

Zag-Zag Air Classifier

25

36

MSW Components by Source

38 
Terminal Velocity Less-Than, and Percent Aluminum with

Terminal Velocity Greater-Than

classification Particles in a $\mathrm{Jig}$

Coefficient Equation Compared with Datapoints

Velocities of Particles for

First Eight Seconds Fall 
particles at Times Before

Attaining Terminal velocity 
"Cut and Quartering" 
CHAPTER I

PULSED-FLOW AIR CLASSIFICATION FOR WASTE-TO-ENERGY PRODUCTION

Garbage and trash, collectively referred to as Municipal Solid Waste (MSW) present an urgent disposal problem for cities throughout the world. Current efforts center on simple disposal either by direct burial or by burning to reduce volume prior to burial. Limited attempts also have been made at selected locations to pass MSW through processing plants which separate components for recycle or refinement into a refuse derived fuel (RDF). One unit operation generally found in RDF Eacilities is the air classifier.

Air classifier technology in RDF facilities has developed as a generally unsuccessful off-the-shelf application of mining and agricultural units. This paper discusses a new type of classifier called the pulsed-flow air classifier in terms of:

- Particle Characteristics

- Theory ot Pulsed-Flow Classification

- Laboratory lesting

- Pulsed-Flow Classification for Waste-to-Energy Production 
The motivation is to design a unit operation that separates by particle density and thus achieve the desired split between combustible organics and non-combustible inorganics.. The basis is a stop-start air motion which forces particles to keep accelerating rather than achieving terminal velocity.

\section{PARTICLE CHARACTERISTICS}

MSW is composed of particles which can be cataloged into combustible and non-combustible fractions by defining a density between that of aluminum and plastics; generally all other non-combustibles are more dense than aluminum, while all other combustibles are less dense than plastics. However, air classifiers separate by aerodynamic characteristics which do not always produce a split based on density alone. Separation is confused by aerodynamic characteristics of the particles. In field application dense particles which should report to the heavy fraction report to the light fraction due to airfoil behavior, while less dense particles that should report to the light fraction report to the heavy fraction due to compact shape.

Research has been conducted at Duke University which shows that the terminal velocities for aluminum and plastic MSW particles overlap so as to cause an overlap in fall times during a drop test. This research is discussed in detail below. The aerodynamic characteristics of the waste confound with the particle densities to produce an overlap which makes 
separation difficult. From studies done by the Environmental Protection Agency (EPA) [9] [10] and one for state of ohio; [7] as well as observations made during experimentation at Duke, it is assumed that plastic, paper, and aluminum are present almost exclusively in MSW as sheet material. Part of MCNabb's work at Duke involves the conducting of a drop test on different MSW components. [4] The separation in a standard air classifier is based largely on the attainment of different terminal velocities specific to the various MSW components. To predict what the behavior of MSW particles would be solely under conditions of falling in air, without the unknown effects of the air classifier confinements, particles are dropped from a height of $3.454 \mathrm{~m}$, and their times of fall recorded. In this manner, the behavior of the particles reaching terminal velocity under free-fall conditions is assessed. The data are shown. in Executive Exhibit 1 .

These data show that an overlap zone between combustible and non-combustible materials occurs in the range of fall velocities between aluminum and plastic. This range of densities is the range that is critical to air classifier separation necessary for optimizing RDF production, and is a focus of this research. 


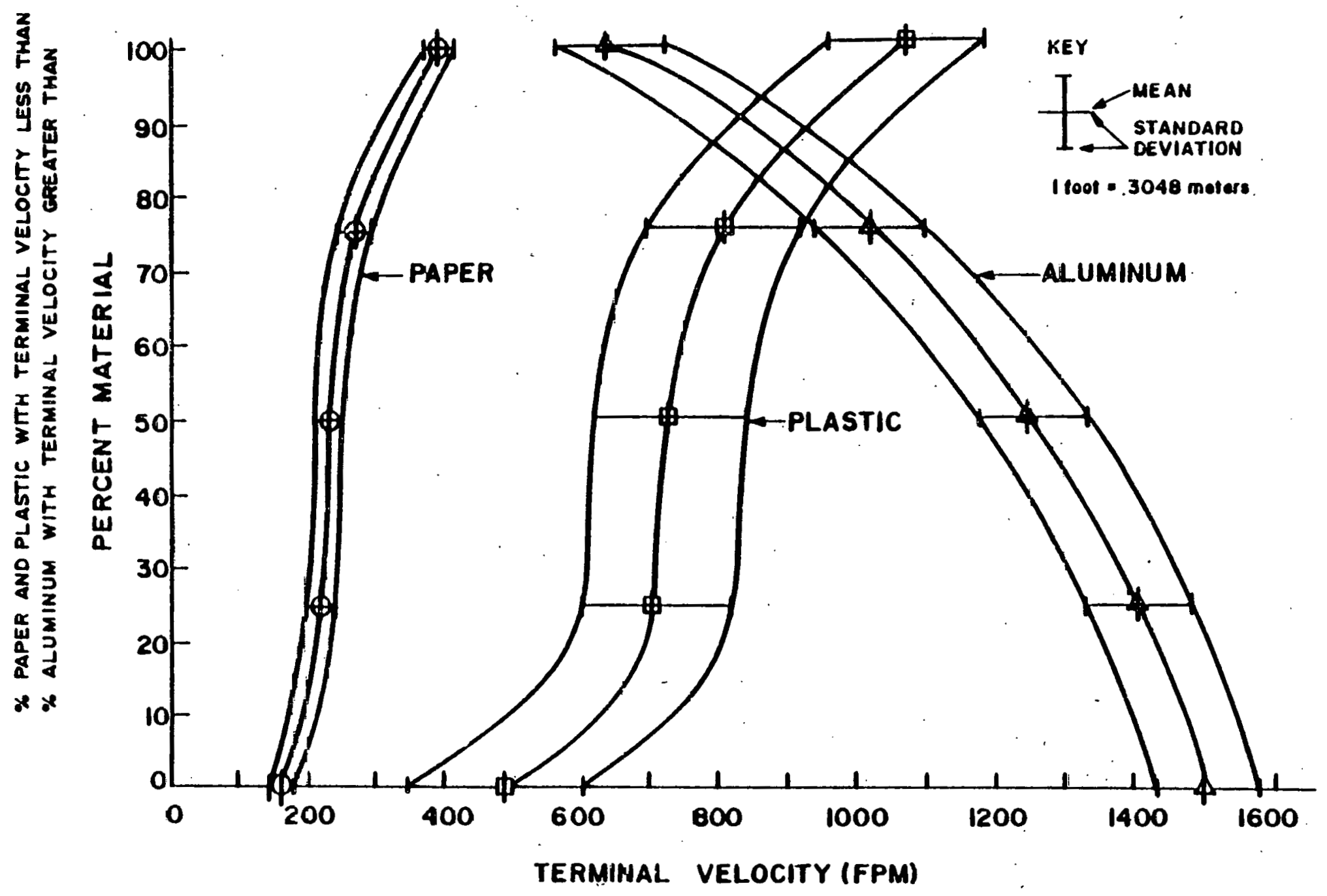

Executive Exhibit 1. Municipal Solid. Waste Particles in Free-Fall 
2. THEORY OF PULSED-ELOW CLASSIFICATION

To date the theory of air classification has largely been based on statistical inference. There have been three major contributors: Senden and Tels [8] in Eindhoven, The Netherlands, and Henrikson [2] at Duke University. All of this work considers zig-zag air classifiers. Zig-zag air classifiers are that type of classifier which is divided into stages, each of which consists of a straight throat segment slanted either left or right, opposite to its neighbors.

Both the models of Senden and Tels, and Henrikson, are important as descriptive models. If one has an air classifier which fits into one of the types on which their models are based, then one can use the model to determine the efficiency of performance. However, the major drawback of these models is that they do not help the designer optimize the configuration of the air classifier. The theory and experimentation of pulsed-flow classification addressed in this Report offers a new and potentially useful alternative. The basic model depends on a force balance of a particle falling in air. In simple form:

$$
F=E_{G}+F_{B}+F_{D}
$$

Al.1 terms are defined in Appendix 1. In order to use the similar idea for air classification, it is first necessary to modify the equation to suit the characteristics of particles 
6

falling in air. The use of the resulting quasi-static equation on the microprocessor' will be described 'in the next section.

The total force balance becomes:

$$
m g-\frac{1}{2} \circ_{F} \quad A\left(v_{D}:-\bar{v}_{A}\right)^{2} C_{D}=m \frac{d v_{p}}{d t}, \quad(1-2)
$$

Taking into account empirical results, discussed at length in the chapters of this Final Report the force balance may be written:

$$
\begin{aligned}
& \frac{d v_{j}}{\sigma \tau}=g-\frac{\theta_{f}^{A}}{2 m_{A}}\left[v_{\rho}-\bar{v}_{A}\right]^{2} \\
& {\left[\frac{3.8 \times 10^{-4}}{0\left(v_{0}-\bar{v}_{A}\right)}+\therefore \frac{6}{1+\sqrt{\frac{0\left(v_{0}-v_{A}\right)}{1.5 \times 10^{-5}}}+.4}\right](1-3)}
\end{aligned}
$$


All terms are specified in Appendix 1 , and a computer is utilized to numerically determine the velocity of any particle under consideration. [1] [3] [6] [11] [13] A sample application of Equation $1-3$ helps illustrates the theory of pulsed flow classification: Two spheres are selected as indicated in Executive Exhibit 2. Their respective velocities and accelerations are predicted following Equation 1-3; and the results are plotted in Executive Exhibit 3 . In both Executive Exhibits 2 and 3 note that the terminal velocity of sphere 1 is the higher of the two. One would expect, then, these two spheres to "confuse" a steady-flow classifier by sending the less dense particle out the bottom at the classifier with the heavy particle. Executive Exhibit 4 also shows the rates of acceleration for each particle at each time shown on the right. The acceleration values are calculated from the velocity values in Executive Exhibit 3. Executive Exhibit 4 shows that, as with velocity, acceleration values for sphere 1 are always higher. (The mechanics of the integration system in the computer prevents the accelerations from completely reaching zero.) Observe that the behavior of the particles could be examined on the basis of the time back from terminal velocity. For example, it may not be of interest to compare both spheres " $x$ " seconds after they begin to fall, but rather, of more interest to compare both particles "y" seconds before each reaches terminal velocity. 


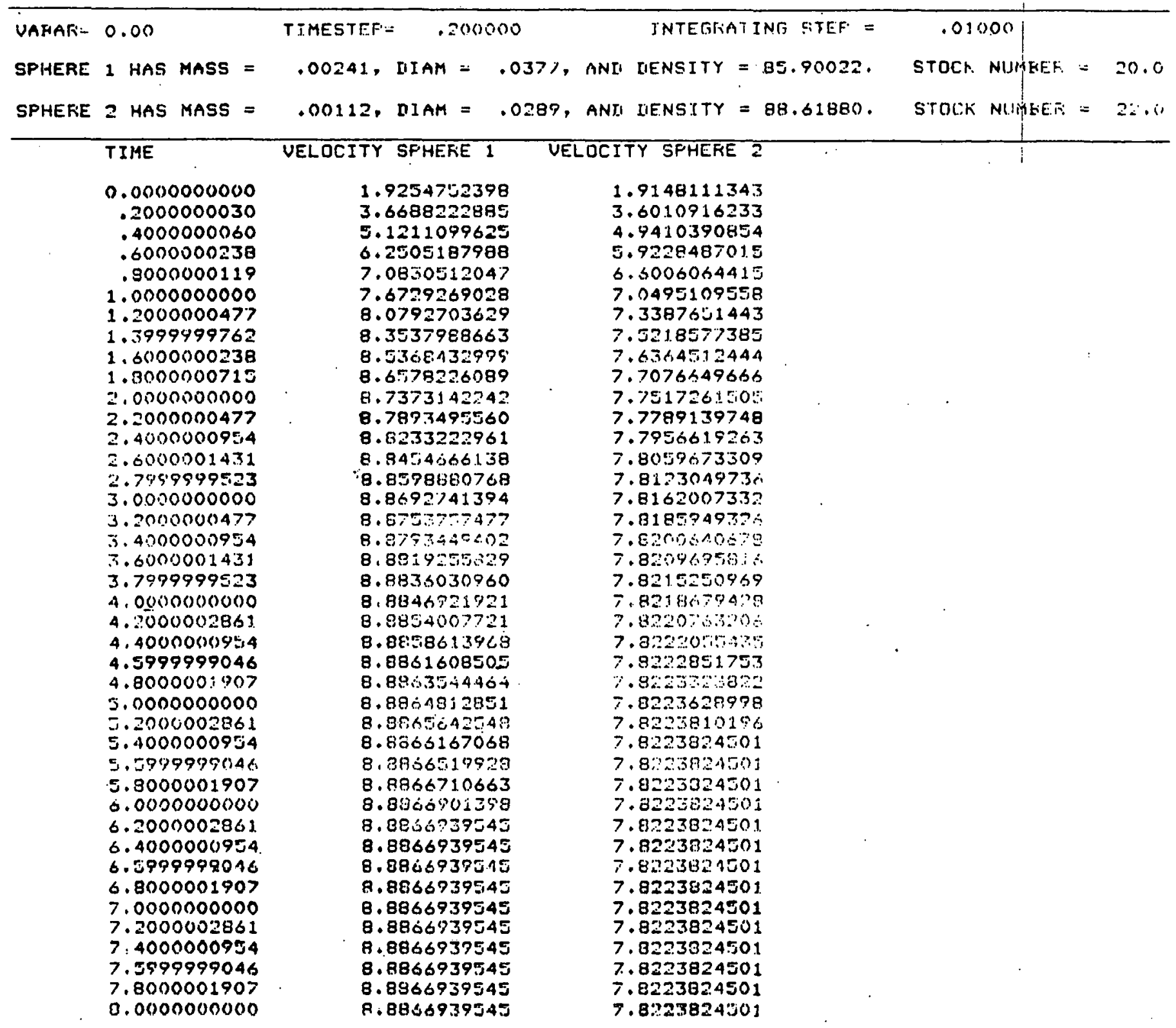

Executive Exhibit 2. Particle and Parameter List; Velocities of Particles for First Eight Seconds Fall 


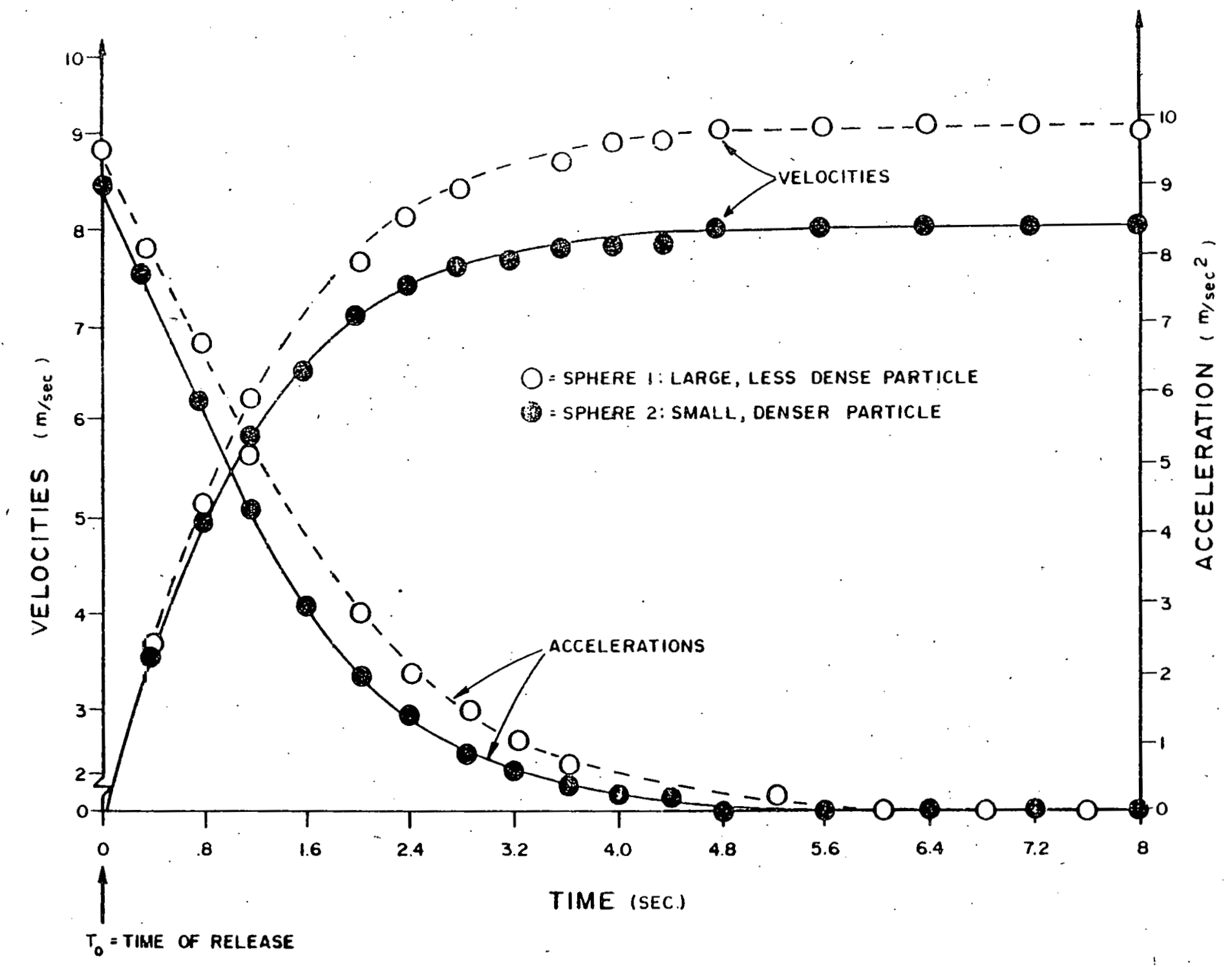

Executive Exhibit 3. Theoretical Particle Velocities and Accelerations in Free-Fall 


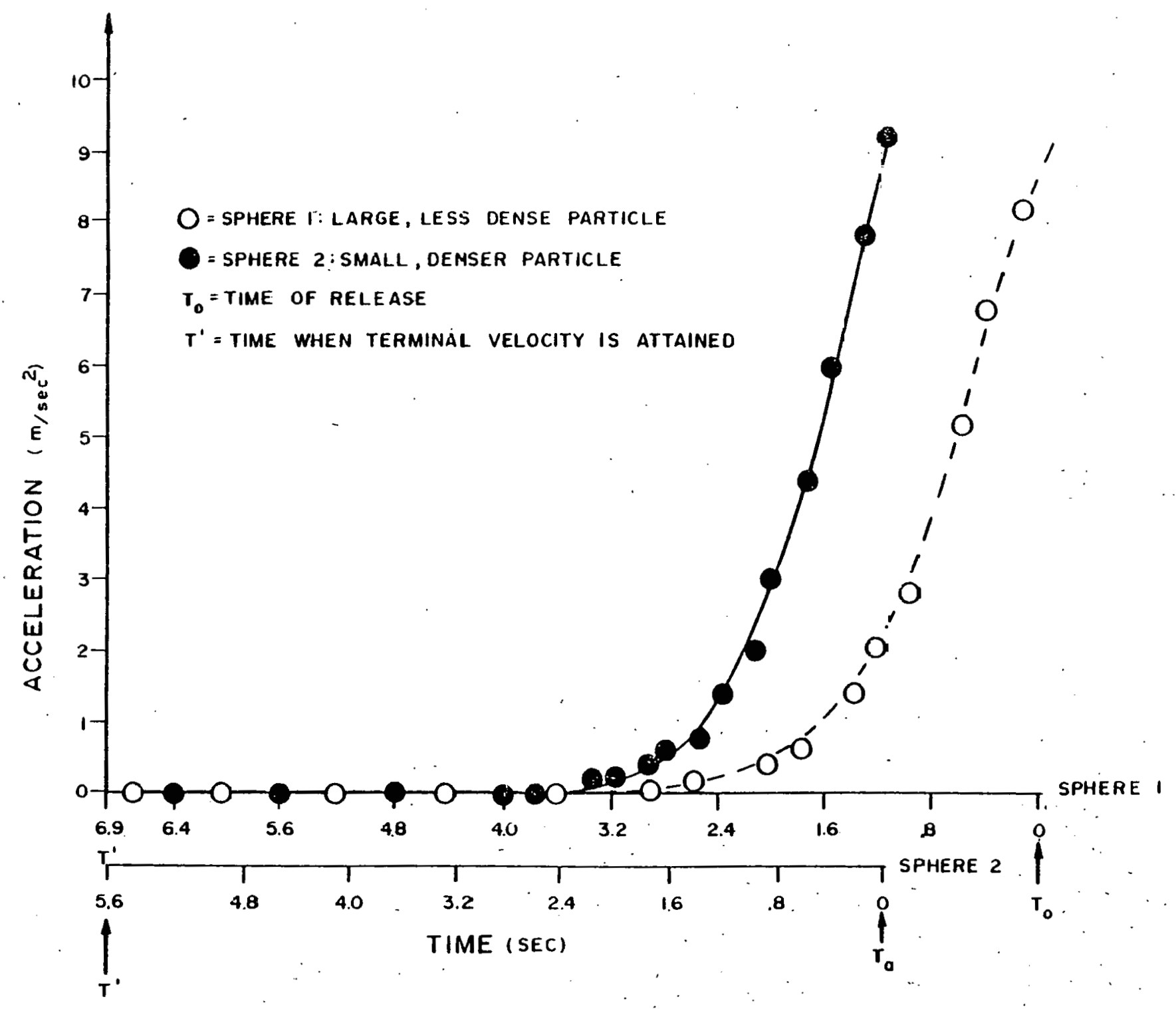

Executive Exhibit 4. Particle Accelerations Referenced to Time When Terminal Velocity is Attained 
Executive Exhibit 4 shows the accelerations of spheres 1 and 2 referenced to the time when terminal velocity is attained, $T^{\prime}$. The purpose is to align the times of reaching terminal velocity for each particle. Executive Exhibit 5 is. a Eurther refinement of Executive Exhibit 4 modified to show the diftail important to this discussion. In Executive Exhibit 5 the time axis is redefined with $T^{\prime}=0$ to indicate seconds before attainment of terminal velocity. The data are again taken directly from Executive Exhibit 2 with the constant acceleration shown at terminal velocity subtracted from each value so that terminal velocity exhibits zero acceleration. Executive Exhibit 5 uses the log of the accelerations to compress the range and illustrate the exponential behavior of the acceleration. A best-fit line is also drawn for each particle.

Executive Exhibit 5 shows that, for the first few timesteps before terminal velocity, the acceleration of sphere 1 remains higher than sphere 2 , just as it did in Executive Exhibit 4. Somewhere around 1.6 seconds before terminal velocity, however, the lines cross at point $A$, and the particle with the higher terminal velocity has the lower acceleration: Thus, if one could, through pulsing, prevent sphere 2 from attaining terminal velocity for periods long enough to allow its average acceleration to be higher than that of sphere 1 , sphere 2 would, eventually accelerate to a higher falling velocity than sphere 1 . The dense sphere 2 would then fall out the bottom of the classifier as desired 


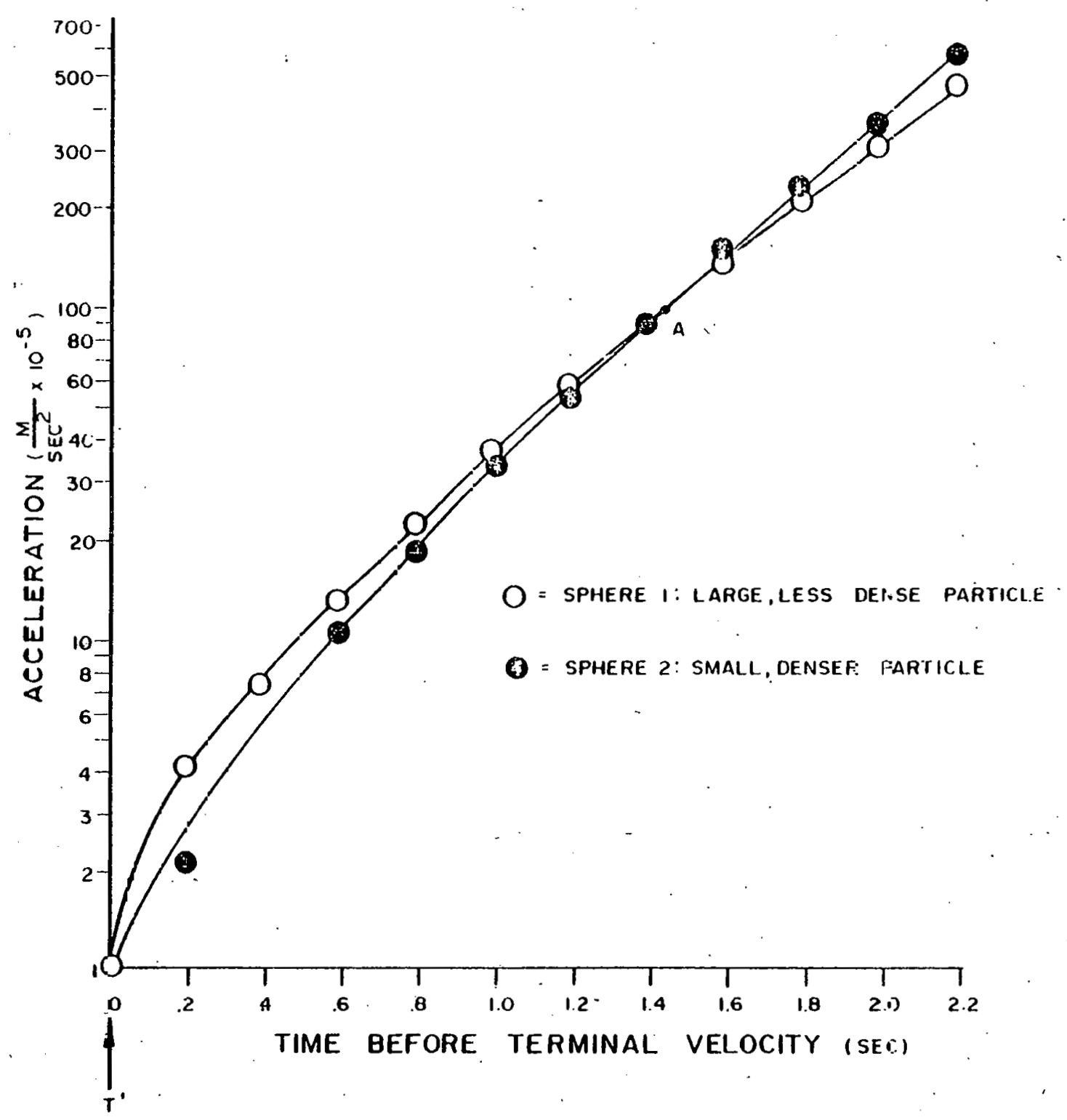

Executive Exhibit 5. Log of Accelerations of Falling Particles at Times Before Attaining Terminal Velocity 
while less-dense sphere 1 would rise out the top, again as desired. In this manner, pulsing would rectify the confusion originally described as less dense particles dropped down and out through a non-pulsing classifier.

It must be kept in mind that the objective of this research is to find a way to reverse the order of fall, which translates to manner of separation, for particles whose aerodynamic behaviors are similar. In terms of waste-toenergy production, one is concerned with correcting an overlap in separation between two components of the feed; the dense, generally non-combustible inorganics and the less dense, generally combustible organics. The result would be an improvement in separation efficiency.

The following section documents success in moving from this theoretical development into the laboratory.

\section{LABORATORY TESTING}

The experimental system required for investigation of pulsed flow air classification is made up of three parts:

- The Classifier. A straight vertical air classifier was required for this preliminary investigation of pulsed-flow air classification. The variable-wall air 
classifier that was constructed for the air classifier research program of which this investigation formed a part was used.

- The Injection System. A system was required to introduce single particles or small groups of particles into the air classifier throat as inobtrusively as possible. For single particles, the injector was designed to position the particle within the throat, release it, then withdraw to form a smooth part of the air classifier wall.

- Pulsed-Flow valve and Classifier Configuration. The pulsing valve used in this research is very similar to a movie camera shutter; two discs, one stationary, and one rotating just above the stationary one, each disc has wedge-shaped cutouts. The blower/motor combination is the only major component of the experimental equipment that was purchased off-theshelf. This valve is used in the development of the theory of pulsed flow classification; classifier conflgurations are designed and tested in the laboratory to study effect of the pulsing action on classifier efficiency. 
Four classifier configurations were tested under similar conditions: a straight wall and zig-zag model to serve as benchmark conditions, and two configurations designed to pulse the flow through the classifier: the zag-zag model in Executive Exhibit 6 and the inverted triangle in Executive Exhibit 7. The final separation efficiencies and corresponding velocities are plotted in Executive Exhibit 8 , 9 and 10, as characteristic efficiency curves, according to feed type.

The separation efficiency, E, of the classifier at a certain velocity for the continuous feed was determined by the following formula:

$$
E=\sqrt{\frac{X_{e}}{X_{0}} \cdot \frac{Y_{I}}{Y_{0}}}
$$

Again, all symbols are defined in Appendix 1.

As indicated in Executive Exhibit 8,9 , and 10, three different types of feed were used to test different characteristies of separation capability. . Feed 1 was used to compare the separation capability of each classifier on particles with similar aerodynamic characteristics but different densities. The feed consisted of a mixture of aluminum and plastic plates, sut into 25.4 แm (1.0 in) squares from large sheets of each material. 


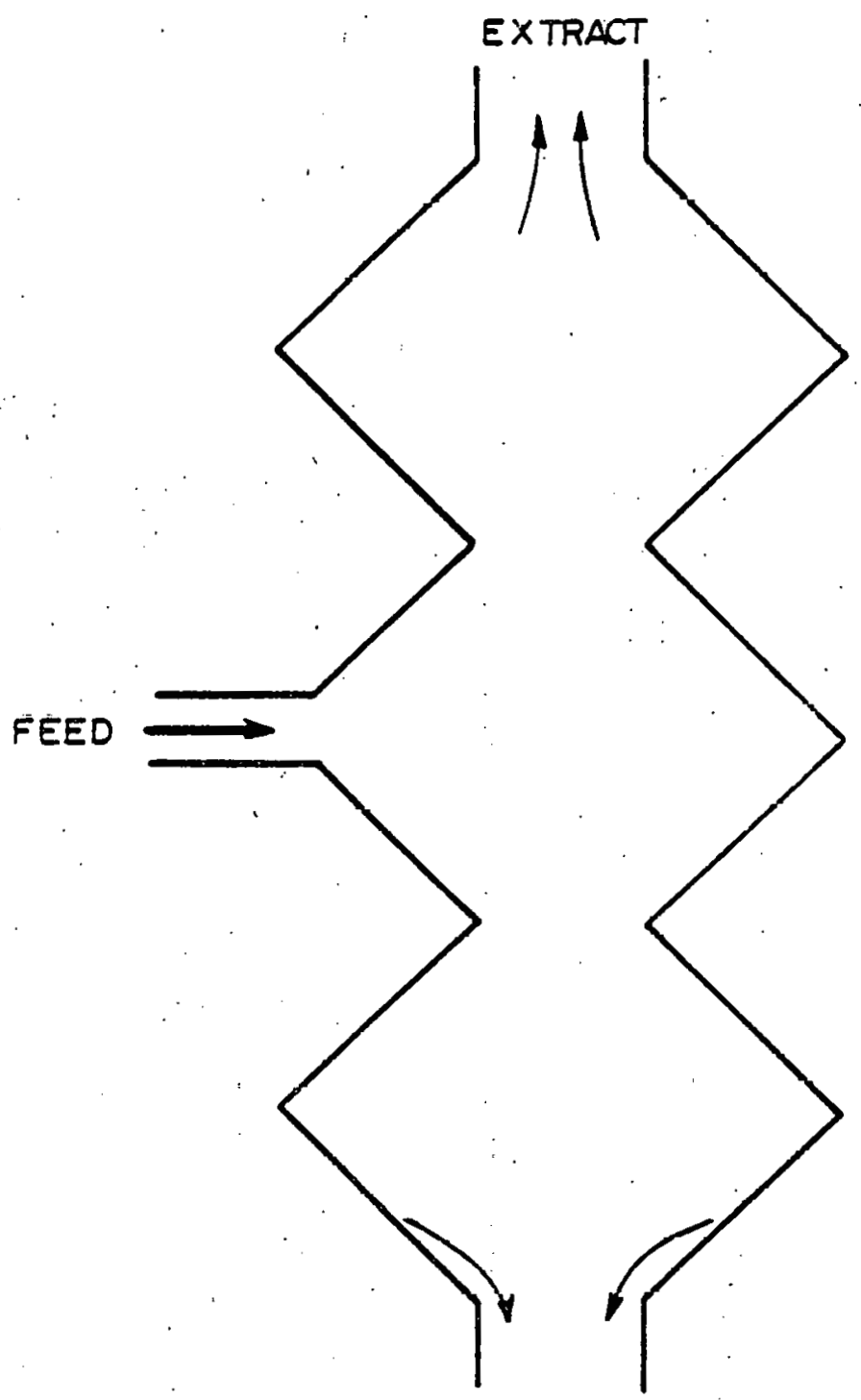

REJECT

Executive Exhibit 6. Zag-Zag Pulsed Flow Air Classifier 


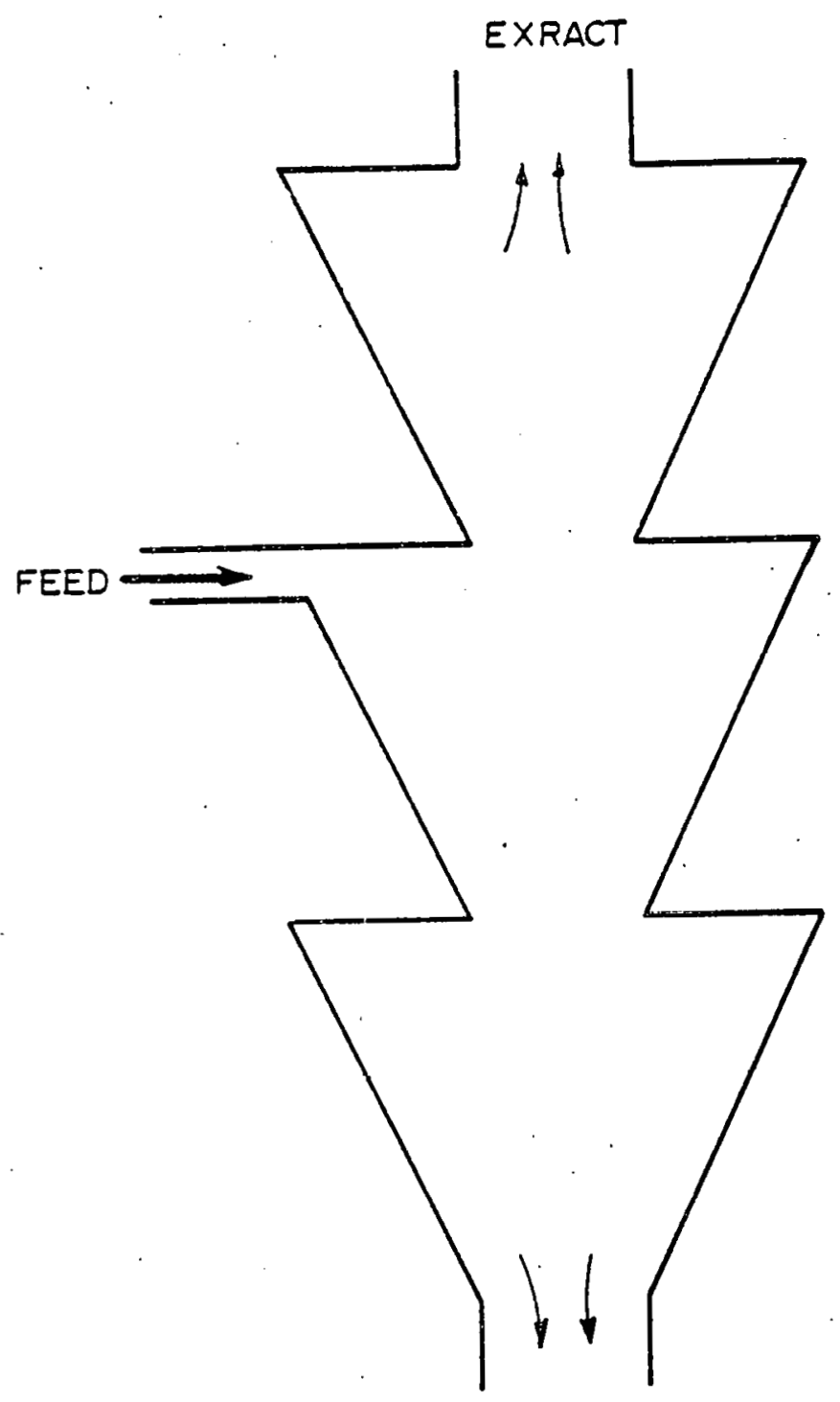

REJECT

Executive Exhibit 7. Stacked Triangle Pulsed-Flow Air Classifier 


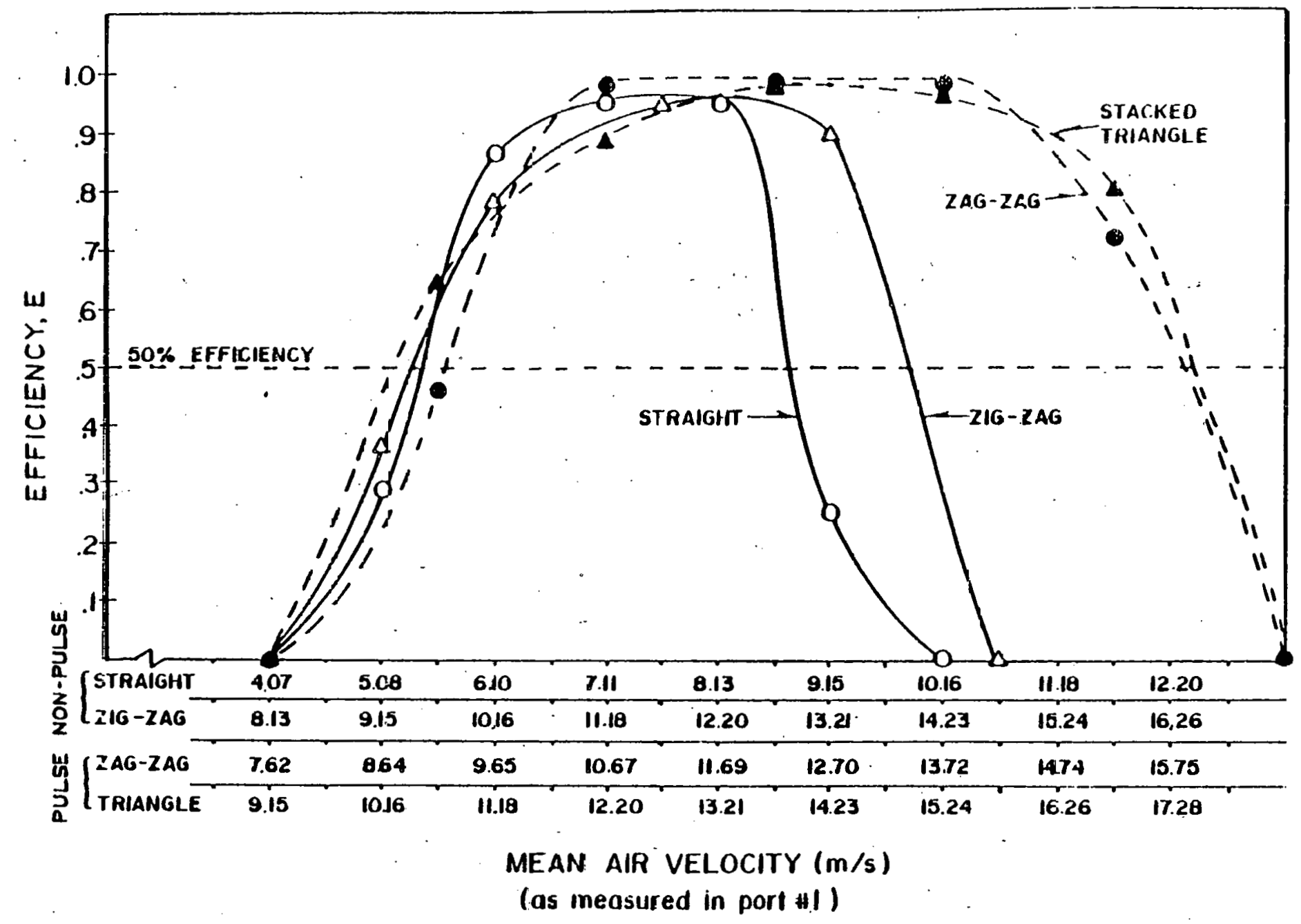

Executive Exhibit 9 . Separation Efficiency for Feed 1: Aluminum and Plastic Plates 


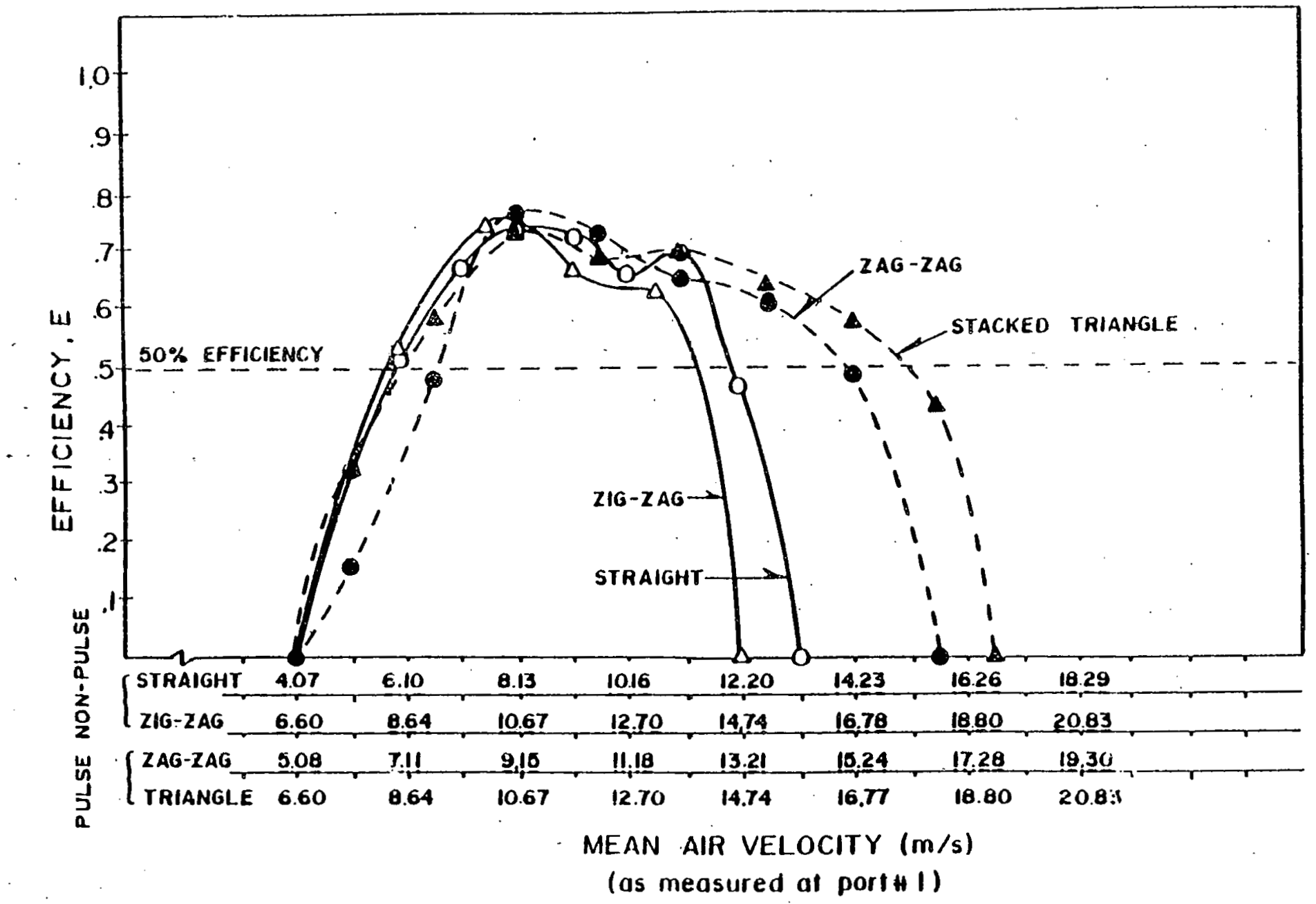

Executive Exhibit 9. Separation Efficiency for Feed 2: Shredded Aluminum and Plastic 


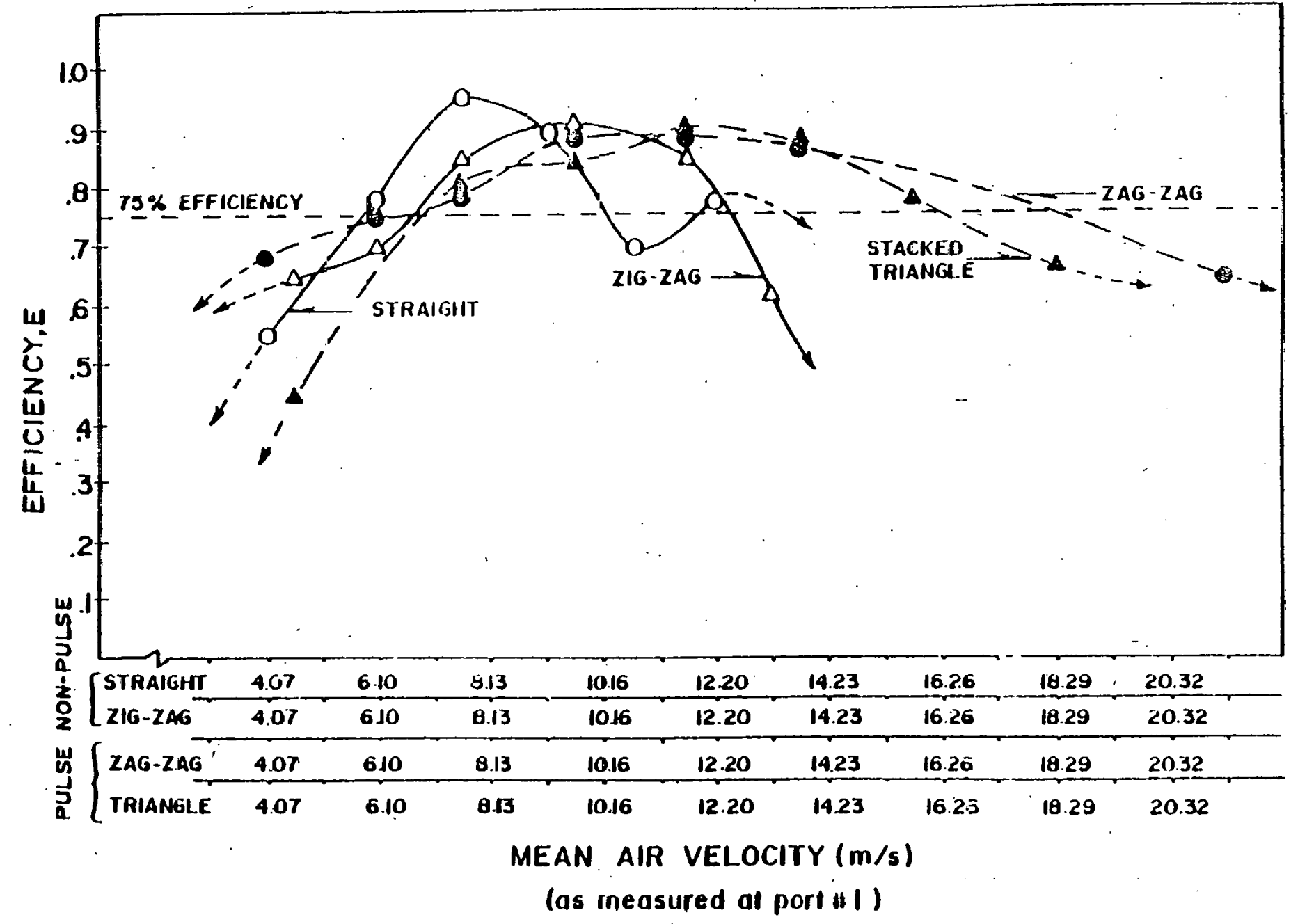

Executive Exhibit 10. Separation Efficiency for Fee 3 : Shredded Simulated Municipal Solid waste 
Feed 2 was used to simulate aluminum and plastic components of MSW. The feed was created by shredding aluminum beverage cans and plastic soap bottles in a garden. variety shredder with $25.4 \mathrm{~mm}(1.0 \mathrm{in})$ openings. This mixture was cut änd quartered according to ASTM standard procedure until 8 equivalent samples were obtained. Each sample weighed approximately $20 \mathrm{gm}(.70 \mathrm{oz})$.

Feed 3 was used to simulate MSW components of paper, plastic, glass, aluminum and steel, in the approximate proportions which might be expected in actual MSW as discussed above. The feed was created by shredding the following materials in a garden variety shredder with $25.4 \mathrm{~mm}$ (1.0 in) openings: paper magazines, plastic soap bottles, glass beverage bottles, aluminum beverage cans, and steel beverage cans. Each component was separated by size using standard soil sieves.

The four configurations which were tested were assumed to be representative of pulsing and non-pulsing classifiers. This was verified by examining characteristic velocity profiles of each classifier. The profile in Executive Exhibit 11 and 12 are superimposed upon one stage of the particular classifier shape in which it was recorded. The base line in each profilo roprosents a velocity of $0 \mathrm{~m} / \mathrm{sec}$. The profiles drawn are representative of profiles from other stages in the same classifier. 


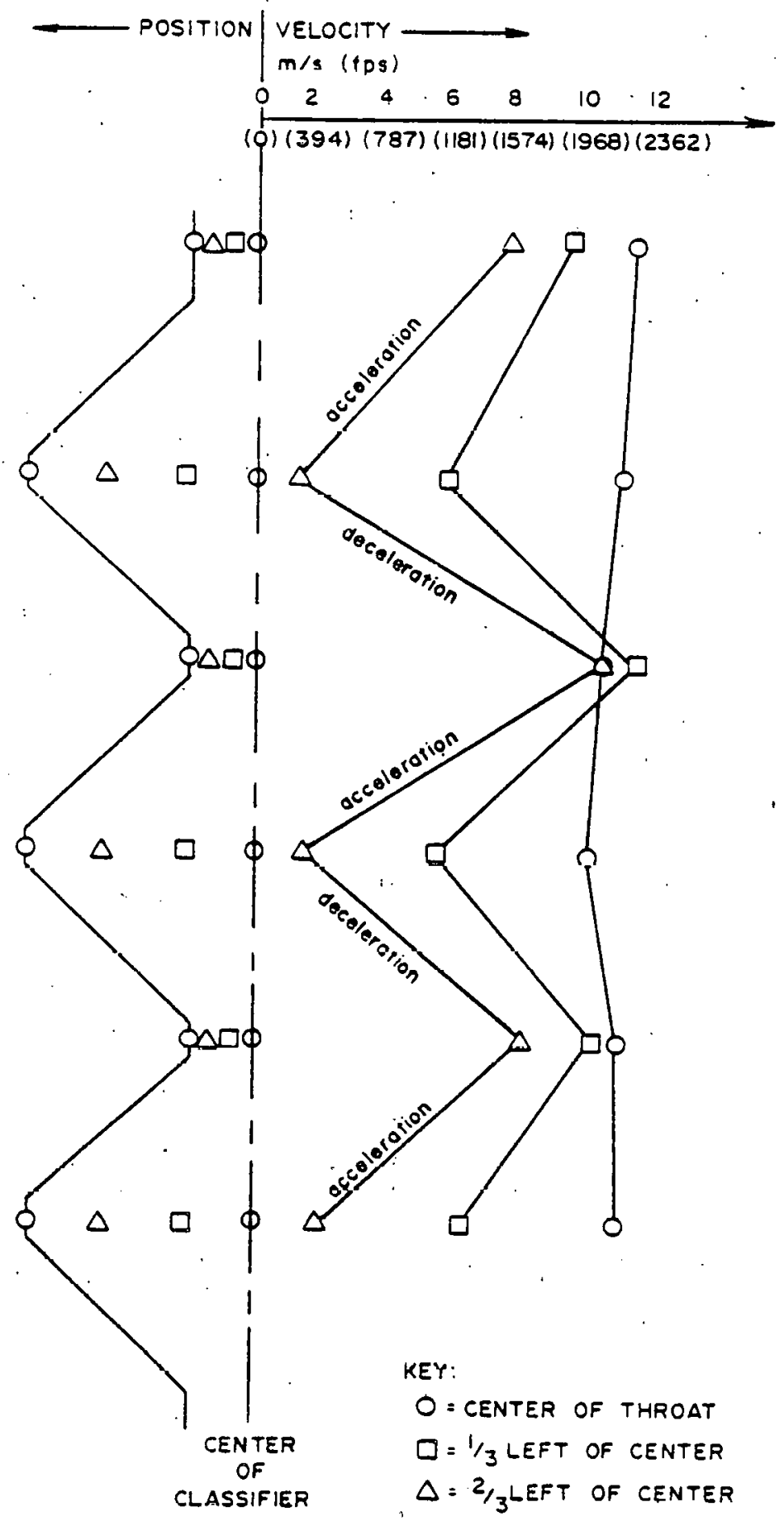

Executive Exhibit 1l. Zag-Zag Velocity Grid 


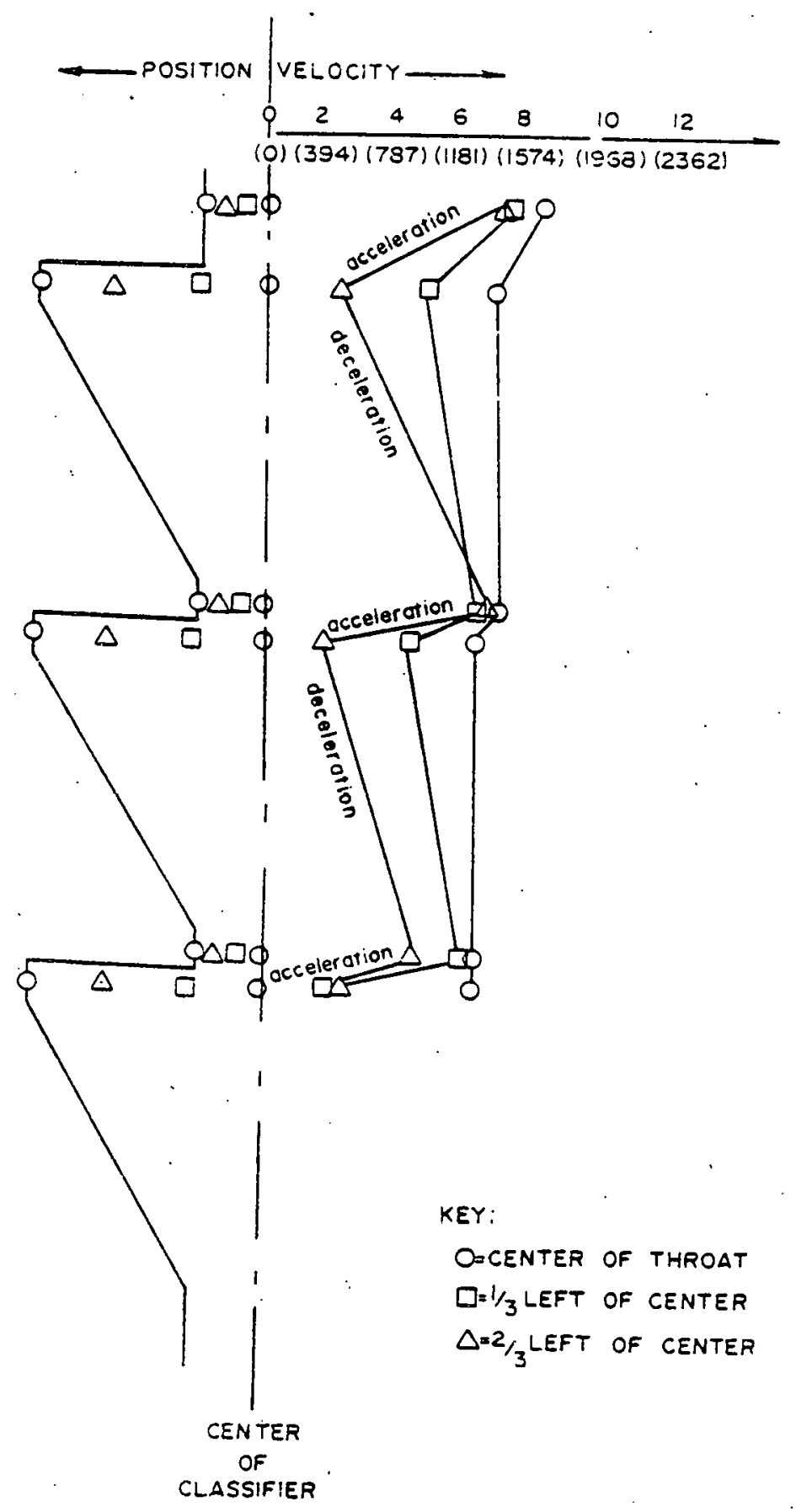

Executive Exhibit 12. Stacked Triangle Velocity Grid 
In the Zag-Zag and Stacked Triangle Classifiers, the maximum velocity is much greater at the constricted throat sections than at the expansions. Also, the velocity decreases significantly toward either wall at the expanded section, while it is relatively constant throughout the width of constricted sections. Note that regions of pulsing action where particles are sequentially accelerated and decelerated. similar velocity profiles show that horizontal changes in velocity, i.e. pulsing actions, are not evident in the straight and zig-zag configurations.

\section{PULSED-FLOW AIR CLASSIEICATION FOR ENERGY PRODUCTION}

Classifiers which use the pulsing principle and which can be used in field application must be designed. Executive Exhibit 13 shows a generalized diagram of this type of classifier. Where the sides of the classifier are close together, the air velocities are high. Where the sides are Ear apart, the pressures, and therefore the velocities, are lower. As the particle travels up or down the throat, it experiences a pulse. In this case, the pulsing term in the force-balance equation of the model would be dependent upon distance traveled and particle location, rather than time. The amplitude of the pulses could be controlled by the distance between the side walls. Different magnitudes, waveforms and durations of pulses thus could be generated by designing the walls in different configurations. Classifier 


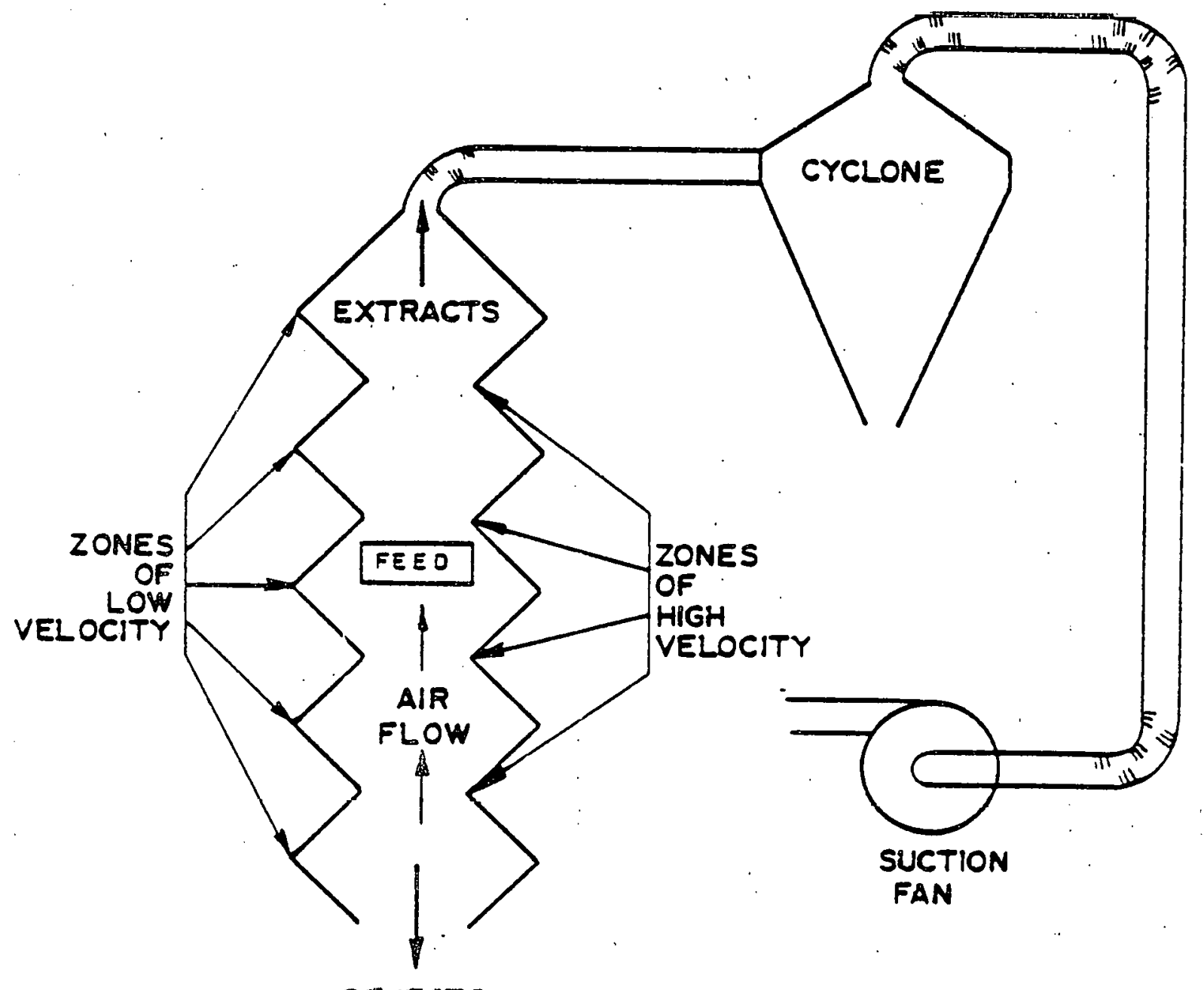

REUECTS 
design and operation thus could be structured to effectively separate the less-dense organic material from the non-dense inorganic material typically found in waste-to-energy production facilities. 
5. CONCLUSIONS

From the Literature survey, the following conclusions are drawn:

- Previous modeling efforts have been largely statistical.

- Such statistical models are of limited use to the design engineer working on variations of the zig-zag classifiers for which the models were developed, but are of little or no use in considering different types of classifiers.

- Past experimental work has revolved around determinin efficiencies of existing classifiers. and verifying or calibrating statistical models.

- Deterministic models of classifier performance are lacking in the literature. 
- No research is documented which addresses the behavior of particles under conditions critical to air classifiers: particles larger than aerosols in pulsing (rather than oscillating) air f́low under a control body force (gravity) in direction of the flow.

Our investigations of Llie theory of air classitication lead to the following conclusions:

- This pulsed-flow model is deterministic, and can guide the design of pulsed-flow air classifiers. Of particular importance is the design considerations of pulse frequency amplitude and wave form.

- The theory behind pulsed flow air classification indicates that current designs for air classifiers cannot avoid poor separation of particles in a complex mixture because the classifiers do not cause prolonged or repeated periods of acceleration. 
- Pulsed-flow air classification theoretically separates particles by retarding particle approach to terminal velocity and/or forcing repeated retreats and renewed approaches.

From laboratory analysis of passive pulsed-flow air classification, it is apparent that:

- Constrictions and expansions in the width of the classifier throat produce a pulsed air stream within the classifier, as indicated by the characteristic velocity profiles in Exhibit 11 and 12 .

- The pulsing classifiers permit more complete separation of mixed particles than do the non-pulsing classifiers.

- The pulsing classifiers operate more efficiently over a wider range of air velocities than do the non-pulsing classifiers. 
- The Zag-zag and Stacked Triangle classifiers, do not necessarily represent the optimal configuration of pulsing classifiers. Studying these shapes has indicated, however, that there are beneficial effects of pulsing on particle separation. The pulse wave form, duration and magnitude must be studied further. 


\section{REFERENCES}

1. Birkhoff, G., A Study of Logic Fact and Similitude, Revised Edition. Princeton N. J.: Princeton University Press, $1960, \mathrm{Ch} .6$.

2. Henrikson, F. A., A Descriptive Mathematical Model of Air Classification. Duke University: Center for Environmental Engineering, Durham, N. C., 1979.

3. Lamb, H., Hydrodynamics. New York: Dover Publications, 1932, Ch. 6 .

4. McNabb, M. B., Fundamental Aspects of Air Classification and Design: A New Test for the Evaluation of Air Classifier Performance. Duke University: Center for Environmental Engineering, Duke University, Durham, N. C., 1980 .

5. Midwest Research Institute, Equipment Tests and Evaluations. Vol. 2, A Study of Processing Equipment for Resource Recovery systems (Cincinnati, Ohio: U. S. Environmental Protection Agency, December, 1978, pp 74-5. ; 
6. Ower, E., and Pankhurt, F. C., The Measurement of Airflow. Elmsford, N. Y.: Pergamon Press, 1977, Chapter XII.

7. Resource Recovery from Municipal Solid waste in ohio. Columbus, Ohio: Ohio Environmental Protection Agency, 1975 .

8. Genden, M. M. G., Performance of $\bar{Z}$ ig-Zag Air Classifiers at Low Particle Concentrations. The Netherlands: Eindhoven Technical University, 1978.

9. Significance of Size Reduction in Solid Waste Management. Cincinnati, Ohio: U. S. Environmental Protection Agency, 1977, page 7.

10. Third Report to Congress: Resource Recovery and waste Reduction, Washington, D. C.: U. S. Environmental Protection Agency, 1975.

11. Torobin, L. B., and Gauvin, W. H., "Fundamental Aspects of Solids-Gas Flow: Part III. Accelerated Metron of a Particle in a Fluid." Canadian Journal of Chemical Engineering, December, 1959, pp. 224-36. 
33

12. Worrel1, W. A., Testing and Evaluation of Three

Air Classifier Throat Designs. Duke University:

Center for Environmental Engineering, Durham,

N. C. ; p. 49-53.

13. Yin, C. Fluid Mechanics. N. Y.: McGraw-Hill, 1966, Ch. 4 . 


\section{CHAPTER II \\ LITERATURE SEARCH}

This chapter documents that no previous research addresses the theory or experimentation of pulsed-flow air classifiers. The Center for Environmental Engineering at Duke University maintains a collection of publications dealing with resource recovery. That collection, as weil as computer data bases were searched, and yielded information of two types:

- Information as to the characteristics of MSW which cause separation difficulties.

- Efforts at theoretical modeling of standard configurations of steady-flow vertical air classifiers.

The library at the Center for Environmental Engineering is quite unique: it contains many hard-to-get publications dealing with resource recovery. In addition, publications obtained by those associated with the center, either through personal communication or while visiting other institutions, are collected and cataloged. The center often receives prepublication copies of material. As such, the Center has a 
complete and up-to-date collection of information on resource recovery. In addition, computer searches of relevant publications were undertaken to take advantage of levels of keywords beyond those available in printed indices.

i. CHARACTERISTICS OF MUNICIPAL SOLID WASTE

The first grouping of informational material deals with identifying the characteristics of MSW which cause poor separation. While many studies have been done on the composition of MSW, few list the components broken down by source material. Three investigations were found which yielded useful information on the configurations of the types of materials making up MSW:

1) An Environmental Protection Agency (EPA) publication [6] described much of the noncombustible MSW as consisting of packaging material and paper: steel, aluminum, cardboard, paper, plastic (polyvinylchloride), and plastic (polyethylene) samples were all taken from cans, boxes, gags, and bottles, This implies that most of the materials were in sheet form. See Exhibit 1. [6] 


\begin{tabular}{|c|c|c|c|c|c|c|}
\hline Material & $\begin{array}{l}\text { Type of } \\
\text { container }\end{array}$ & $\begin{array}{l}\text { Contalner shape } \\
\text { and opecimen } \\
\text { locations }\end{array}$ & $\begin{array}{l}\text { Specimen } \\
\text { thlcknets } \\
(1 n .)\end{array}$ & $\begin{array}{l}\text { ult Imate } \\
\text { gtrength } \\
\text { (pgi) }\end{array}$ & $\begin{array}{l}\text { Ultimate } \\
\text { straln } \\
(1 n . / \ln .)\end{array}$ & $\begin{array}{l}\text { Rupture } \\
\text { energy } \\
\left(\mathrm{ft} .-\mathrm{Ib} / \mathrm{ln} .{ }^{3}\right)\end{array}$ \\
\hline steel & $\begin{array}{l}12-o z \\
\text { beveraga } \\
\text { can }\end{array}$ & $\begin{array}{l}\text { Cylinder, } \\
\text { opeclinen cut } \\
\text { frum olde. } \\
\text { oxially and } \\
\text { clrcumferen- } \\
\text { tlally }\end{array}$ & 0.007 & 82,000 & 0.005 & 9.1 \\
\hline A lumf IIIm & $\begin{array}{l}12-0 z \\
\text { beverage } \\
\text { can }\end{array}$ & $\begin{array}{l}\text { Same as } \\
\text { above }\end{array}$ & 0.006 & 31,000 & 0.012 & 26.5 \\
\hline $\begin{array}{l}\text { Card- } \\
\text { board }\end{array}$ & $\begin{array}{l}\text { Laundry } \\
\text { detergent } \\
\text { box }\end{array}$ & $\begin{array}{l}\text { Rectaingular box, } \\
\text { specimen cut } \\
\text { from front and } \\
\text { back panels }\end{array}$ & 0.025 & 6.400 & 0.025 & 0.3 \\
\hline Paper & $\begin{array}{l}\text { Drown paper } \\
\text { bag }\end{array}$ & $\begin{array}{l}\text { "Grocery" type } \\
\text { bas opeclmen } \\
\text { cut at varlous } \\
\text { locatlong }\end{array}$ & 0.009 & 1.000 & 0.025 & $\begin{array}{c}5.1 \\
\ddots\end{array}$ \\
\hline $\begin{array}{l}\text { Plastic, } \\
\text { poly- } \\
\text { vinyl- } \\
\text { chlorlde }\end{array}$ & $\begin{array}{l}\text { I.lquid } \\
\text { soap } \\
\text { tottle }\end{array}$ & $\begin{array}{l}\text { Sculpted molding, } \\
\text { opecimen cut } \\
\text { from front and } \\
\text { back panels }\end{array}$ & $\begin{array}{c}0.19 \\
\text { to } \\
0.026\end{array}$ & $\begin{array}{c}4.000 \\
t 0 \\
5.000\end{array}$ & $\begin{array}{l}0.360-\dot{e}=0.1^{a} \\
0.130-\dot{e}=1.0 \\
0.060-8=10\end{array}$ & $\begin{array}{c}111-\dot{e}=0.1 \\
41-\dot{e}=1.0 \\
19-\dot{e}=10\end{array}$ \\
\hline $\begin{array}{l}\text { Plastic, } \\
\text { poly- } \\
\text { ethylene }\end{array}$ & $\begin{array}{r}\text { Shampoo } \\
\text { bottle }\end{array}$ & $\begin{array}{l}\text { Cylinder, } \\
\text { specimen cut as } \\
\text { In cans above }\end{array}$ & $\begin{array}{l}0.028 \\
\text { to } \\
0.036\end{array}$ & 1,000 & $\begin{array}{l}0 \text { for } \dot{e}=0.1 \\
14 \text { for } \dot{e}=1.0 \\
0 \text { for } \dot{e}=10\end{array}$ & $\begin{array}{l}56-d=0.1 \\
60-d=1.0 \\
66-d=10\end{array}$ \\
\hline
\end{tabular}

Twere $e=$ elongation rate, all materialo weretested at $e=0.1,1.0$ and $101 n .7 m i n .$, with the plastics showing the effects of elongation rate ag glven abcive. Materiala other than the plastics showed no elongation rate effects.

Exhibit 1. MSW Components by Source [6] 
2) A second EPA report [7] lists sources of MSW in a table, shown here in Exhibit 2. [7] Durable goods are the smallest category, and contains such items as major appliances, furniture, and tires. Nondurable goods are largely paper products and include clothing. The remainder of the nonfood wastes is given over to packaging. This table also reveals a large amount of material in sheet form as being non-putrescible MSW.

3) The state of Ohio Environmental protection Agency analyzed wastes from the state. [4] They give a table showing some breakdown by source. This table is shown here as Exhibit 3. [4] Steel is shown to be about 508 "appliance and other." Again, the "appliance and other" category is assumed largely sheetmetal. No information is given for plastic.

From this information and observations made during experimentation at Duke, it is assumed that plastic, paper, and aluminum are present almost exclusively in MSW as sheet material. This result, determines that particles of plastic, paper and aluminum will be derived from sheet material in various stages of crumpling. An important inference is that, even with a fairly large grate șize in the shredder, the partirles will probably be aerodynamically quite light. 


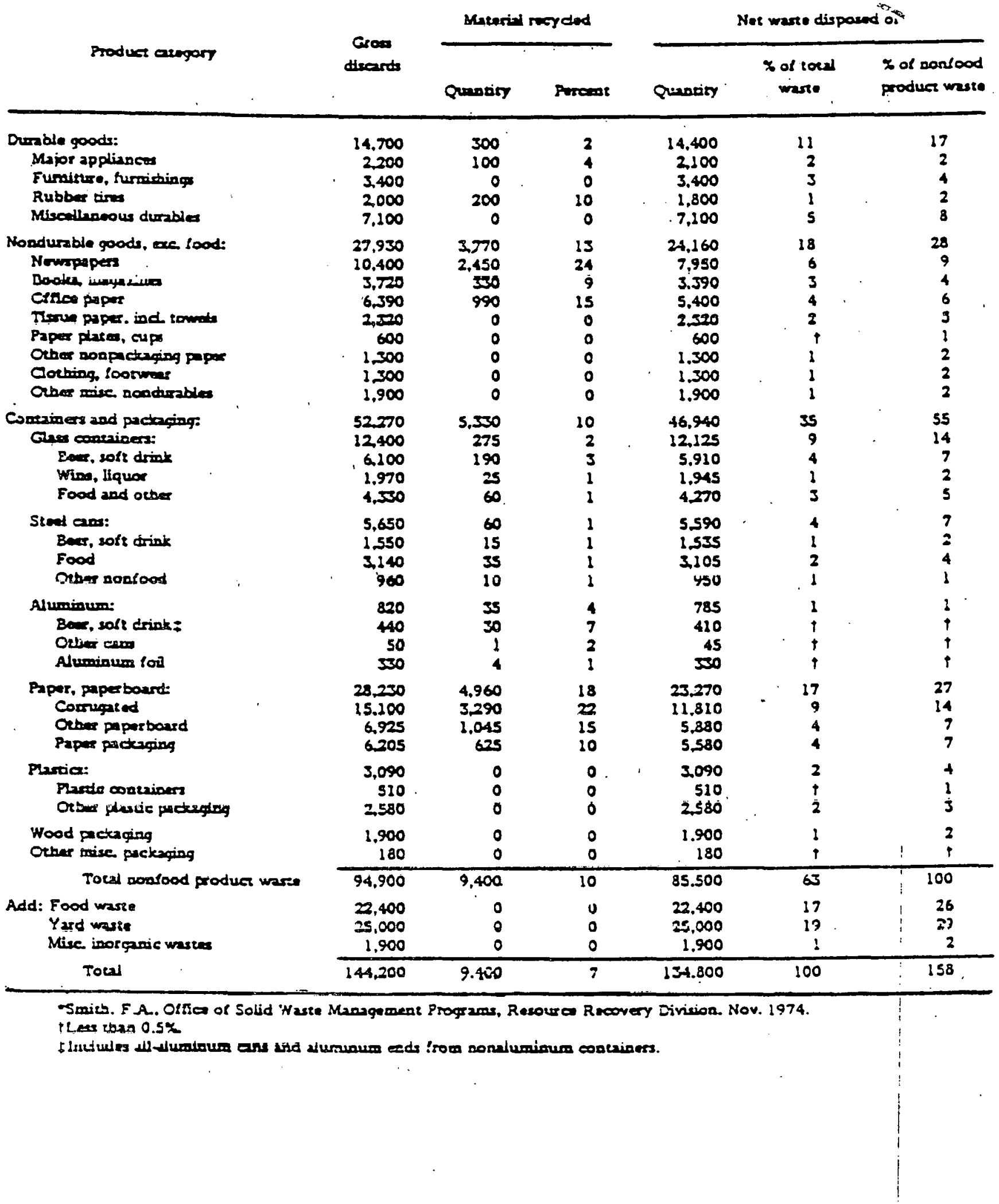




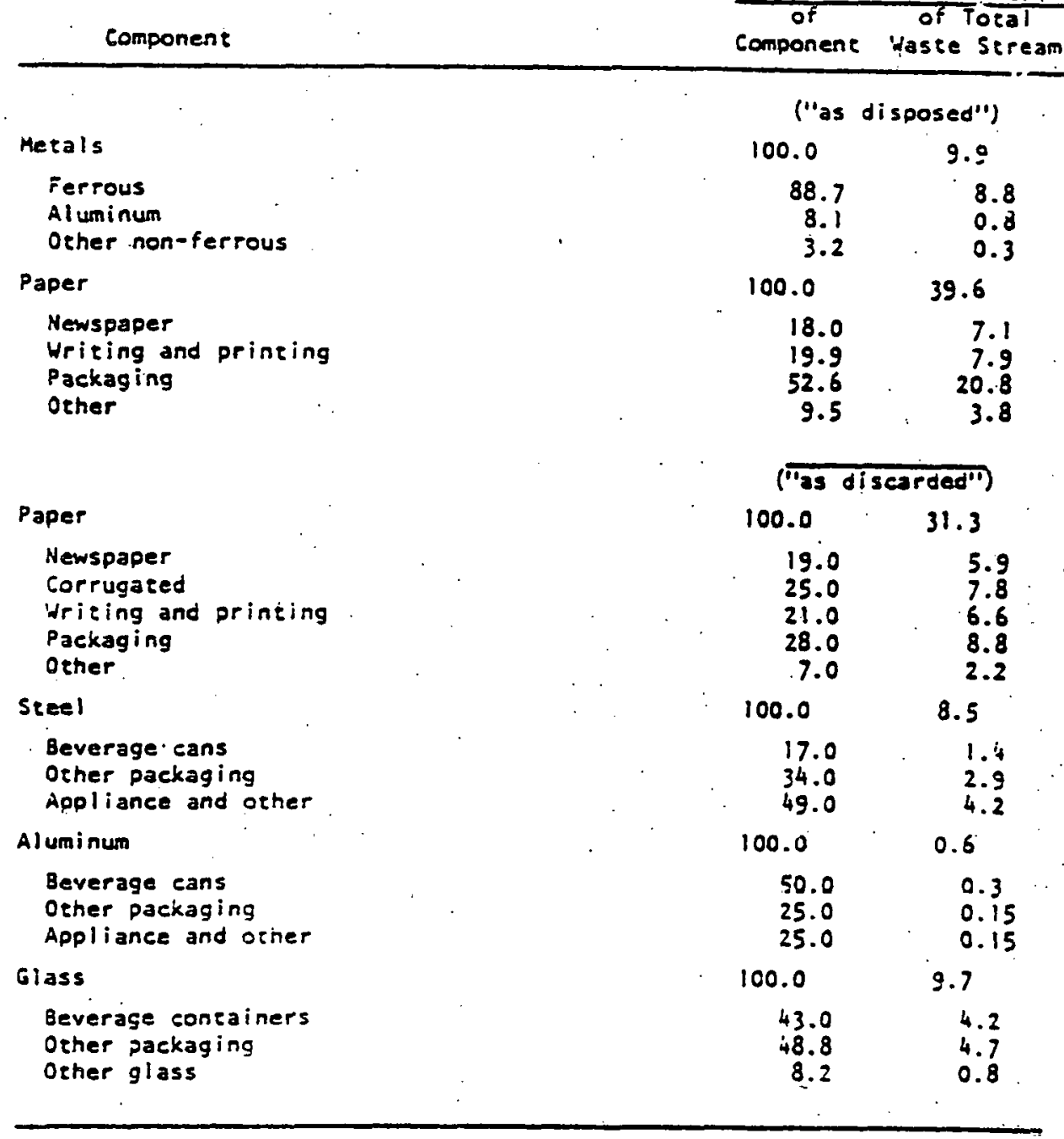

Exhibit 3. MSW Components by Source [4] 
Part of McNabb's work at Duke [2] involves the . conducting of a "drop test" on different MSW components. The separation in a standard air classifier is based largely on the attainment of different terminal velocities specific to the various MSW components. The behavior of the particles reaching terminal velocity under free-fall conditions is assessed. The data, presented in graphical form, are shown in Exhibj.t 4 . [2]

These data show that an overlap zone betweenl cumbustible and non-combustible materials occurs in the range of fall velocities between aluminum and plastic. This range of densities is the range that is critical to air classifier separation necessary for optimizing RDF production, and is a focus of this research. We were able to assemble an overview of past directions taken in modeling standard, vertical air classifiers. It was determined that none of the newer directions were suitable for our efforts, and our best THEORY course of action would be to return to a traditional forcebalance from fluid mechanics, and develop our theory in this deterministic fashion.

2. THEORY OF AIR CLASSIFIERS

Previous theories of the air classification of particles have been largely statistical, and there have been three major contributors: Senden and Tels in the Netherlands, and Henrikson at Duke. [3] [1] All of these researchers used a 


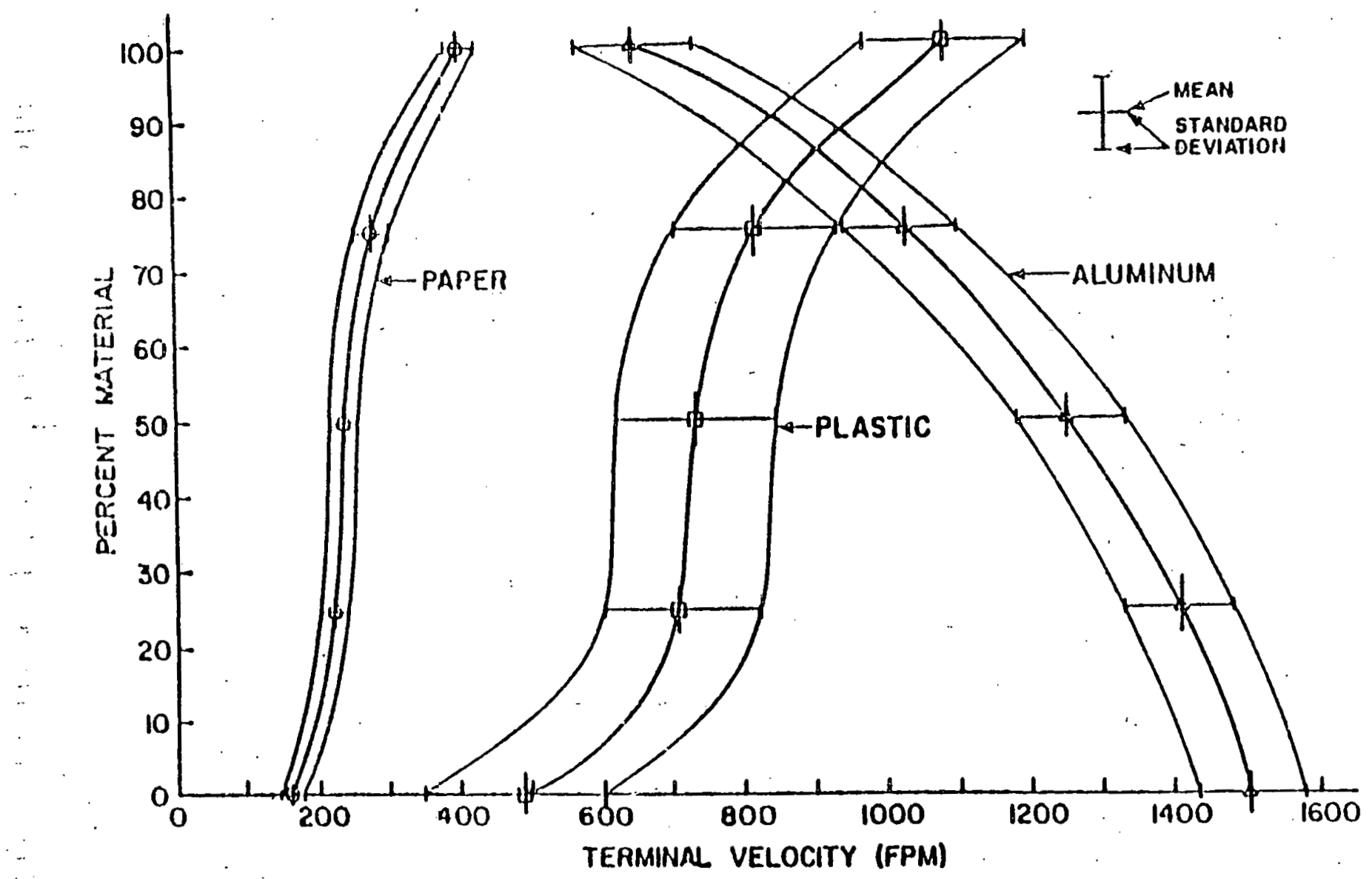

Fxhibit 4. Percent Paper and Plastic with Terminal Velocity Less-Than, and Percent Aluminum with Terminal Velocity Greater-Than [8] 
type of classifier known as a zig-zag classifier. A zig-zag classifier is divided into stages, each of which consists of a straight throat segment slanted either left or right, opposite to its neighbors.

Senden and Tels use a box model, with each stage being represented by a box. Four probabilities are defined:

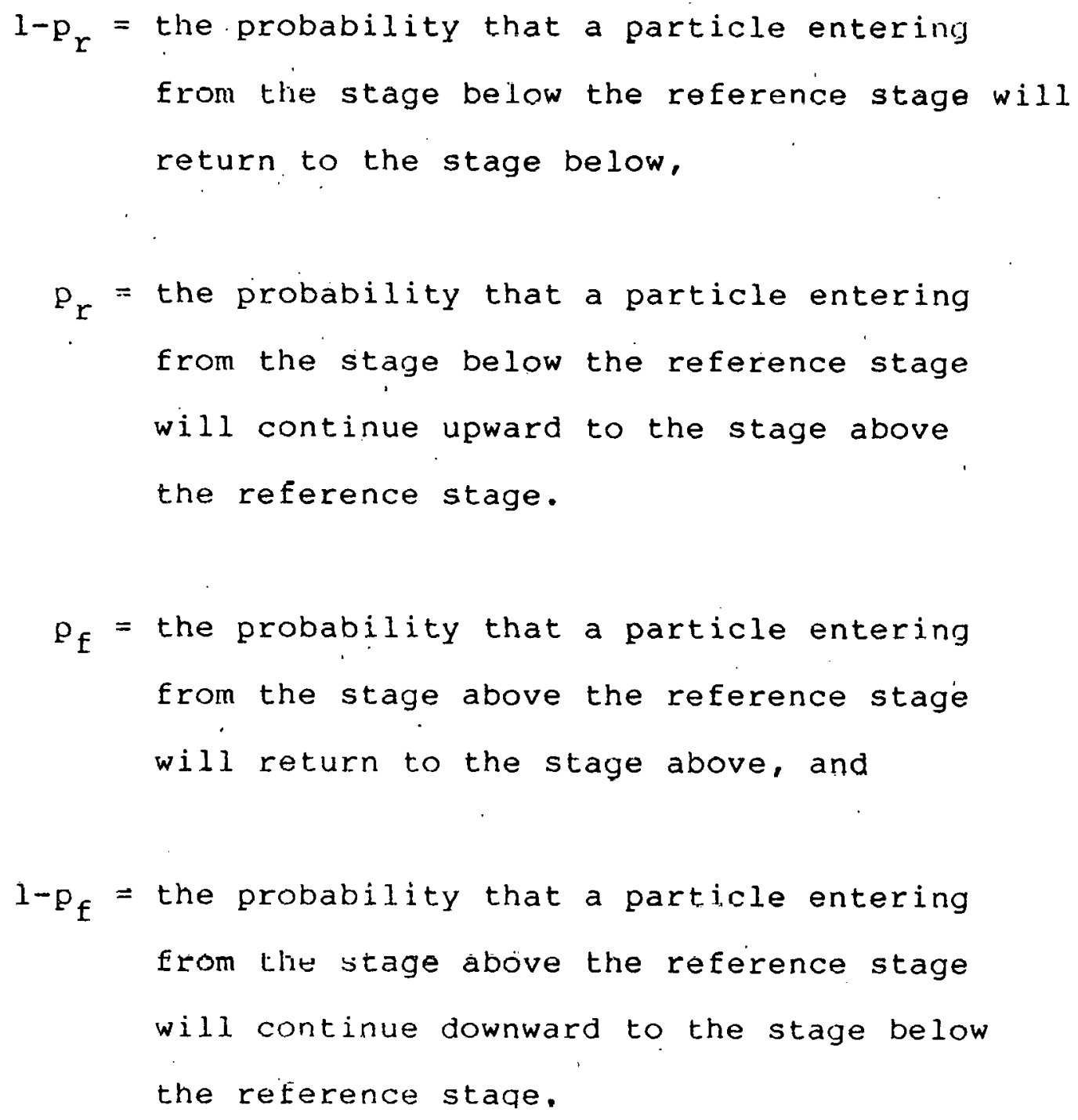


Senden and Tels then combine these probabilities into an efficiency expression:

$$
S_{R}=I_{R r} \cdot S_{\text {or }}+I_{R f} \cdot S_{\text {of }}
$$

where:

$$
\begin{aligned}
S_{R}= & \text { cumulative separation efficiency } \\
S_{O f}= & \text { single stage separation efficiency for } \\
& \text { falling particles } \\
S_{O r}= & \text { single stage separation efficiency for } \\
& \text { rising particles } \\
& \text { I } \\
I_{R x} & \text { single stage efficiency } \\
T_{K f}= & \text { amplification factor" for falling particle } \\
& \text { single stage efficiency }
\end{aligned}
$$

Empirical results serve to calibrate the model. The efficiency expression deals with the light fraction of the feed stream, that is, the stream important in RDF production. [3] 
Henrikson, rather than centering on one stage, chose to center on a particle. He followed the particle, statistically, along its path through the air classifier, using a Markovian random walk model. By combining probabilities of a particle entering at the feed point going through each of the stages of the air classifier to reach either the bottom or the top, Henrikson produced a model dependent on the number of stages in the classifier. He was able to reduce the number of variables requiring calibration to one. Like senden and Tels, he did experiments to calibrate his model. His aim, however, was to identify a function to which the calibrated variable could be fitted with acceptable accuracy. On the basis of the experimental results, he chose the error function. His final representation is shown in Exhibit 5 .

Both the models of Senden and Tels, and.Henrikson, are important as descriptive models. If one has an air classifier which fits into one of the types on which their models are based, then one can use the model to determine the efficiency of performance. However, the major drawback of these models is that they do not help the designer with the configuration of the air classifier. 'The models only describe what will happen if the design of the air classifier is changed. Senden and Tels' model distinguishes between three different angles of zig-zag, but only because experiments were conducted with those three distinct classifier configurations. A further difficulty is that 


$$
U_{B}(V)=1-\left[\frac{1+\sum_{m=1}^{V-1} \prod_{j=1}^{m}\left(\frac{1-\operatorname{erf}\left(\frac{k C_{A}}{C_{j}}\right)}{\operatorname{erf}\left(\frac{k C_{A}}{C_{j}}\right)}\right.}{1+\sum_{m=1}^{A-1} \prod_{j=1}^{m} \frac{1-\operatorname{erf}\left(\frac{k C_{A}}{C_{j}}\right)}{\operatorname{erf}\left(\frac{k C_{A}}{C_{j}}\right)}}\right]
$$

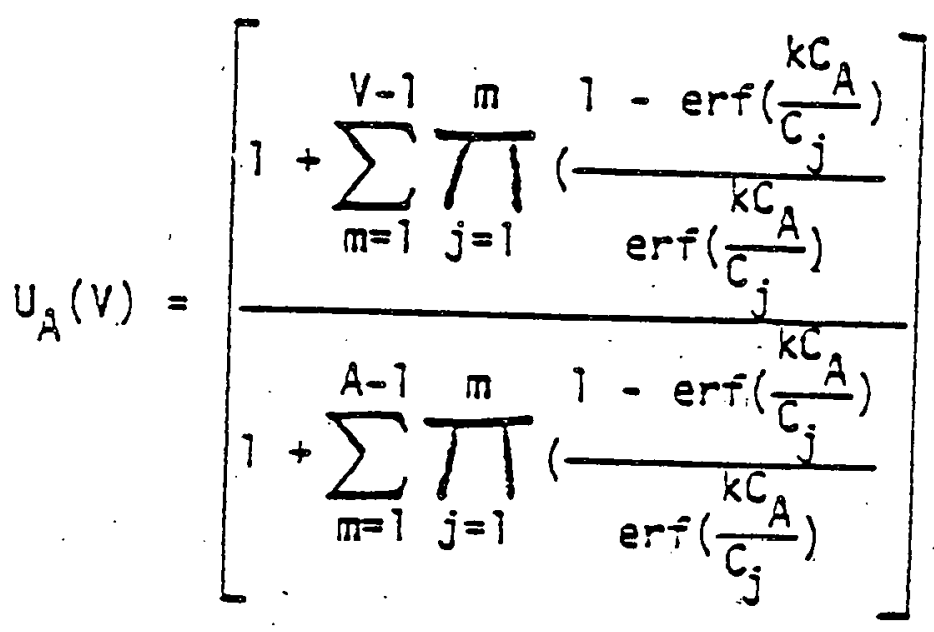

where:

$$
\begin{aligned}
\mathrm{U}_{\mathrm{B}}(\mathrm{V})= & \text { the probability that a particle will } \\
& \text { exit with the heavy fraction } \\
\mathrm{U}_{\mathrm{A}}(\mathrm{V})= & \text { the probability that a particle will } \\
& \text { exit with the light fraction } \\
\mathrm{C}_{\mathrm{A}} / \mathrm{C}_{J}= & \text { the concentration ration between stage } j \\
& \text { and the top stage } \\
& \text {. }
\end{aligned}
$$


neither model manages as complete a description of efficiency as, say, the modified worrell efficiency formula. [9] The modified worrell formula takes into account both feed streams in the same equation, penalizing the efficiency for both feed streams in the same equation, penalizing the efficiency for both poor recovery and impurity in both output streams to same extent.

This literature search yielded information concerning past efforts at theory of and experimentation on air classifiers. To date, mathematical models have been largely statistical; valid for' a specific type of air classifier, but not useful to the design engineer. Experimental work has revolved around determining efficiencies of existing classifiers and verifying or calibrating statistical models. 


\section{REEERENCES}

1. Henrikson, R. A., A descriptive Mathematical Model of Air Classification. Duke University: Center for Environmental Engineering, Durham, N. C., 1979.

2. McNabb, M. B., Fundamental Aspects of Air Classifier Operation and Design: A New Test for Evaluation of Air Classifier Performance. Duke University: Center for Environmental Engineering, Durham, N. C., 1980.

3. Senden, M.M.G., Performance of Zigzag Air Classifiers at Low Particle concentrations. Eindhoven, The Netherlands: Eindhoven University of Technology, 1979

4. Stanley Consultants, Resource Recovery from Municipal Solid Waste in Ohio. Columbus, $\mathrm{OH}$ : Ohio Environmental Protection Agency, 1975.

5. Taggart, A. F., Handbook of Mineral Dressing. New York: John Wiley \& Sons, Inc., 1945), sec. 11, p. 48. 
6. Trezek, G. J., Significance of Size Reduction in Solid Waste Management. Cincinnati: Municipal Environmental Agency, 1977, p. 7.

7. U. S. Environmental Protection Agency, Third Report to Congress: Resource Recovery and Waste Reduction. Washington, D. C.: U. S. Environmental Protection. Agency, 1975.

8. Vesilind, P. A. and Rimer, A. E., Unit Operations in Resource Recovery Engineering. Englewood Cliffs, N. J.: Prentice-Hall, Inc., 1981), p. 181:

9. Worrell, W. A., Testing and Evaluating of Three Air Classifier Throat Designs. Duke University: Conter for Environmental Engineering, Durham, N. C., 1978 . 
CHAPTER III

THEORY OF PULSED-FLOW AIR CLASSIFICATION

This chapter develops the theory of pulsed-flow air classification in terms of:

- Pulsed-flow Concept Development

- Mathematical Models

- Acceleration Effects

- Conclusion

Each section of the chapter builds on existing knowledge and expands to a point where the meaningful laboratory analysis can be discussed in subsequent chapters.

\section{PULSED-ELOW CONCEPT DEVELOPMENT}

- The interest in pulsed-flow air classification arose while trying to differentiate between separation by aerodynamic characteristics and particle densities. The elimination of such aerodynamic characteristics as those involving airflow behavior and tumbling leads to the isolation of mass and overall size as defining particle 
behavior, thereby isolating particle density as the particle characteristic defining the separation. In the ideal air classifier, density alone should define the separation.

The theory of pulsed-air classification can be illustrated in a comparison to the theory of jigging. Jigs, used often, for example, in mining to separate ores from tailings, are fundamentally similar in design to the jig shown in Exhibit 6 . A plunger on the right hand side of the jig moves up and down in short strokes, causing the surface of the fluid on the left hand side of the jig also to oscillate up and down. Particles of material on the left hand side of the jig are forced to follow the motion of the liquid to a certain extent. The extent to which they do so is governed by a force balance comprising gravity, buoyancy, and drag. The equation is

$$
\dot{F}=F_{G}+F_{B}+F_{D}
$$

where:

$$
\begin{aligned}
F & =\text { force on the particle } \\
F_{G} & =\text { force of gravity } \\
F_{B} & =\text { buoyancy torce } \\
F_{D} & =\text { drag force }
\end{aligned}
$$




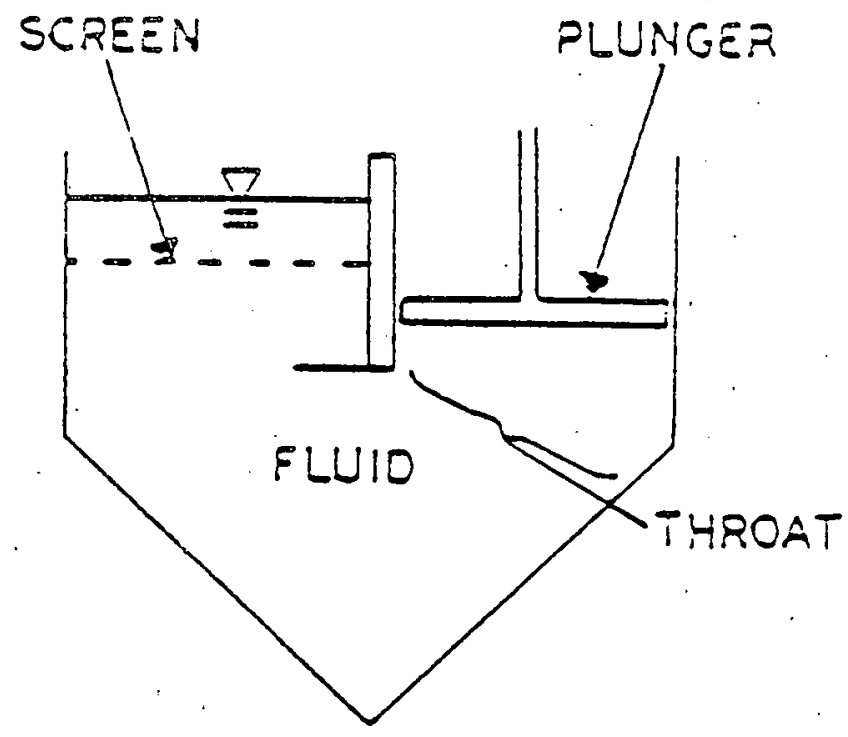

Wxhibit 6.. Diagram of a Jig 
The discussion must begin with the consideration of particle motion in the jig liquid bath before the plunger begins motion. As the particles begin to sink, their drag force is essentially zero. This leaves a force balance between gravity and buoyancy. One can plug into Equation 3 the parameters defining drag, gravitational acceleration, and buoyancy for any particle to obtain a description of particle motion. Examples of this type of calculation are clearly illustrated in subsequent sections of this paper using a modified and refined version of Equation 2-1.

An interesting special case is shown in Exhibit 7. [6] A pair of spheres, A and B, is selected so that A is less dense than $B$, and at the same time larger than $B$. If these particles are put into a jig bath, again with the plunger stationary, the denser, smaller particle, B, begins to fall faster than the less dense, larger particle, A. This occurs because $B^{\prime} s$ higher density causes a higher initial acceleration. After a time, A begins to move faster than B as the drag force on the denser particle becomes controlling. The operation of a jig is based on isolating the segment of the velocity curve where the denser particle is moving (falling) faster than the less dense particle, ie. at all times less than $t$ in Exhibit 7.

It is the plunging action of the $j$ ig which accomplishes this goal. For example, before the plunger begins motion, a particle will have been accelerating downward due to 


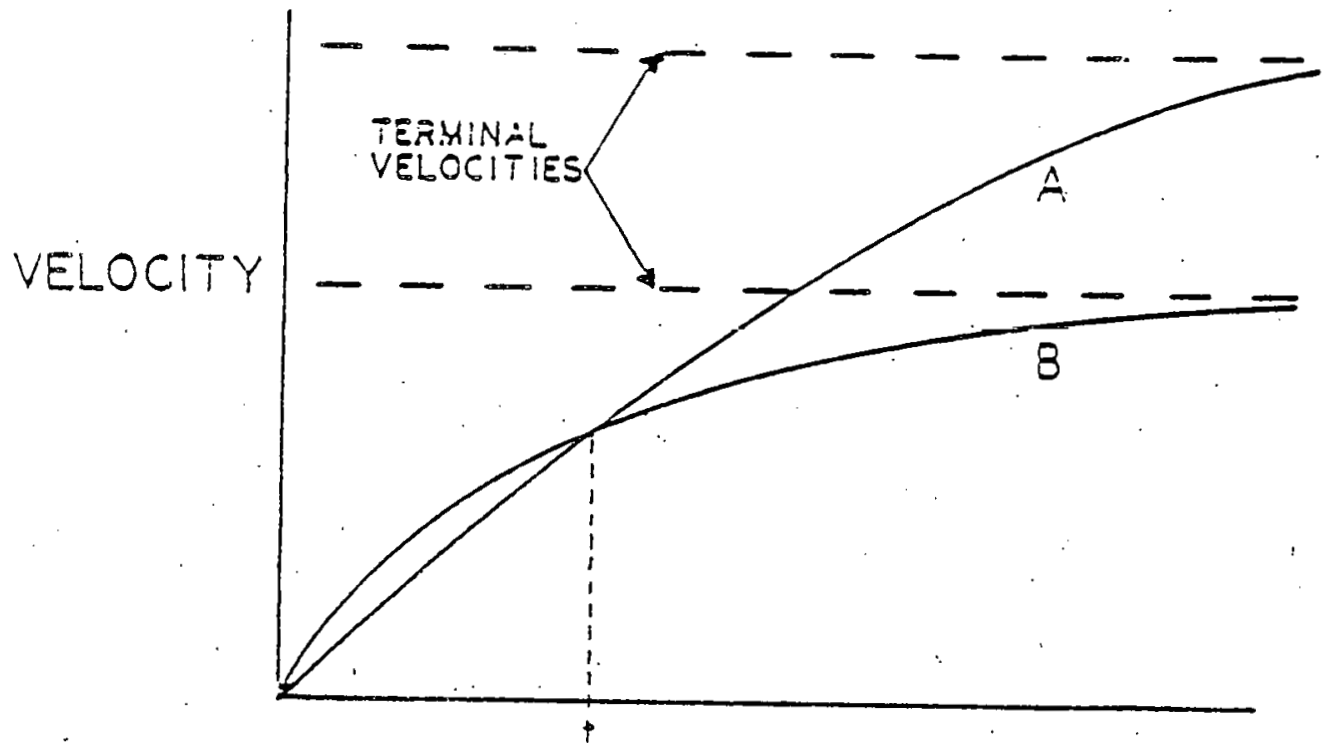

TIME

Fxhibit. 7. Arrelerations from Rest of Particles in a Jig 
gravity. When the plunger is activated, the particle's motion is slowed, stopped, or reversed by an upward motion of liquid. As the plunger reverses direction, the liquid returns to its original level, the original force balance again tends to predominate, and the particle resumes accelerating downward.

Sequential plunges cause particles in a jig to repeatedly lose downward velocity. Referring to Fxhibit 7 , which shows velocities of particles falling from rest in a liquid, a jig causes particles to return again and again to the zone less than time $t$. In this zone, particles $A$ and $B$ separate according to density. After time $t$, particle $A$ begins to fall faster than particle $E$, so that the particles separate according to terminal velocity. Ideally, plunging forces the particles to repeatedly return to accelerations illustrated at times less than $t$.in Figure 2 , causing $B$, the less dense particle, to accelerate as if denser than $A$. No plunging would allow the particles to reach terminal velocity, where the less dense particle, A, would fall faster, as though it were denser than the denser particle, $B$. [6]

Thus, in this ideal system, the particles are separated by density rather than terminal velocity. In processing MSW, such a separation by density would serve to separate the less dense combustible organic matter from the denser noncombustible inorganic matter, producing a higher quality RDF. 


\section{MATHEMATICAL MODELS}

To study pulsed airflow, it is necessary to develop mathematical models which reflect different situations and different ways of modeling the same conditions in air classifiers. Results of these models can be compared and studied in laboratory analyses. In our research efforts, different analyses are incorporated in mathematical models including:

- Mocieling of particles falling through still air. This condition allows computation of particle terminal velocities which can be useful in predicting how à particle will initially behave in an air classifier.

- Modeling of particles falling through a rising airstream. The rising airstream simulates the conditions inside a straight, vertical, air classifier.

- Modeling of particles in an airstream with superimposed ideal pulses. The airflow is divided into a given velocity of steady rising air, onto which is added a pulising airstream with the velocity going from zero to a selected value. 
- Modeling of an airstream with superimposed pulses, generated by a series of Fourier coefficients. The concept of this model is the same as that of Model \#3 above. The difference is that the waveform of the pulsing part of the airflow is determined by a series of Fourier coefficients. In connection with laboratory equipment which allows the Fourier analysis of airstreams, this model allows direct calculation of the theoretically predicted behavior of particles under conditions generated in laboratory equipment.

Extensive laboratory research has been completed using the first model. The other models, which are extensions of this first model, have been developed and subjected to early testing .

The basic model depends on a force balance of a particle falling in air. In simple form, this equation is the same as the force balance in Equation 3-1. Recall: 


$$
F=F_{G}+F_{B}+F_{D}
$$

In order to use the similar idea for air classification, it is first necessary to modify the equation to suit the characteristics of particles falling in air. The use of the resulting quasi-static equation on the microprocessor'will be described in the next section.

The force of buoyancy is assumed to be too small to be significant, and is neglected.

Given:

$$
E_{G}=m g
$$

where:

$$
\begin{aligned}
& \mathrm{m}=\text { mass of particle } \\
& \mathrm{g}=\text { acceleration of gravity }
\end{aligned}
$$

and given:

$$
F_{D}=\frac{1}{2} o_{F}\left(v_{P}-\bar{v}_{A}\right)^{2} A C_{D}
$$


where:

$$
\begin{aligned}
{ }^{\rho}= & \text { fluid density } \\
v_{p}= & \text { particle velocity } \\
v_{A}= & \text { velocity of the air relative to the same } \\
& \text { frame of reference as the particle } \\
& \text { velocity } \\
A= & \text { area of the particle normal to the fluid } \\
& \text { tlow. } \\
C_{D}= & \text { drag coefficient. }
\end{aligned}
$$

The total force on the particle can be expressed as:

$$
\bar{F}_{p}=m \frac{d v_{p}}{d t}
$$

So' the total force balance becomes:

$$
m g-\frac{1}{2} \rho_{F} \quad A\left(v_{p}-\bar{v}_{A}\right)^{2} C_{D}=m \frac{d v_{p}}{d t}
$$


where:

$$
\begin{aligned}
\rho_{F}= & \text { fluid density } \\
v_{p}= & \text { particle velocity } \\
v_{A}= & \text { velocity of the relative to the same } \\
& \text { frame of reference as the particle velocity } \\
A= & \text { area of the particle normal to the fluid flow } \\
m= & \text { mass of particle } \\
g= & \text { acceleration of gravity } \\
C_{D}= & \text { drag coefficient } \\
t= & \text { time }
\end{aligned}
$$

The drag coefficient, $C_{D}$, must be determined às à function of particle velocity. Since it is determined that the Reynolds number could be assumed less than .5 at terminal velocity, it is possible to use an empirical formula that follows the first section of the drag coefficient curve up to the sharp dropoff fairly closely. Exhibit 8 shows the drag coefficient curve and the performance of the empirical equation in following that curve. The equation is: [6]

$$
C_{D} \cdot \frac{24}{\operatorname{Re}}+\frac{6}{1 T+\sqrt{R e}}+0.4
$$




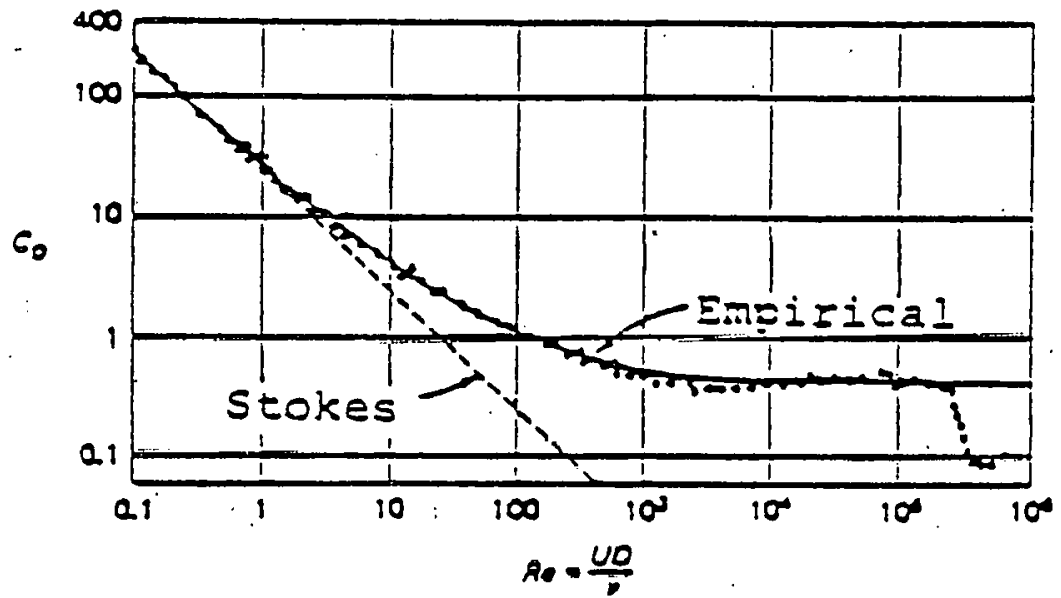

Exhibit 8. Performance of Empirical Drag Coefficient Equation Compared with Datapoints [6] 
where:

$$
\text { Re = Reynold's number }
$$

Using:

$$
\operatorname{Re}=\frac{v D}{v}
$$

where:

$$
\begin{aligned}
v= & \text { relative velocity of particle of air } \\
& \left(=v_{P}-v_{A}\right) \\
v= & \text { fluid (air) kinematic viscosity } \\
D= & \text { particle diameter }
\end{aligned}
$$

The viscosity of air at $20 \mathrm{C}$ is:

So:

$$
\begin{aligned}
& v=1.5 \times 10^{-5} \text { poise. } \\
& \operatorname{Re}=\frac{O\left(v_{P}-\vec{v}_{A}\right)}{1.5 \times 10^{-5}}
\end{aligned}
$$


Therefore:

$$
C_{D}=\frac{(24)\left(1.5 \times 10^{-5}\right)}{D\left(v_{D}-\bar{v}_{A}\right)}+\frac{6}{1+\sqrt{\frac{0\left(v_{D}-\bar{v}_{A}\right)}{1.5 \times 10^{-5}}}}+.4
$$

Now the force balance may be written:

$$
\begin{aligned}
\frac{d v_{Q}}{d t} & =g-\frac{\rho_{F} A}{2 \pi}\left[v_{P}-\vec{v}_{A}\right]^{2} \\
& \cdot\left[\frac{3.6 \times 10^{-4}}{D\left(v_{P}-\vec{v}_{A}\right)}+\frac{6}{\left.1+\sqrt{\frac{0\left(v_{D}-v_{A}\right)}{1.5 \times 10^{-5}}}+.4\right]}\right]
\end{aligned}
$$

All terms are as defined above and summarized in Appendix 1. Even though this equation is separable, it would be very difficult to integrate analytically due to the form of what would become the expression of $\mathrm{v}_{\mathrm{p}}$. The $l$ in the denominator of the second term in the drag coefficient algorithm presents most of the trouble. A computer is necessary.

Numerical methods were used to determine the velocity of the particle. A fourth-order Runge-kutta method designed to handle one equation was chosen. It is RK2, an IBM subroutine, which is shown in the program listing in Appendix 
2. The subroutine is capable of integrating at any selected increment and outputting data at any other increment that is a multiple of the integrating step.

In order to gain a better understanding of what is occurring, it was decided to use a plotting routine. The plotting routine selected is called MGRAPH. MGRAPH is. used together with the ROUND subroutine. Both are shown in the program 1isting in Appendix 2. (4)

A large selection of spheres was obtained for these experiments. The characteristics of these spheres formed the data that were used in the program. At certain stages during this investigation, some of the parameters were varied outside of the range of available particles to enable the determination of the effects of small changes in particle characteristics. Specifically, the program asks for:

- The rising airflow

- The output timestep

- The diameter of the first particle

- The mass of the first particle

- The diameter of the second particle

- The mass of the second particle

- The integration step

- The particle number 
For whatever timestep is chosen, the program will calculate: 41 data points, using however many integration steps are - required. Versions of this program which deal with pulsing airflow include consideration of:

- The steady rising airflow

- The pulsing airflow amplitude

- The pulsing airflow period

- The output timestep

- The integration step

- The particle characteristics as in the previous listing for the general program

The program was run carrying the particles over times.

sufficient for them to reach terminal velocity, in order to permit observation of behavior over the entire acceleration of the particle. In order to insure sufficient resolution to detect as many aspects of particle behavior as possible, the program was run with many different integration and recording steps, with many different particles covering the entire range of particle accelerations to find where effects similar to those found in jigging are located. 
Exhibits 9,10 and 11 show the output of a computer run using the data for sample particles. This set of data gives a good understanding of the theoretical value of pulsed-flow: air classification by showing how density can be isolated as the separation parameter.

The top of Exhibit 9 shows the input to the program. Since it was desired to use the program only to investigate particle falling behavior, VABAR, the average rising air velocity, was set equal to 0 . The timestep of . 2 indicates that the values the program calculates are stored in the output array at intervals of .2 seconds. The integrating step of .01 means that the program calculated the integral over every .01 seconds. The sphere data are taken from laboratory measurements.

The remainder of Exhibit 9 shows the particle fall velocity which the program calculated for each time shown on the far left. The values do not begin at zero because the integrating technique calculates between values. The values are always higher for aphere 1 , which is the less dense, but larger, of the two spheres. The last several values in both columns are constant, indicating that the particles have reached terminal velocity. The table shows that sphere 1 attains the higher terminal velocity. Exhibit 10 shows the velocities for both spheres graphed with time. In both Exhibit 9 and 10 , it can be seen: that the terminal velocity of sphere 1 is the higher of the two. One would expect, 


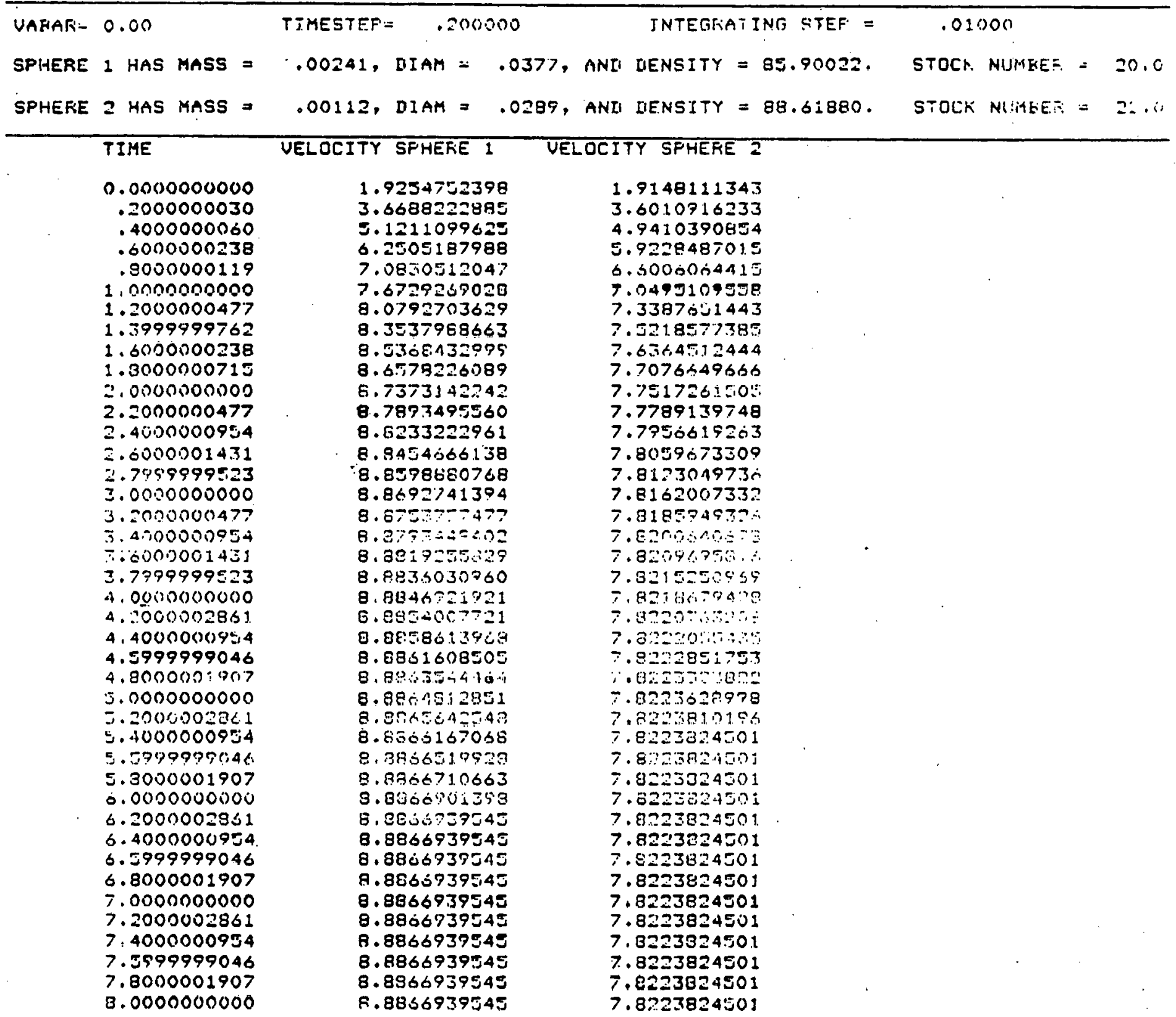

Exhibit 9. Particle and Parameter List; Velocities of Particles for First Eight Seconds Fall 


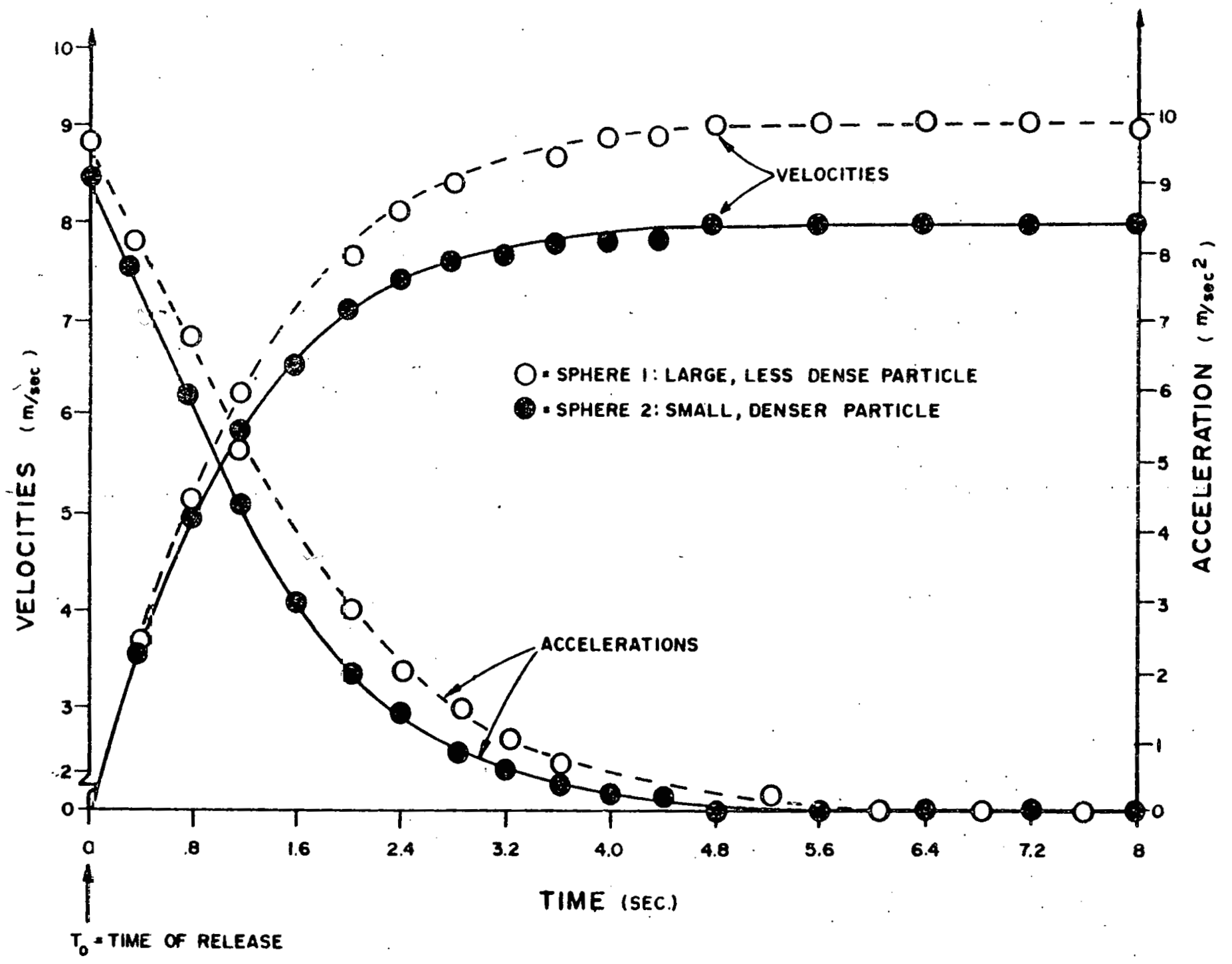

Exhibit 10. Particle Accelerations and Velocities While Approaching Terminal Velocity 
then, these two spheres to "confuse" a steady-flow classifier by sending the less dense particle out with the heavy fraction.

Exhibit 10 also shows the rates of acceleration for each particle at each time shown on the right. The acceleration values are calculated from the velocity values in Exhibit 9. Exhibit 10 shows that, as with velocity, acceleration values for sphere 1 are always higher. The mechanies if the integialiun system prevents the accelerations from completely reaching zero.

Recall the theory of jigging, where buoyancy is important in generating the crossing-over of the velocity curve's which leads to jigging's ability to separate particles by density. In paralleling the theory of jigging in air classification, however, the buoyancy term is assumed to be negligible and is thus neglected. Therefort, one must look for properties of the particle fall curves, in Exhibit 9 and 10, which would lead to similar changing of the order of fall velocities and subsequent separation of particles by density.

Three sequential hypothetical cases are considered. The purpose of these cases is to discuss the role of terminal velocity. in pulsing flow. All cases invulve pulsed airflow. The first two cases use any particle. In the first case, the airflow is adjusted so the particle is in equilibrium in the air classifier frame of reference. In the second case, the average airflow is adjusted so the particle has a net 
movement with respect to the air classifier. In the final case, two particles are selected where terminal velocities are very close to one-another, and the airflow is adjusted so one particle rises slowly and the other falls slowly. Recall the purpose of the cases is to discuss the role of terminal velocity in pulsing airflow.

The first case is a pulsing, rising airstream through which a particle is falling. The speed of the rising airstream is increased to hold the particle in equilibrium about a constant vertical height relative to the reference frame of the classifier. At least at some instant in the cycle of any pulse, the particle would, theoretically, be at terminal velocity in relation to the instantaneous rising air velocity. If the particle were never to reach terminal velocity at any point during the pulse, the particle would exhibit a net acceleration, and would not be at equilibrium. At a given point in the pulse, the particle would be below terminal velocity relative to the airflow. It is also possible that, due to the particle's momentum, it might accelerate to slightly beyond terminal velocity at some other point during the pulse when the pulse is causing the rising airstream to accelerate.

Extending the first situation, if the particle were not held hovering about the same point in the classifier, but were instead allowed to proceed slowly up or down by increasing or decreasing the average air velocity, one would 
expect the variations about terminal velocity to be analogous to the situation with a rising airstream adjusted for equilibrium; namely, that the particle would be reaching terminal velocity at some point during the pulse cycle, but these periodic attainments of terminal. velocity occur in this case when the particle is moving slightly up or down, depending on the situation selected, relative to the reference frame of the classifier.

Going to the final situation, if one were to inject two particles whose terminal velocities were only slightly different into the air classifier, with the pulsing airflow adjusted such that each particle would move very slowly, but with one rising and the other falling, then both particles attain terminal velocity at some point during the pulse, with respect to the rising airstream. The terminal velocity considerations for each particle are the same as in the first and second cases, but, as the flow is adjusted, with one particle having a net movement upwards and the other having a net movement downwards. This progression of situations 1 through 3 indicates that the behavior of the particles should be examined on the basis of the time back from terminal velocity. For example, one is not interested in comparing both particles $x$ seconds after they begin to fall, but rather, one is interested in comparing both particles $Y$ seconds before each reaches terminal velocity. 
Exhibit 11 shows the accelerations of spheres 1 and 2 referenced to the time when terminal velocity is attained, $I^{\prime}$. The purpose is to align the times of reaching terminal velocity for each particle. Exhibit 12 is a further refinement of Exhibit 11 modified to show the detail important to this discussion. The time axis is redefined with $T^{\prime}=0$ to indicate seconds before attainment of terminal velocity. The data are again taken directly from Exhibit 10. with the constant acceleration shown at terminal velocity subtracted from each value so that terminal velocity exhibits zero acceleration. As was mentioned earlier, this step is merely a correction for the small error caused by the method of integration. Exhibit 12 uses the log of the accelerations to compress the range and illustrate the exponential behavior of the acceleration. A best-fit line is also drawn for each particle.

Exhibit 12 shows that, for the first few timesteps before terminal velocity, the acceleration of sphere 1 remains higher than sphere 2 , just as it did in Exhibit 11. Somewhere around 1.6 seconds before terminal velocity, however, the lines cross at point $A$, and the particle with the higher terminal velocity has the lower acceleration. Thus, if one could, through pulsing, hold sphere 2 far enough from terminal velocity for periods long enough to allow its average acceleration to be higher than that of sphere 1 , sphere 2 would eventually accelerate to a higher falling 


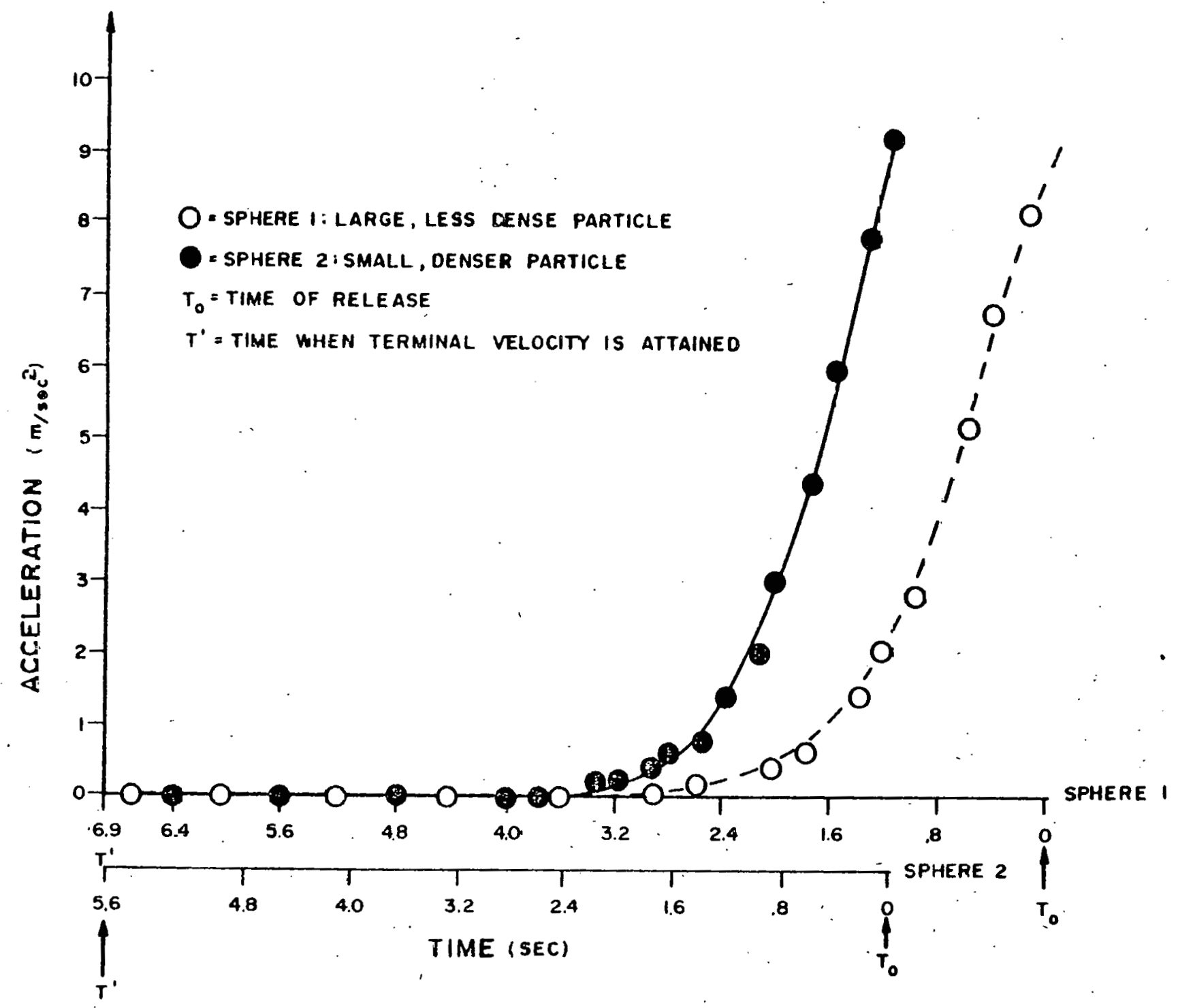

Exhibit 11. Particle Accelerations Referenced to Time when Terminal Velocity is Attained 


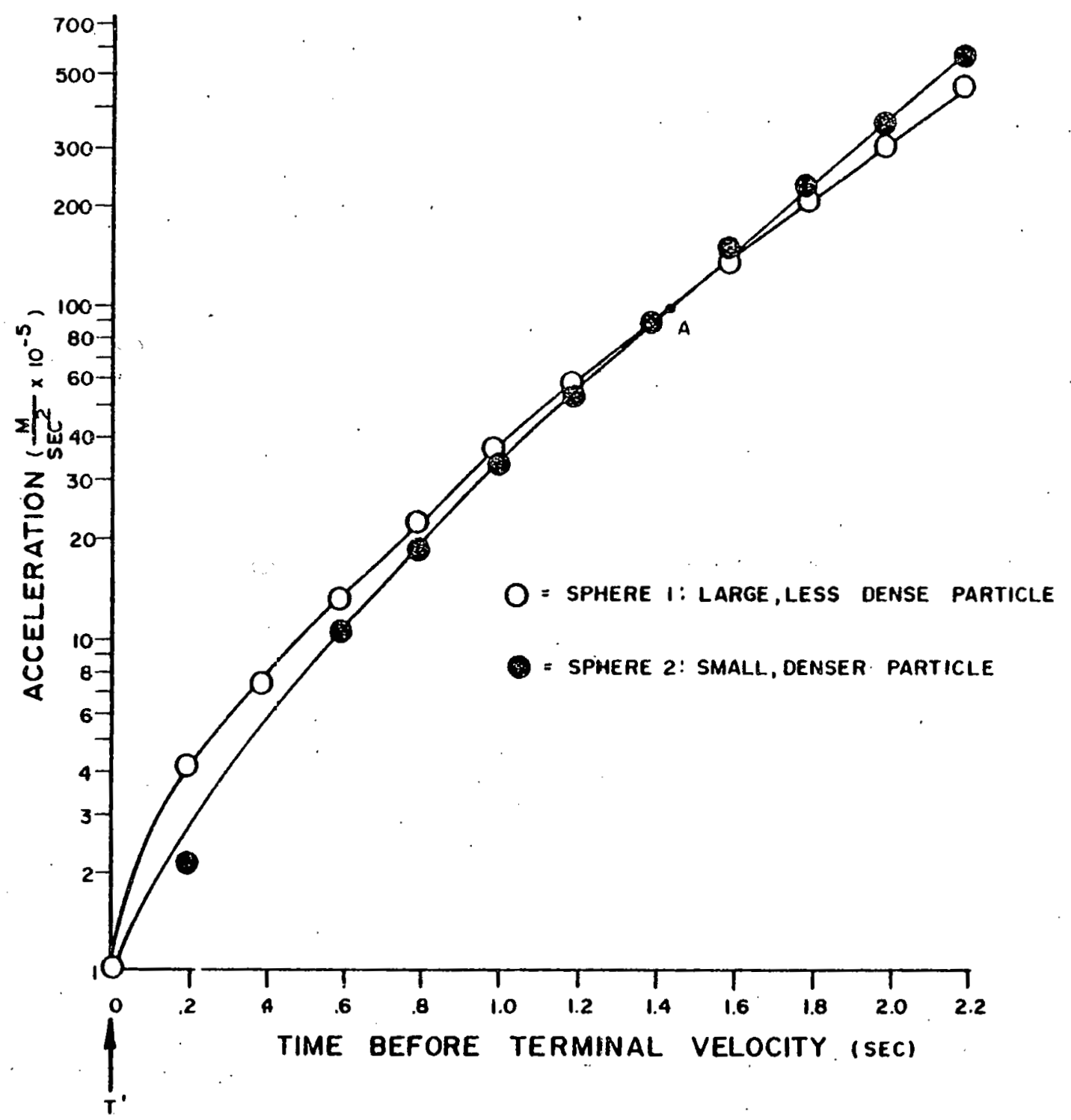

Exhibit 12. Log of Accelerations of Falling Particles at Times Before Attaining Terminal Velocity 
velocity than sphere 1 . Sphere 2 would then fall out the bottom of the classifier, while sphere 1 would rise out the top. In this manner, pulsing would rectify the confusion in the air classifier split.

\section{ACCELERATION EFFECTS}

It must be kept in mind that the objective of this research is to find a way to reverse the order of fall, which translates to manner of separation, for two particles whose aerodynamic behaviors are similar. In tërms of refusederived fuel, one is concerned with correcting an overlap in separation between two components of the feed; the dense, generally non-combustible inorganics and the less dense, generally combustible organics. the result would be an improvement in separation efficiency.

One of the most important effects is that termed, variously, the acceleration effect, the acceleration reaction, or the added-mass effect. For spheres, the force manifests itself in the opposite direction of the sphere acceleration and is expressed as:

$$
F=-\frac{1}{2} m_{E} a
$$


where:

$$
\begin{aligned}
& F=\text { force due to the acceleration reaction } \\
& m_{f}=\text { mass of the displaced fluid } \\
& a=\text { particle acceleration }
\end{aligned}
$$

The experimental implications indicate that a net acceleration is required in the passage of a particle through an air classifier to achieve a net added-mass effect. This indicates that any symmetric waveform of constant amplitude will probably not show any acceleration effects. While still requiring verification, examination of asymmetric waveforms for the pulsed air is indicated by the theory. Success with pulsers in the laboratory is probably due to slight asymmetry in the sharply peaked waveform which the pulsers produced. The literature review discussed above disclosed that very little theoretical work on large particles in air was done after the early 1960 's. We studied the most important works dealing. with the acceleration effects in the phases of the literature search which entailed personal interviews with researchers using the theory. Books by Birkhoff, [1] Lamb, [2] and Yin [7] werc suggester and examined. An interesting series u[ review articles by Torobin and Gauvin [5] was also discovered. 
Some authors question the validity of the theoretical expression for acceleration reaction in certain real-life slow regimes. It appears that, depending on the type of fiuid and the magnitude of the accelerations, the theoretical expression may hold for only a diameter or so of particle motion. After moving a, diameter, vortex shedding occurs, and the particles no longer feel the full acceleration effect. other research cited in the literature suggests that the effect is greater than that predicted by theory.

Most researchers tend to resort to experimentation. However, there is a huge range in the conditions which one might test, and it appears that there are no selected studies with results directly applicable to our work. For example, some researchers have tested various geometric shapes oscillating in water, very small particles injected into high-velocity air-streams, and particles in an oscillating fluid. Howcver, no researcher has tested spheres in an airstream with superimposed oscillation acting against a body Force.

To expand this discussion and develop an expression involving the acceleration effect, begin with equation $3-6$, repeated herc 


$$
m g-\frac{1}{2} \rho_{F} A\left(v_{p}-\bar{v}_{A}\right)^{2} C_{D}=m \frac{d v_{p}}{d t}
$$

Then, the acceleration effect term, expressed in equation 312 is added, so that:

$$
m g-\frac{1}{2} m_{f} a-\frac{1}{2} \rho_{F} A\left(v_{p}-\bar{v}_{A}\right)^{2} C_{D}=m \frac{d v_{p}}{d t}
$$

using notation as before. Then equation 3-i0 is input for drag coefficient term. After algebraic manipulation is performed, the final force balance becomes:

$$
\begin{aligned}
& \frac{d v_{p}}{d t}=1-\frac{\pi D^{3} \rho_{F}}{12 m}\left\{g-\frac{\rho_{F} A}{2 m}\left[v_{\dot{P}}-v_{A}\right]^{2}\right. \\
& \left.\left[\frac{3.6 \times 10^{-4}}{D\left(v_{P}-\bar{v}_{A}\right)}+\frac{6}{1+\frac{D\left(v_{p}-\bar{v}_{A}\right)}{1.5 \times 10^{-5}}}+.4\right]\right\}
\end{aligned}
$$


where:

$$
\begin{aligned}
& v_{p}=\text { particle velocity } \\
& t=\text { time } \\
& D=\text { particle diameter } \\
& F=\text { fluid density } \\
& A=\text { cross-sectional area of particle } \\
& m=\text { mass of particle } \\
& v_{A}=\text { air velocity, incorporatinq expression for pulsing } \\
& \text { air flow (e.g. Fourier series, sine wave) }
\end{aligned}
$$

Equation $3-15$ is a force balance containing the important forces acting on spheres in a rising air stream as found in a vertical air classifier. This force balance thus can be used to model the behavior of particles in a pulsed-flow air classifier. Adjustment of terms in $v_{A}$ in equation 3-15, i.e. terms which describe air flow behavior, including absolute magnitude of air flow, pulse amplitude, frequencyi, and wave form, will change the predicted separation performance of the air classifier. Based on these predictions a classifier can be designed and constructed in the laboratory to produce a desired air flow pattern and subsequent desired separation of particles. The next, chapter in this report documents initial attempts to move from this theoretical development into the laboratory. 


\section{CONCLUSIONS}

The conclusions from this development of the theory of pulsed-flow air classification can be listed as:

1) Previous research efforts on air classifier theory have been statistically based, and give little aid to the design engineer. This pulsed-flow effort is deterministic, and can guide the design of pulsed-flow air classifiers. Of particular importance are the design considerations of pulse frequency, amplitude and wave form.

2) The theory behind pulsed flow air classification indicates that current designs for air classifier cannot avoid poor separation of particles in a complex mixture because the classifiers do not cause prolonged or repeated periods of acceleration. 
3) Pulsed-flow air classification theoretically separates particles by retarding particle approach to terminal velocity and/or forcing repeated retreats and renewed approaches.

4) The applicability of the acceleration effect to air classification using pulsed airflow cannot be understated. The state of knowledge in acceleration effects indicates that laboratory analysis go hand and hand with theoretical work so the exact manner in which the acceleration effect behaves can be determined.

The computer programs supporting the development of this theory to date are listed in Appendix 2. 
REFERENCES

1. Birkhoff, G., A study in Logic Fact and similitude, Revised Edition. Princeton, N. J.: Princeton University Press, 1960, Ch. 6.

2. Lamb, H., Hydrodynamics. New York, Dover Publications, $1932, \mathrm{Ch} .6$.

3. McNabb, M. Fundamental Aspects of Air Classifier Operations and Design: A New Test for Evaluation of Air Classifier Performance. Duke University: Durham, N.C.: Center for Environmental Engineering, October, 1980, pp. 16-17.

4. Medina, M. A., Level III: Receiving Water Quality Modeling Eor Urban Stormwater Management. Cincinnati, Ohio: U. S. Environmental Protection Agency, August 1979, pp. 192-195.

5. Torobin, T.. R., and Gauvin, W. Il., "Fundamental Aspects of Solids-Gas Flow: Part III. Accelerated Motion of a Particle in a Fluid." Canadian Journal of Chemical Engineering, December, 1959, pp, 224-36. 
6. Vesilind, P. A., and Rimer, A. E., Unit Operations in Resource Recovery Engineering. Englewood Cliffs,

$$
\text { N. J.: Prentice-Hall, Inc., 1981, p. } 165 .
$$

7. White,. F., Viscous fluid Flow: McGraw Hill, 1974,

$$
\text { p. } 207 .
$$

8. Yih, C., Fluid Mechanics. N. Y., McGraw-Hill, 1969, Ch. 4 . 
CHAPTER IV

LABORATORY ANALYSIS

The goal of this laboratory analysis is to quantitatively compare pulsing air classifier configurations with two non-pulsing air classifier configurations. In order to achieve this goal, the following objectives are met as described in this chapter:

- Design and construct four representative pulsing classifier configurations.

- Determine the extent to which pulsing occurs in each configuration.

- Obtain separation data for various types of feed in pulsing and non-pulsing configurations.

- Evaluate the data and calculate the level of perlormance for each configuration. Compare the performance of pulsing to non-pulsing classifiers. 
Section $I$ addresses the basic design considerations for pulsed air classifiers. Section 2 contains a'description of the laboratory equipment that was used during experimentation. This includes the air classifier apparatus, the velocity measuring device, and the feed types which were tested: Section 3 . contains a detailed account of the methodology used in this research. This is divided into sections on preparing the feed, performing the experiments; and obtaining the separation data.

In section 4 , the results of the experiments are presented and analyzed. The method of calculating a level of performance for each configuration is described, and the classifiers are compared on the basis of these values. Section 5 summarizes the cruclusions of this research.

\section{- DESIGN CONSIDERATIONS FOR LAB-SCALE CLASSIFIERS}

The general premise of air classification is that a mixture of particles entering an airstream will be separated into constituents by a vertical air flow. One example of an air classifier, the straight-walled classifier, is shown in Exhibit 13. Devices such as this have been used successfully in the mining and agricultural industries, where the feed is relatively homogeneous, except for the weight difference of the components. For example, ore and tailings are separated readily in an air classifier, since their densities are very different. Grain and chaff are easily separated for the same reason. The 


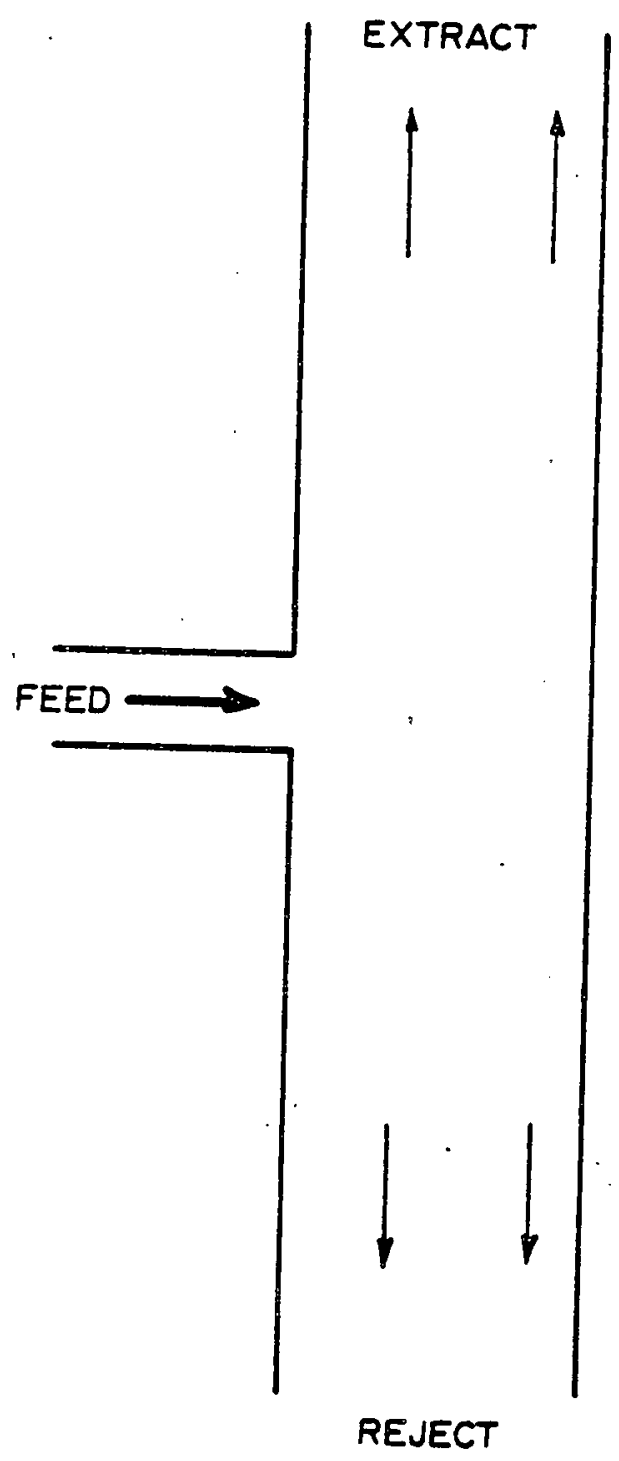

Exhibit 13. Straight-walled Air Classifier 
composition of feed at a waste-to-energy production facility though, is much more complex than these examples, so this mixture is not as easy to separate.

In this facility, the combustible materials such as paper, plastic, yard waste, and other organics, are ideally extracted from the incoming MSW and converted to refuse-derived fuel (RDF). The non-combustibie materials such as ferrous and non-ferrous metals, glass, rocks, and other inorganics are ideally collected and recycled. Coincidentally, the combustible materials are generally of lower derisities than the non-combustibles, so the two groups are further described as "lights" and "heavies". The effectiveness of the waste-to-energy process is largely dependent or effective separation of the MSW into these two categories.

Past and current research at Duke University indicates that the effectiveness of air classification in MSW separation is partly dependent on characteristics of the feed. Preliminary investigation by Bartlett and Vesilind [1] shows moisture content to be a major variable in air classifier performance. Taub and Peirce [7] determined that performance is also affected by feed composition. Saul and Peirce [3] found that varying the proportion of paper in the feed has a significant effect on the purity of the extract. Paper tends to entrain glass particles, and at high concentrations results in greater contamination of the extract. 
The particle-to-particle interaction observed by Taub, Saul and Peirce is discussed by Savage, Diaz and Trezek [4] in terms of a general parameter, the air/solids ratio. This value is defined by them as the mass flowrate of air divided by the mass flowrate of total solids. Their evaluations of several different classifiers show that operation below a critical air/solids ratio can significantly jeopardize the quality of separation. Only above this critical value is particle-to-particle interaction prevented, and stable air classification obtained.

Since varying the characteristics of the feed has significant effects on separation, most experimental research in air classifier design is done with a simple feed composition and at a high air solids ratio. For instance, senden [5] used square, paper particles and a very high air/solids ratio to study the effect of variations in stage geometry on particle behavior. As he varied the angle of bend in a zig-zag classifier, shown in Exhibit 14, he not only observed particle behavior but also determined flow patterns of free-floating, helium-filied soap bubbles.

Wittenberg and Peirce [9] also studied the effect of varying the stage angle of zigzag air classifiers. Two important results of their research are that increasing the stage angle above 120 degrees has a detrimental effect on performance, and that increasing the number of stages has a beneficial effect on performance. 
.88

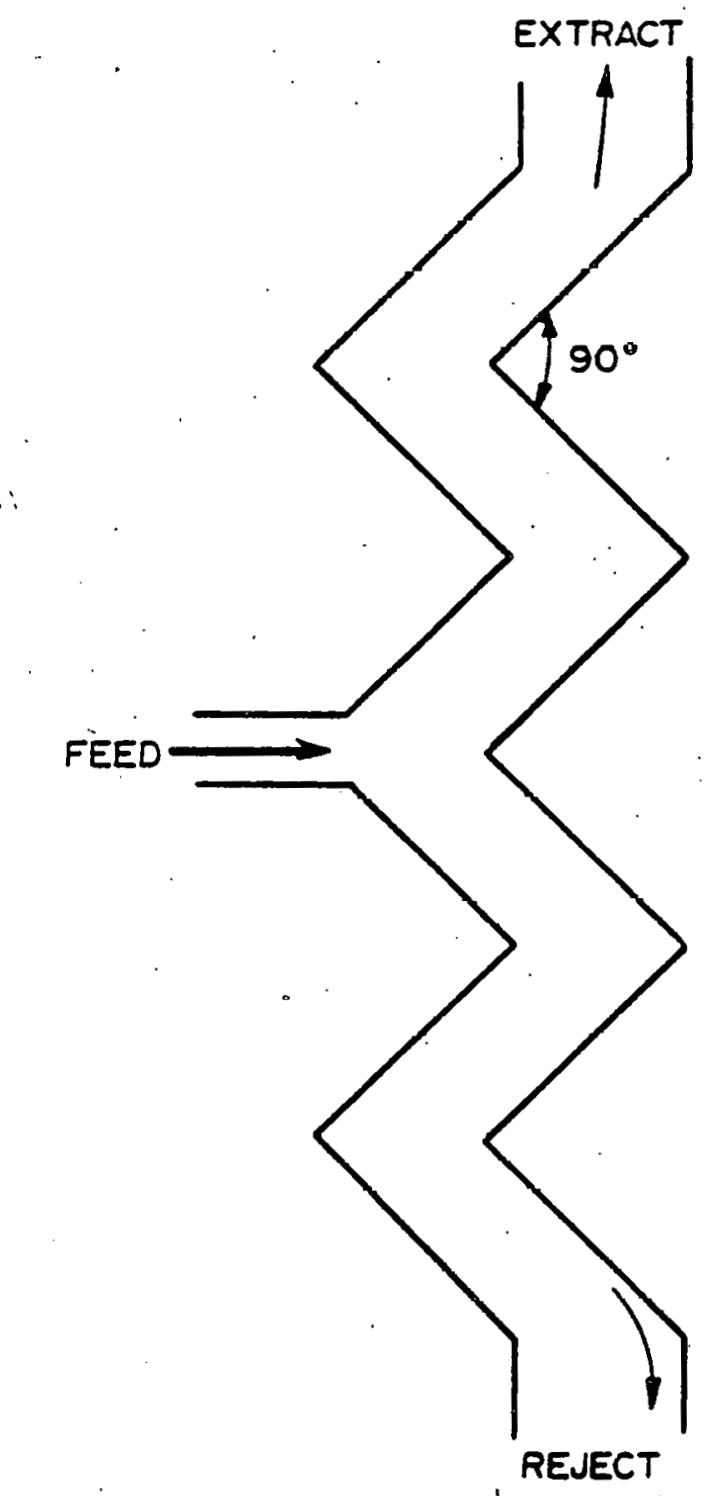

Exhibit 14. Zig-Zag Air Classifier 
An interesting theory in air classifier design was introduced by Stessel and Peirce in 1981. [6] They proposed that the classifier airstream be turned alternately "on" and "off", creating a pulsing effect. This was expected to diminish the effect of aerodynamic characteristics on separation by preventing particles from reaching their terminal velocities. As a result of repeatedly changing particle accelerations, the particles would accelerate downward at a rate more directly proportional to their respective densities. Thus the effect of density on particle separation would be amplified.

Stessel and Peirce tested this theory by applying a. mechanical pulser to a vertical volume of air. After obtaining encouraging results from these tests, they proposed that the pulsing effect be achieved passively, by altering the design of the classifier walls. They suggested the construction and testing of a "Multiple-waisted Classifier", shown in Exhibit 15, which they expected to exhibit pulsing by alternately constricting and expanding the area through which the air flowed. This design was adapted to the present research, and renamed the " $\mathrm{Zag}-\mathrm{Zag}$ " classifier.

A particle within the Multiple Waisted Classifier ideally experiences alternating regions of positive and negative acceleration. In order to magnify the effecte of the pulsing, each region of gradual acceleration could be replaced by a sudden restriction in the throat, which would create a small area of 


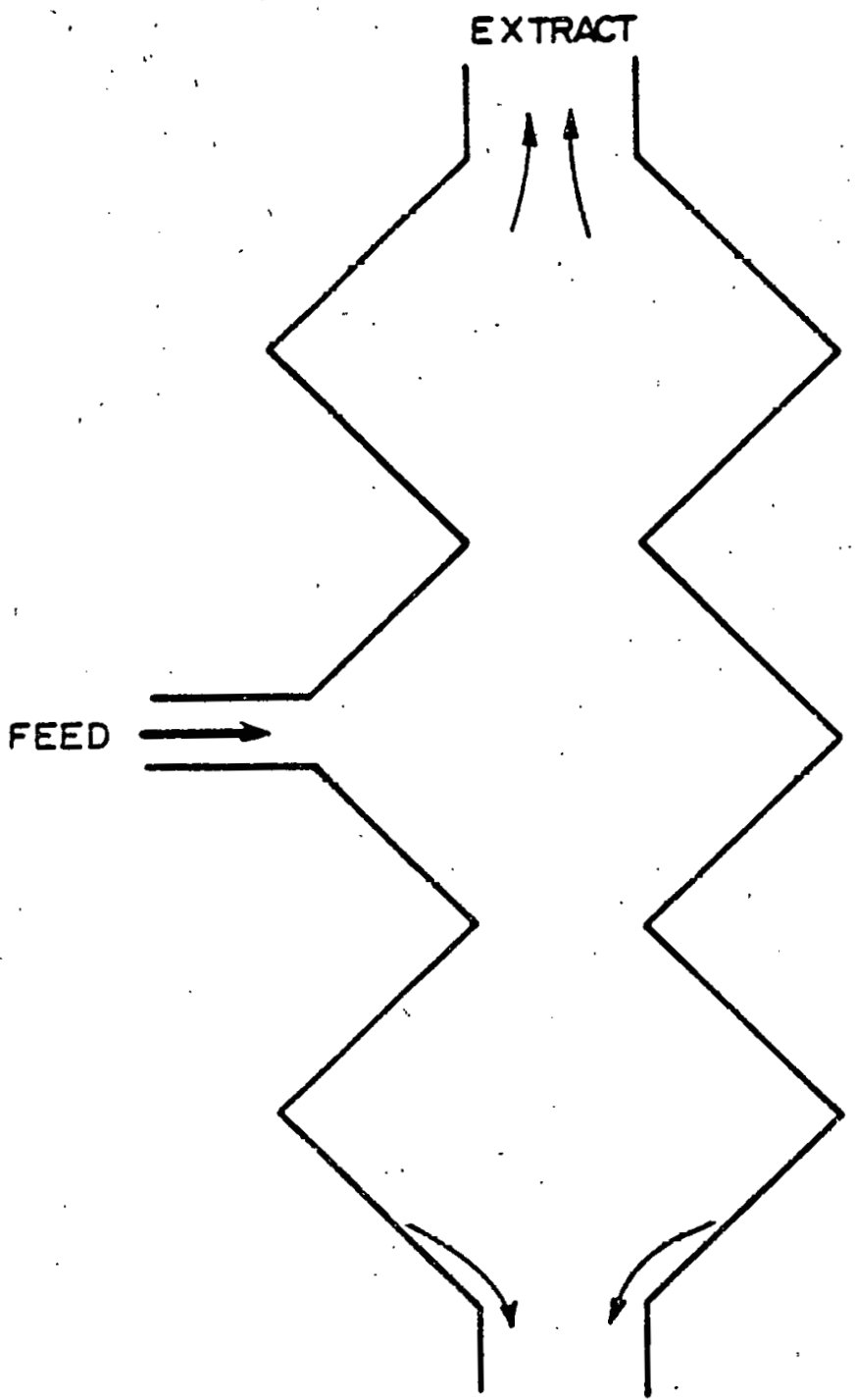

REJECT

Exhibit 15. Zag-Zag Classifier 
sharp acceleration. The resulting shape is tested in this research, and referred to as the "stacked Triangle" configuration, shown in Exhibit 16 .

While air classification has been studied by several different teams of researchers, there is yet to be developed a standard means of evaluating the performance of an individual classifier. Savage, Diaz and Trezek [4] use the ratio of recovered energy to retained ash as their parameter for comparison among classifiers at waste-to-energy facilities. This value is useful in predicting the energy recovery from the light fraction, but ignores the heavy fraction completely.

A more appropriate method of assessing performance was developed by Worrell. [10] He suggested that an efficiency, E, of a classifier be obtained by the following formula:

$$
E=\frac{X_{e}}{X_{0}} \cdot \frac{Y_{r}}{Y_{0}}
$$

where: $x_{e}=$ mass of lights extracted

$x_{0}=$ mass of lights in feed

$Y_{r}=$ mass of heavies rejected

$Y_{O}=$ mass of heavies in feed 


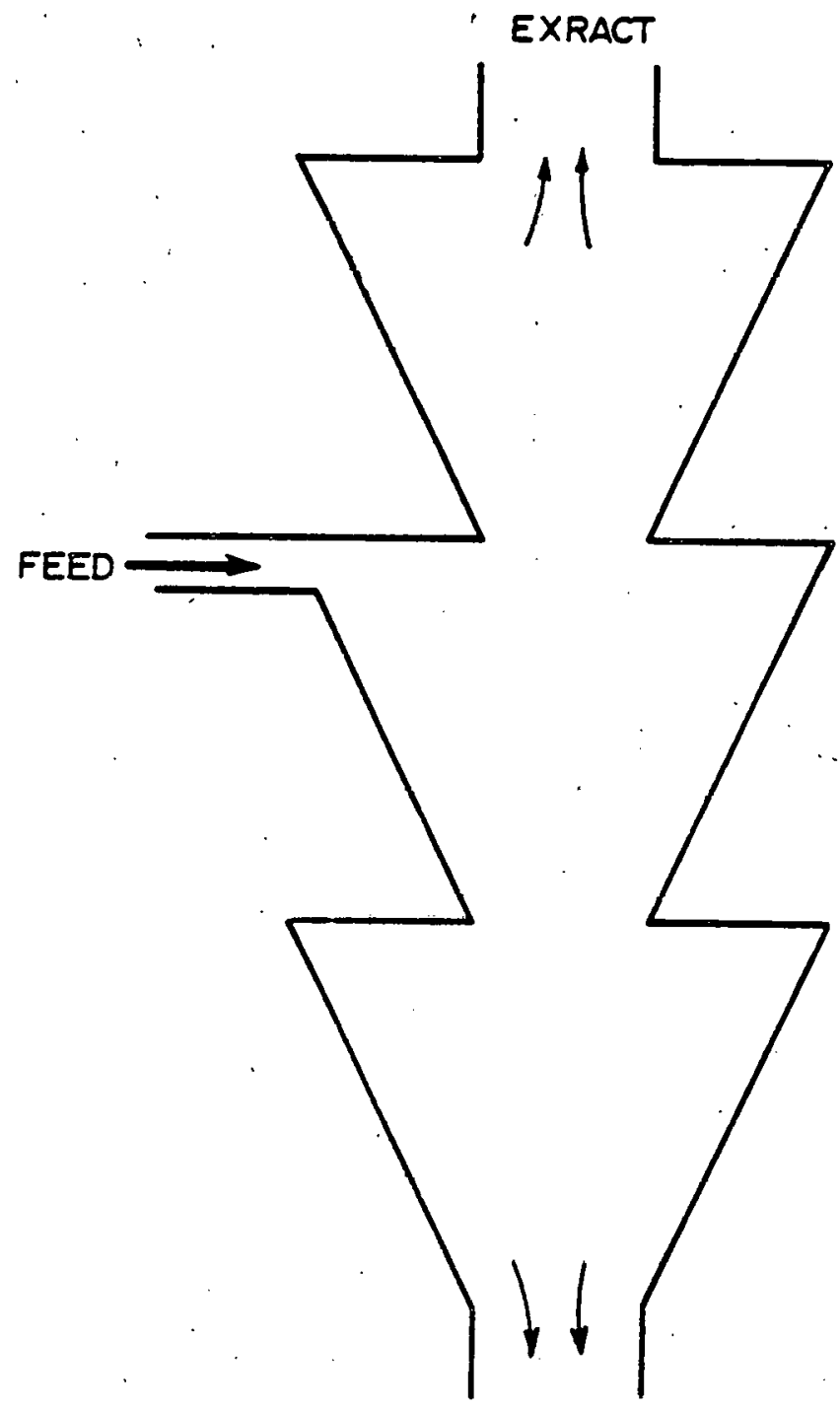

REJECT

Exhibit 16. Stacked-Triangle Classifier 
This method was used by several subsequent researchers at Duke University, but was eventually revised by Stessel and Peirce. [6] Stessel and Peirce, in effect, transformed Worrell's parabolic equation into a linear relationship by using the square root of the final efficiency.

$$
E=\sqrt{\frac{X_{e}}{X_{0}} \cdot \frac{Y_{r}}{Y_{0}}}
$$

By this new expression, a 508 recovery of each fraction yields a final efficiency of 50\%, whereas by worrell's original expression the final efficiency would be $25 \%$. It is this modified form of Worrell's efficiency which is used in the present research.

\section{EQUIPMENT}

The air classifier used in this project was a "variable-wall" laboratory model, constructed at Duke University. Air was drawn through the classifier by an industrial induction fan, connected to the classifier by 7 meters $(23 \mathrm{ft}$ ), of 26 centimeter (cm) (10 in) diameter. flexible hosing. The air speed was varied by adjusting the sliding gate valve between the fan and the connecting hosing. The entire system is shown in Exhibit 17. 


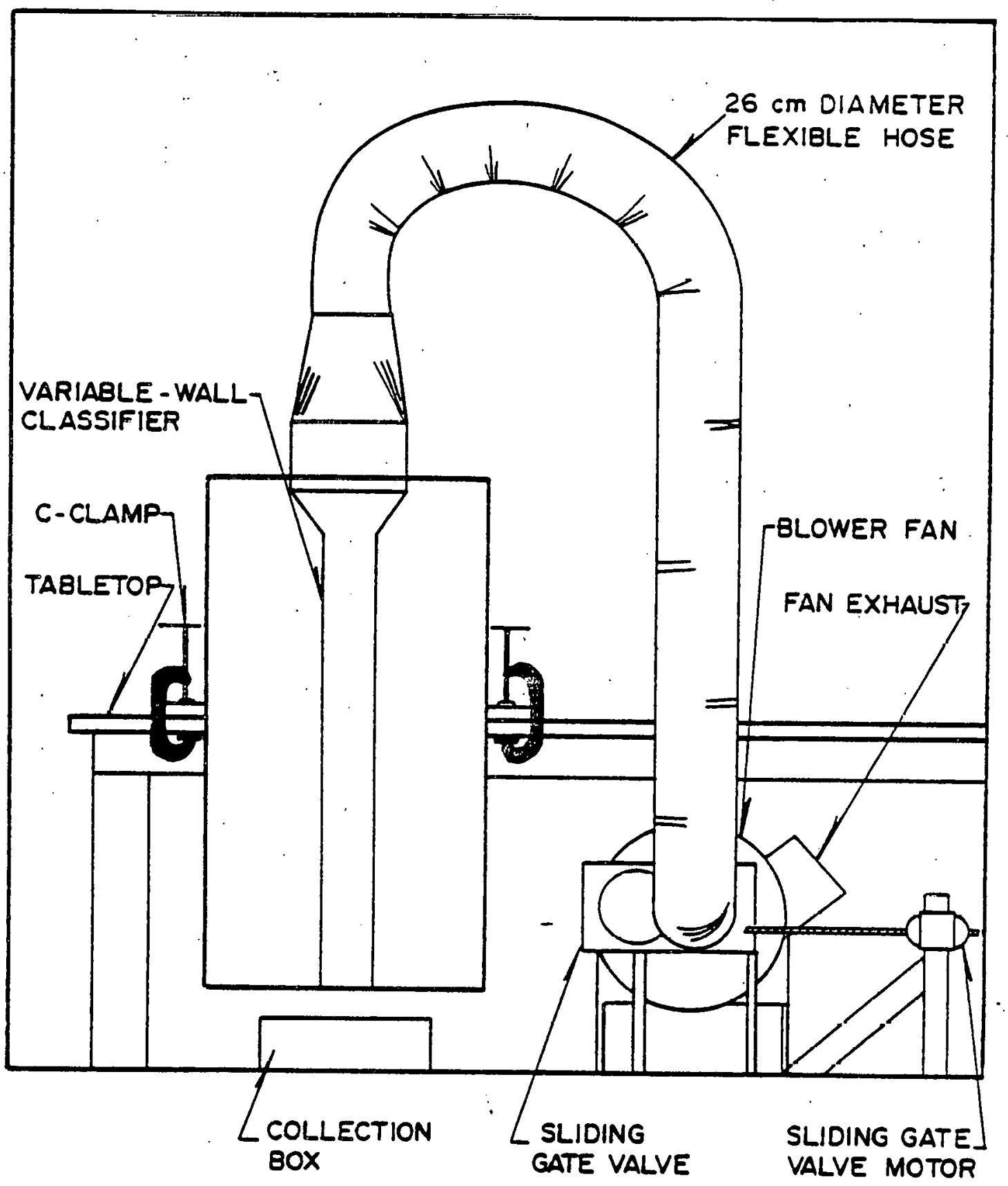

Exhibit 17. Laboratory Classifier System 
The term, "variable-wall", refers to the feature that allowed different shaped walls to be formed on the same basic classifier. The $12.5 \mathrm{~cm}(5 \mathrm{in})$ deep walls consisted of varying lengths of plexiglass, connected by duct tape, and held in place by bearing pressure from the plexiglass face. Weather-stripping was used to prevent air leaks between the walls and the face. The interchangeable walls facilitated easy transition among the Straight, Zig-Zag, Zag-Zag, and stacked Triangle configurations, the details of which are shown in Exhibits 18 through 21 .

Based on results from the literature search, design parameters such as wall depth, throat width, stage height, stage angle and number of stages were held constant where applicable. The only variable among the classifiers was the shape of the enclosed throat.

Air speed in. the classifier throat was measured by inserting a TSI hot wire anemometer through Port \#I which was located along the centerline of the classifier wall, at the height shown in Exhibits 18 through 21. The voltage drop across the sensor was read from a Micronta vultimeter, and converted to the corresponding calibrated velocity. Velocity profiles were obtained at each of the six ports by linking the voltimeter to a Vector-Graphics microprocessor. Three different types of feed were used in this research. The first type consisted of a 40 gram $(1.4 \mathrm{oz}$ ) sample of $2.5 \times 2.5 \times 0.1 \mathrm{~cm}(1.0 \times 1.0 \times .04$ in) plates in various proportions of aluminum and plastic. The second type was a $20 \mathrm{gm}(0.7 \mathrm{oz})$ mixture of shredded aluminum and plastic. The last type was a $100 \mathrm{gm}(3.5 \mathrm{oz})$ mixture of shredded paper, 

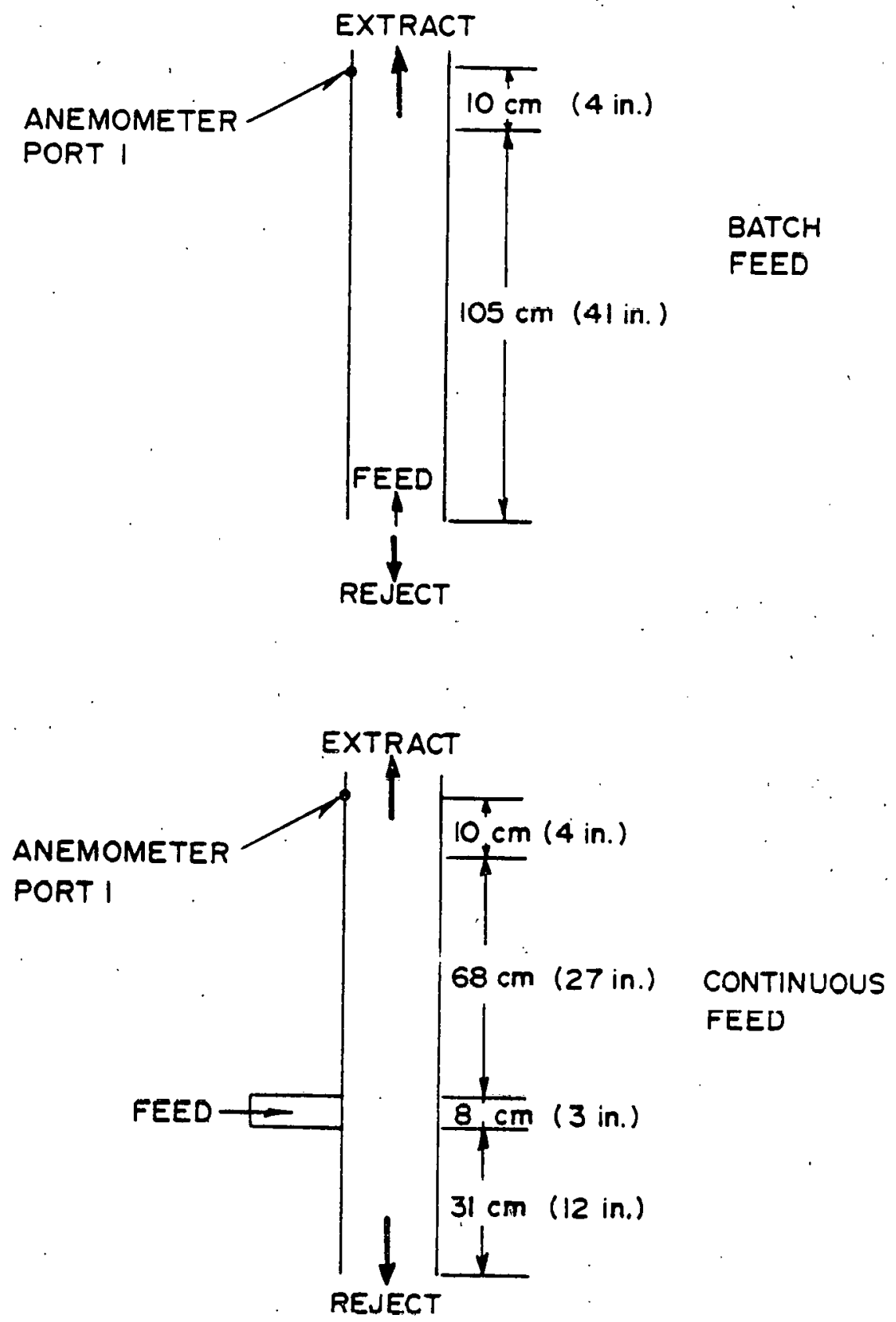

Exhibit 18. Straight Wall Classifier 

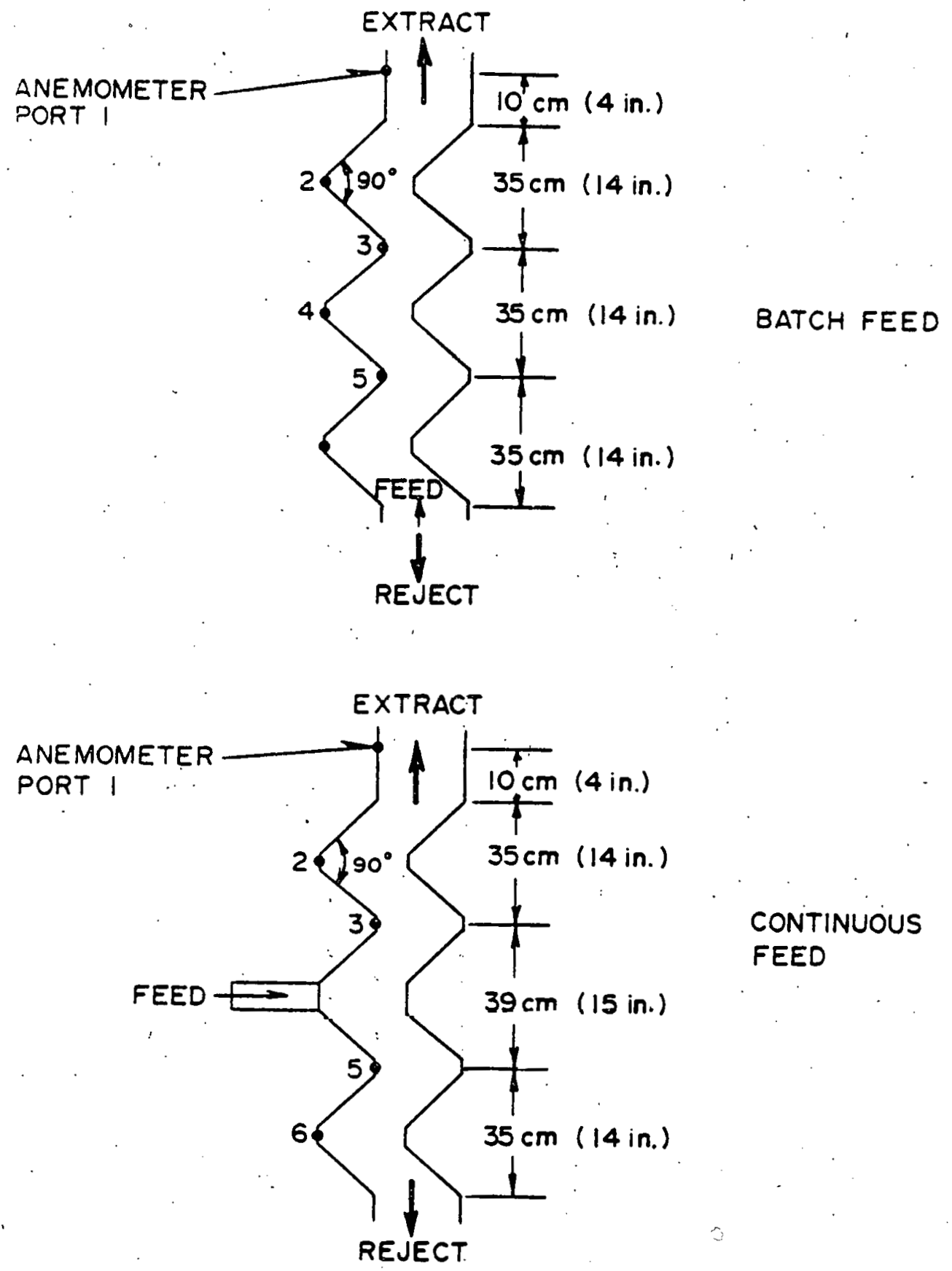

Exhibit 19. Zig-Zag Classifier 

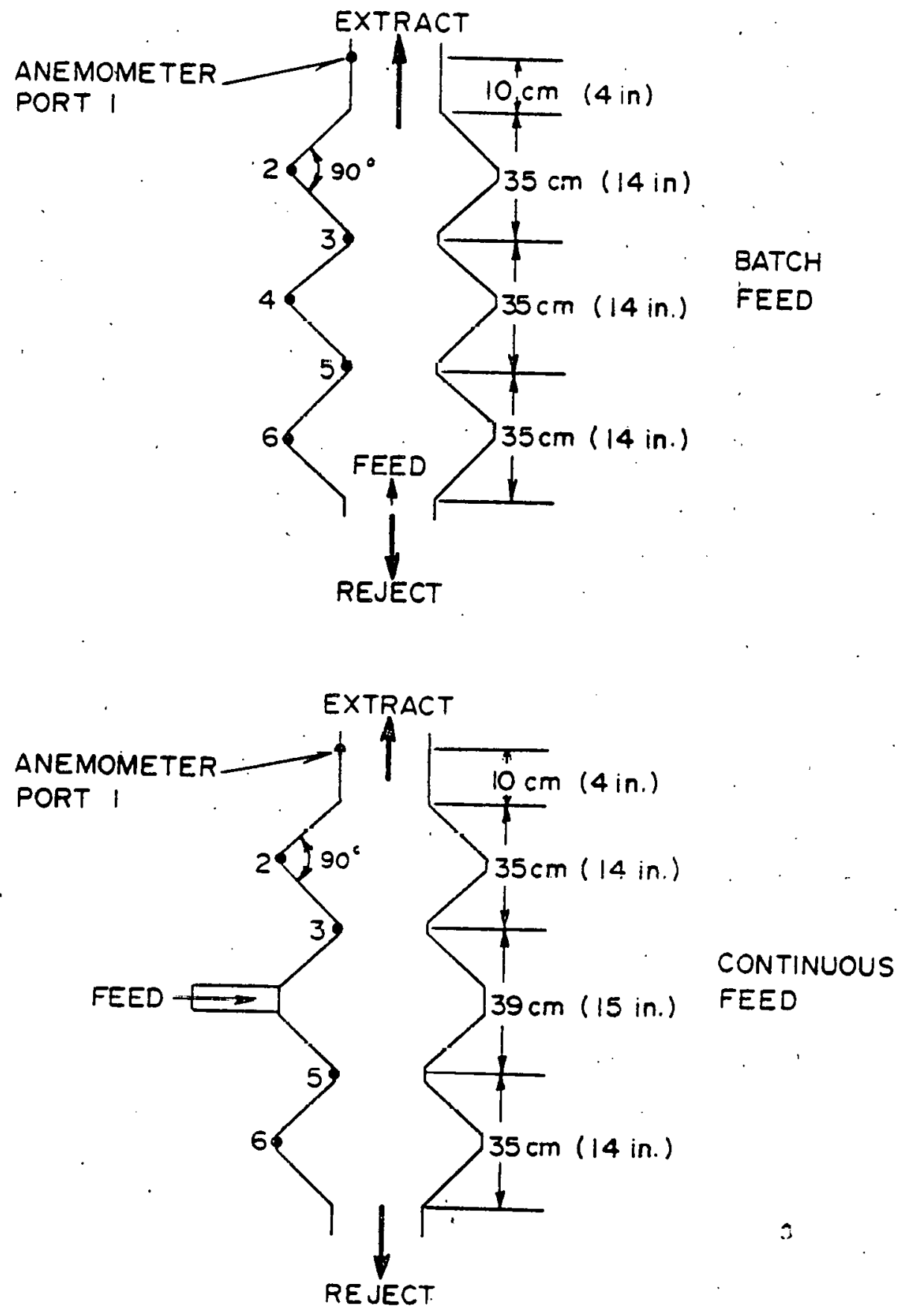

Exhibit 20. Zag-Zag Classifier 


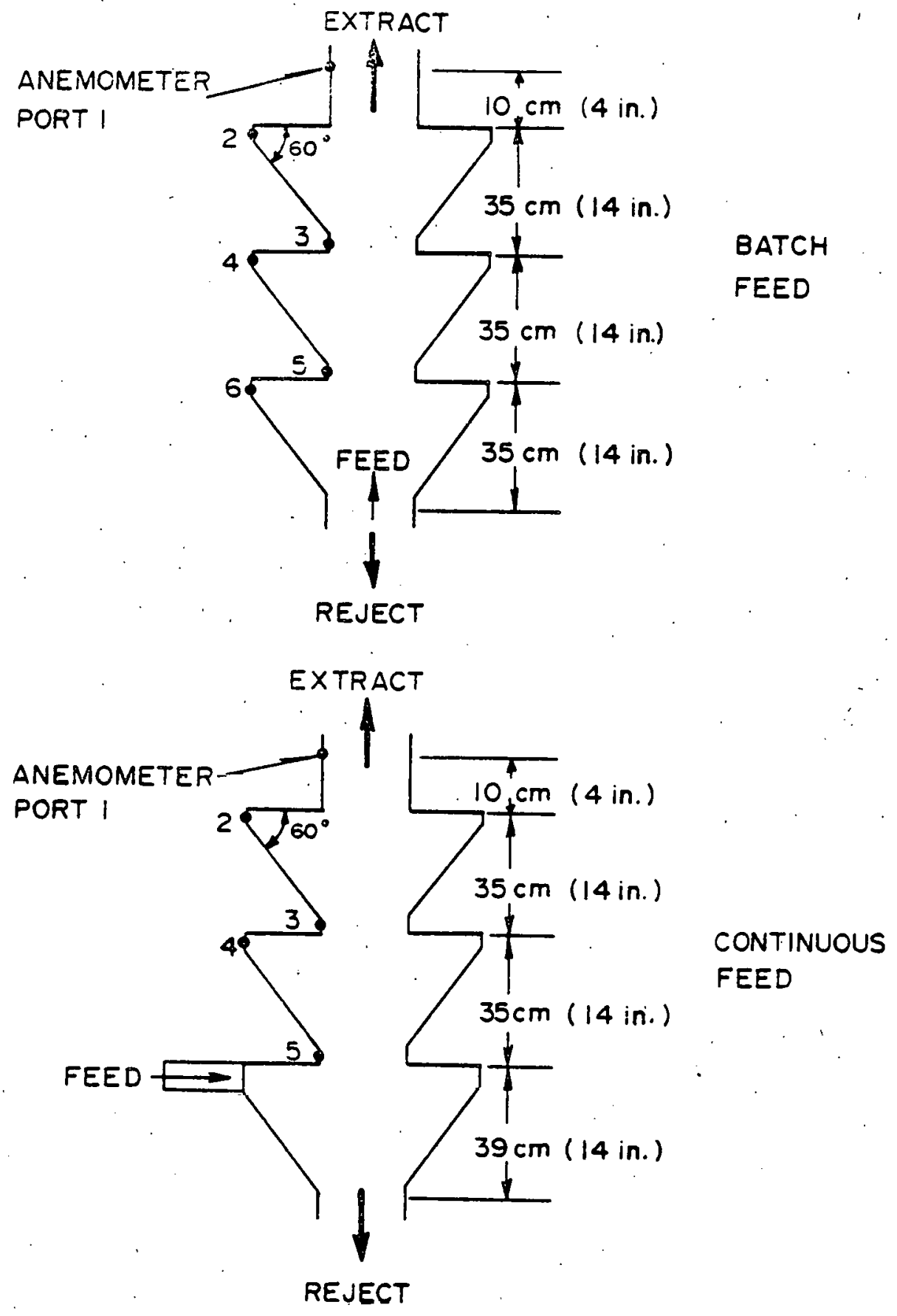

Exhibit:21. Stacked Triangle Classifier 
plastic, glass, aluminum and steel. A garden variety shredder, standard soil sieves and a laboratory scale were used in the preparation of the second and third types of feed. Particle densities and sizes for each feed are listed in Exhibit 22.

Injecting the sample was done by hand for the batch feeds, while a $4.0 \times 4.0 \times 30 \mathrm{~cm}(1.6 \times 1.6 \times 12 \mathrm{in})$ plastic injector was used to simulate continuous feed. The injector was installed at the middle stage of each classifier, accounting for the added stage height in the continuous feed classifiers.

\section{LABORATORY METHODOLOGY}

Four different classifier configurations were examined in this research: the straight, the 2 ig-zag, the Zag-zag, and the Stacked Triangle. Each classifier was subjected to the same series of experiments. 'Ihe exact methodulogy employed in the experiments was dependent upon the type of feed being injected. For each of the three feeds described in Exhibit, 18, the methodology is presented below in terms of teed preparation, experimental procedure and determination of results. Also discussed is the experimental procedure used in obtaining the characteristic velocity profiles of each classifier. A flow chart, outlining the methodology of this research, is presented in Exhibit 23. This methodology is detailed below for the testing of three feed materials and the determination of the velocity profiles. 


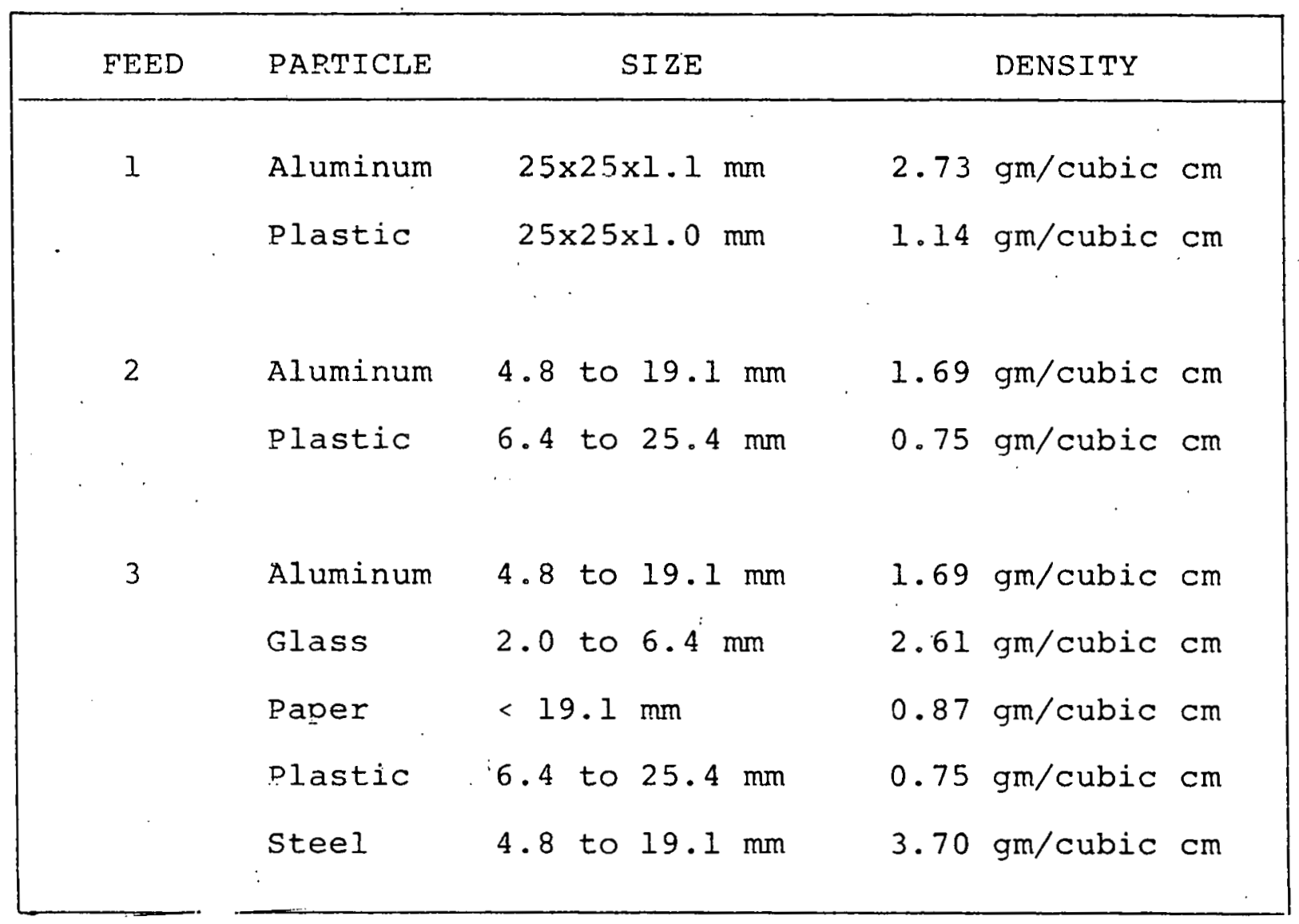

Exhibit 22. Particle Sizes and Densities 


\section{METHODOLOGY}

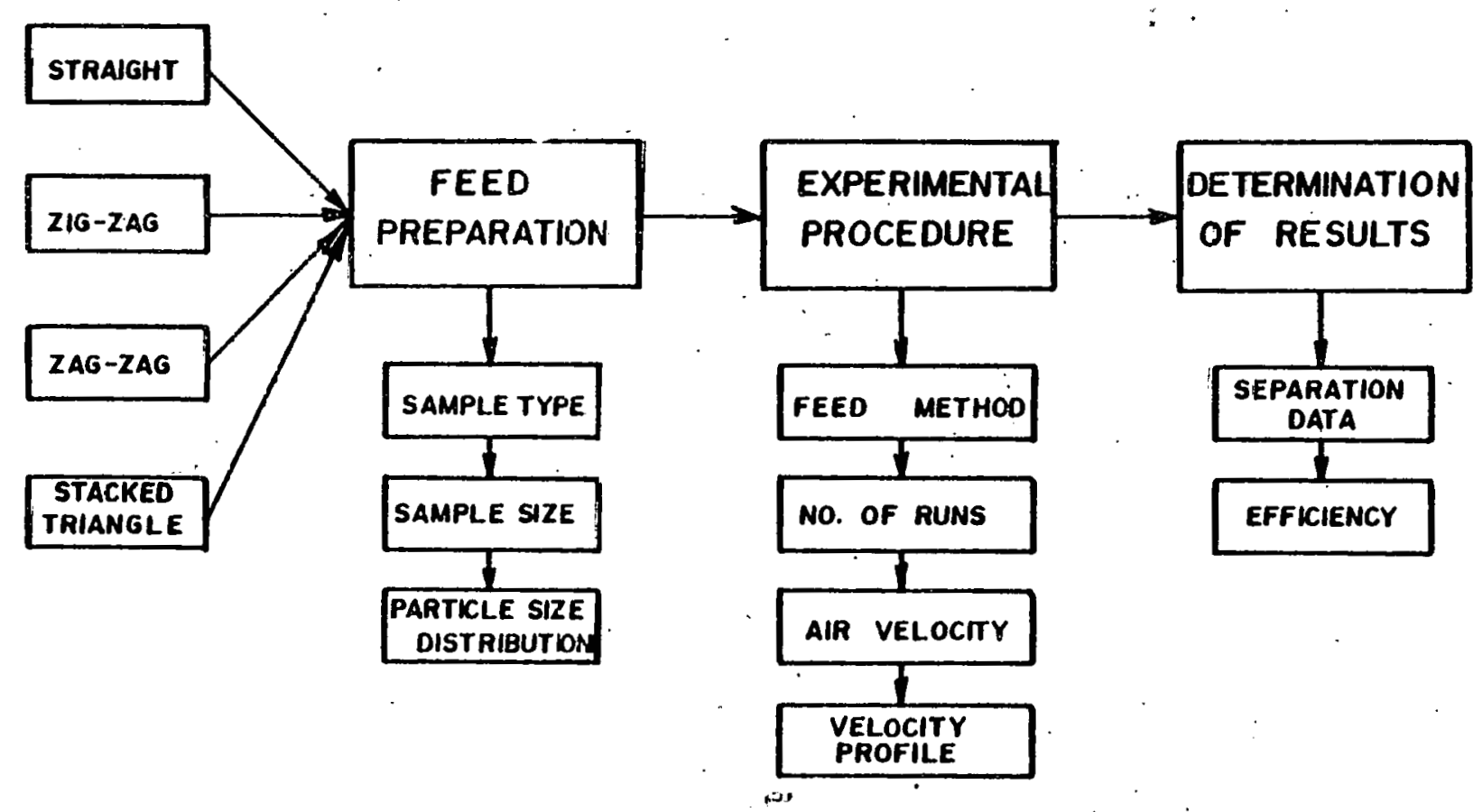

Exhibit 23. Methodology 


\section{1) FEED \# I}

Feed 1 was used to compare the separation capability of each classifier on particles with similar aerodynamic characteristics but different densities. The feed consisted of a mixture of aluminum and plastic plates, cut into $25.4 \mathrm{~mm}(1.0 \mathrm{in})$ squares from large sheets of each material. The density of each component was determined by weighing 10 plates on a laboratory scale, measuring the volume with a metric ruler, and calculating the ratio.

In order to determine the relative impact of the mass ratio on the efficiency of separation, three different mass ratios of aluminum to plastic were used: $3 / 1,1 / 1$, and 1/3. Sample 1 consisted of $30 \mathrm{gm}(1.1$ $O z)$ of aluminum and $10 \mathrm{gm}(.35 \mathrm{oz})$ of plastic. Sample 2 was composed of $20 \mathrm{gm}(.70 \mathrm{oz})$ of each material, and Sample 3 contained $10 \mathrm{gm}(.35 \mathrm{oz})$ of aluminum and $30 \mathrm{gm}$ (1.1 Oz) of plastic.

The plates were washed with mild soap and water between testing in different configurations. This removed the dust and grime which accumulated during the tesls, and which could have affected the separation data. 
Experimental Procedure. Feed 1 was introduced to the classifier by hand at the bottom opening as a single batch. Care was taken to get the entire batch to the top of the first stage before the particles were affected by the airstream. Any. injection which was. either more or less forceful than this was discounted. Five seconds after injection, the particles which had exited out the bottom were counted as reject and the particles that had been trapued by the wire mesh screen at the top of the classifier were counted as extract. Any particles remaining the the throat at this time were discounted and subtracted from the original feed size.

The sliding gate valve was adjusted to the smallest opening which caused all the particles to be extracted, and the velocity at this opening was recorded as the maximum velocity. Likewise, the velocity at the largest opening which allowed all the particles to be rejected was recorded as the minimum velocity. These two velocities set the range over which experiments were performed on each classifier.

Experiments were run at four or five velocities in between the minimum and the maximum. At each velocity, 10 runs of each sample were performed, to insure repeatability of the results. A run consisted of feeding a batch of particles to the classifier and obtaining the separation data. The particles were 
counted before each run. After the run, many particles that were not part of the reject were collected by blocking the fan exhaust, thus cutting. off the air stream and causing all particles in the classifier to fall.

Determination of Results. Mass separation data for each run was obtained by counting the number of plates rejected, and checked by counting the number of plates that fell after the air stream was cut off. This procedure was chosen for the following reasons: 1) the number of plates of each material was directly proportional to the mass, and 2) the reject portion was more convenient than the extract to count immediately after separation. Each particle that was injected was accounted for by the arithmetic check: Total in $=$ Reject + Extract + Particles remaining in the throat. Data was recorded for both aluminum and plastic as number of particles extracted, number of particles rejected, and total number injected.

The efficiency, E, of a run was determined by the following formula: 


$$
E=\sqrt{\frac{X_{e}}{X_{0}} \cdot \frac{Y_{r}}{Y_{o}}}
$$

where: $x_{e}=$ number of plastic particles extracted $Y_{r}=$ number of aluminum particles rejected $\mathrm{x}_{\mathrm{o}}=$ total number of plastic particles injected

$Y_{0}=$ total number of aluminum particles injected

The final efficiency for each test was obtained by calculating the arithmetic mean efficiency of the 10 runs. It is this value which is used to represent the efficiency of a particular classifier in separating a certain sample at a specified velocity.

The diffcrence in efficiency of separation of each of the three samples when all other parameters were constant was determined to be minimal. Thus, the arithmetic mean efficiency of the samples at a certain velocity was calculated to obtain the feed efficiency.

\section{2) FEED \# 2}

Feed 2 was used to simulate aluminum and plastic components of municipal solid waste (MSW). The Eeed was created by shredding aluminum beverage cans and plastic soap bottles in a garden variety shredder with $25.4 \mathrm{~mm}$ 
( 1.0 in) openings. Component densities were determined by weighing a group of particles on a laboratory scale, finding the volume by displacing the particles in a 10 ml graduated cylinder which was half filled with water, and calculating the ratio of mass to volume.

The original mixture consisted of $114 \mathrm{gm}(4.0 \mathrm{oz})$ of plastic and $46 \mathrm{gm}(1.6 \mathrm{oz})$ of aluminum, approximately the same proportion in which the two materials are present in MSW. (11) This mixture was cut and quartered according to ASTM standard procedure (12), as shown in Exhibit 24, until 8 equivalent samples were obtained. Each sample weighed approximately $20 \mathrm{gm}(.70 \mathrm{oz})$.

Experimental Procedure. Feed 2 was introduced to the classifier by hand at the bottom opening as a single batch. As with Feed 1, the entire batch was allowed to reach the top of the first stage from the bottom before being affected by the air stream. Any injection which was not consistent with this was discounted. Separation of this feed always occurred within 5 seconds, so all the particles were counted either as extract or reject. Minimum and maximum velocities were set as with Feed 1, and several intermediate velocities were chosen for experimentation. Each of the eight samples was injected at every velocity setting, in order to verify 
Step 1

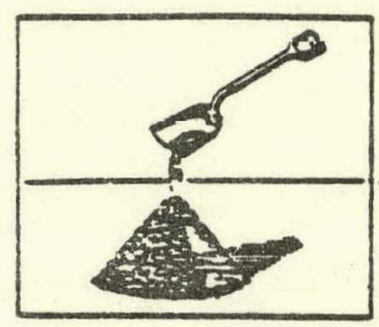

Cone Samples on Hard Clean Surface
Step 2

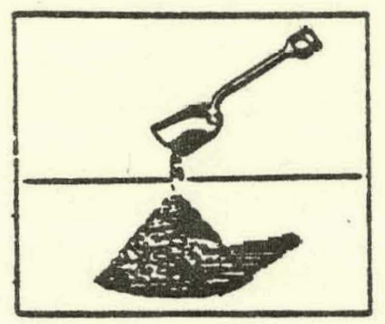

Mix by Forming New Cone
Step 3

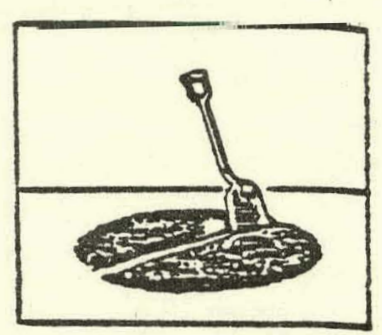

Ouarter After Flattening Cone

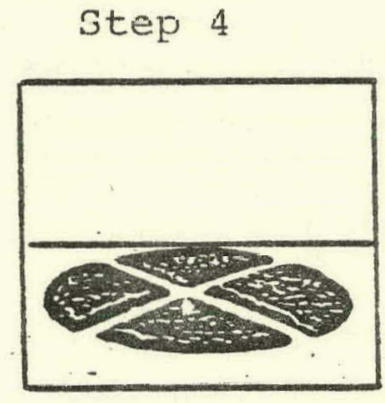

Divide Sample into Quarters
Step 5

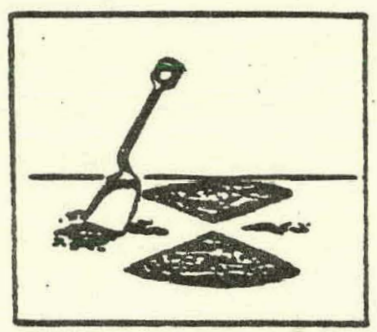

Retain opposite Duarters; Reject other Two Ouarters 
the repeatability of results. After the reject was collected, the air stream was cut off by blocking the fan exhaust, and the extract was collected.

Determination of Results. Mass separation data were determined by separating the rejected particles into aluminum and plastic constituents, and weighing each portion on a laboratory scale. Similarly, the extracted particles were also separated and weighed. The sum of the total extract and the total reject was used as the original feed size. This data was recorded and used to determine the separation efficiency for each sample.

The efficiency, E, was determined by the following empirical formula:

$$
E=\sqrt{\frac{X_{e}}{X_{0}} \cdot \frac{Y_{r}}{Y_{0}}}
$$

where: $x_{e}=$ mass of plastic extracted $Y_{r}=$ mass of aluminum rejected $x_{0}=$ total mass of plastic injected $Y_{0}=$ Lolal mass of aluminum injerted

The efficiency of separation at a particular velucily was obtained by calculating the arithmetic mean of the eight sample efficiencies. 
3) FEED \# 3

Feed 3 was used to simulate MSW components of paper, plastic, glass, aluminum and steel, in the approximate proportions which might be expected in actual MSW. [5] The feed was created by shredding the following materials in a garden variety shredder with $25.4 \mathrm{~mm}(1.0 \mathrm{in})$ openings: paper magazines, plastic soap bottles, glass beverage bottles, aluminum beverage cans, and steel beverage cans. Each component was separated by size using standard soil sieves. Component densities were determined by weighing a group of particles, finding the volume of water which the particles displaced, and calculating the ratio of mass to volume.

Thirty samples were made up with the following composition:

$\begin{array}{ll}\text { paper: } & 40 \mathrm{gm}(1.4 \mathrm{oz}) \\ \text { plastic: } & 30 \mathrm{gm}(1.1 \mathrm{oz}) \\ \text { glass: } & 10 \mathrm{gm}(.35 \mathrm{oz}) \\ \text { aluminum: } & 10 \mathrm{gm}(.35 \mathrm{oz}) \\ \text { steel: } & 10 \mathrm{gm}(.35 \mathrm{oz})\end{array}$

The size of particlcs in each component was almost equally distributed over the range listed previously in Exhibit 6 . 
Experimental procedure. Feed 3 was introduced at the middle stage of each classifier through an injector designed to simulate continuous Eeed. Each $100 \mathrm{gm}(3.5$ oz) sample was packed: into the $4.0 \times 4.0 \times 30 \mathrm{~cm}(1.6 \mathrm{x}$ $1.6 \times 12 \mathrm{in)}$ injector chamber, which had a rubber stopper at the end near the classifier throat. After the air stream was activated and the desired velocity was set, the rubber stopper was removed and the injector was inserted at a rate of $3 \mathrm{~cm} / \mathrm{sec}(1.2 \mathrm{in} / \mathrm{sec})$. Thus, the sample entered the air stream at an approximate rate of $10 \mathrm{gm} / \mathrm{sec}(.35 \mathrm{oz} / \mathrm{sec})$ for a period of 10 seconds. The rejected portion of each sample was collected in a box at the bottom of the classifier. Due to the bulk of material reporting to the extract, the wire screen at the top of the classifier was removed, and the extract was circulated through the system, exiting through a length of hosing that was attached to the fan exhaust.

Determination of Results. Mass separation data were determined by separating the reject into its constituents, and weighing each portion on a laboratory scale. Since the extract was dispersed, it could not be measured, and was assumed to equal the difference between the mass injected and the mass rejected. 
The components were divided into two categories, which are referred to as extract and reject. The extract included paper and plastic, which are materials with low density. The glass, aluminum and steel were included in the reject, as their densities are significantly higher than that of the lights.

The separation efficiency, $E$, of the classifier at a certain velocity for the continuous feed was determined by the following formula:

$$
E=\sqrt{\frac{X_{e}}{X_{0}} \cdot \frac{Y_{I}}{Y_{0}}}
$$

$$
\text { where: } \begin{aligned}
\mathrm{Y}_{\dot{\mathrm{e}}} & =\text { mass of } 1 \text { ights oxtracted } \\
\mathrm{Y}_{r} & =\text { mass of heavies rejected } \\
\mathrm{X}_{0} & =\text { total mass of lights injected } \\
Y_{0} & =\text { total mass of heavies injected }
\end{aligned}
$$

Velocity profiles. The purpose of recording the velocity profiles of the airstream of each classifier was to determine the extent the pulsing classifiers exhibited the expected regions of alternating positive and negative acceleration. Velocity profiles of the non-pulsing classifiers were recorded as controls for comparison. 
The profiles were obtained by inserting a TSI hotwire anemometer in the chosen port, and reading the velocity at increments along the throat width. The sensor was linked to the microprocessor, which read the voltage drop 20 times over a period of 1 second. The average voltage drop was converted to the corresponding calibrated velocity and the sensor was moved to the next position.

A metric ruler was taped to the plexiglass face at the height of the chosen part, in order to read the exact location of the sensor, with respect to the lefthand wall. The locations at which velocities were measured varied with the width of the classifier throat, but they were always in multiples of $.25 \mathrm{~cm}(.1$ in), and were never more than $2 \mathrm{~cm}(0.8 \mathrm{in})$ apart. The sensor was positioned with the aid of a right triangle, whose legs were held parallel to the throat width and depth, respectively. With a straight edge parallel to: the line of sight, the experimenter was able to reduce the effect of parallax in reading the sensor position.

Two people were needed in order to obtain the velocity profiles: one to set the anemometer position, and one to key information into the microprocessor. The microprocessor, in turn, computed the velocity and plotted the profiles. The process was repeated until profiles were obtained at each of the six ports. 
4. RESULTS AND ANALYSIS

The parameters used in this research for evaluating the. qverall efficiency of an air classifier are feed type, air speed, mass of components extracted and mass of components injected. The final separation efficiencies and corresponding velocities are plotted in Exhibit 25 through 27, as characteristic efficiency curves, acconding to feed type.

Different Lypes of feed were used to test different characteristics of separation capability. Feed 1 was used to determine: l) the effect of particle-to-particle interaction as the proportion of the components varied, and 2) the separation capability of each configuration over a range of velocities, when all variables except density are held constant. The data collected in this test indicate that efficiency lues not vary significantly among the compunent Inass ratios which were chosen. Thus, the particle-toparticle interaction was assumed to be minimal for particles wilh simllar aerodynamic characteristics. The arithmetic mean of the three efficiencies at a certain velocity is used as the final efficiency for the experiments involving Feed 1. The curves presented in Exhibit 25 show the comparative peak efficiencies and velocity, ranges over which each classifier separates Feed 1. The high peak efficiency observed in all the configurations is probably due to the aerodynamic similarities of the particles, since it does not 


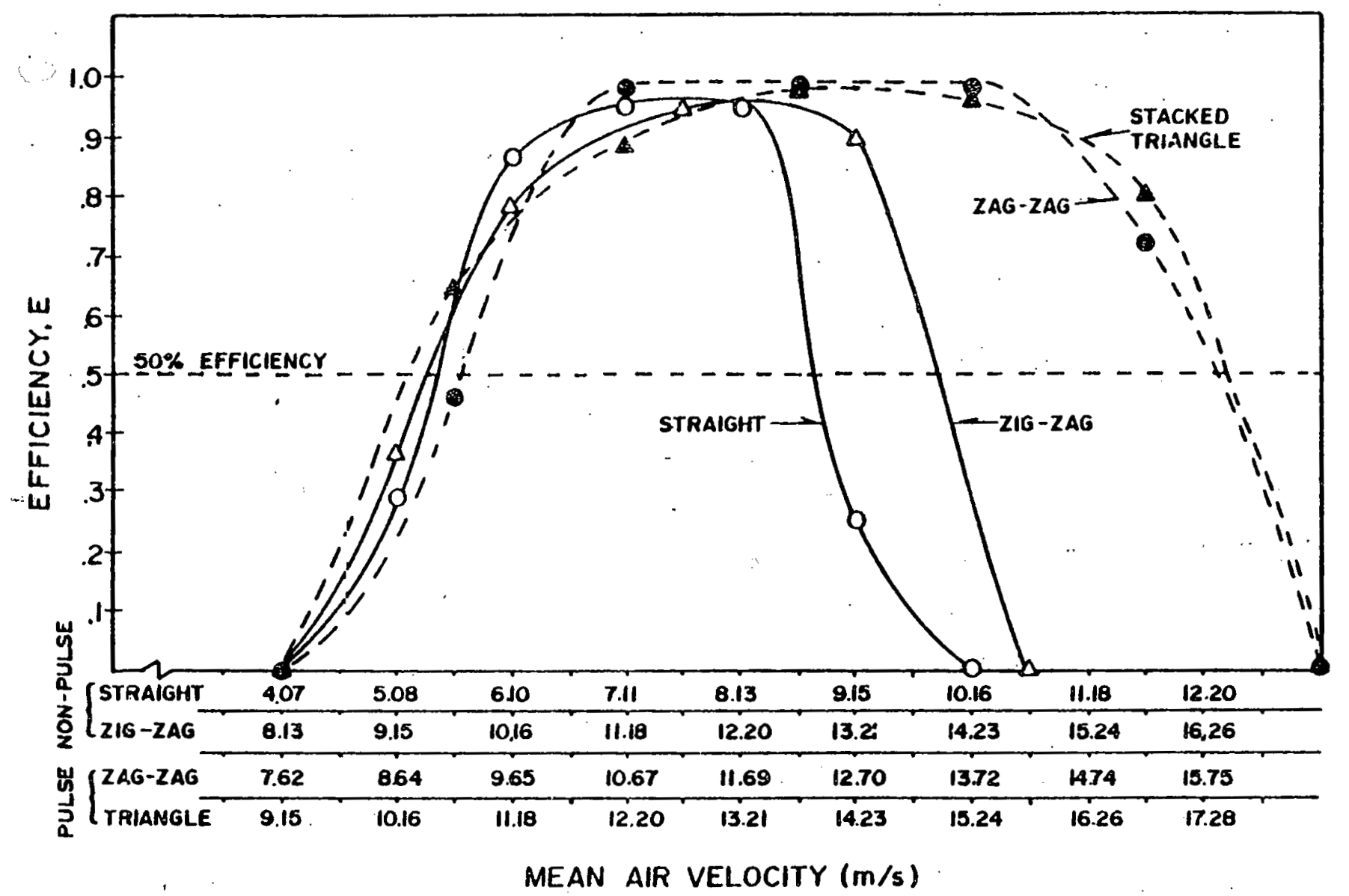

(as measured in port I)

Exhibit 25. Separation Efficiency for Feed 1 


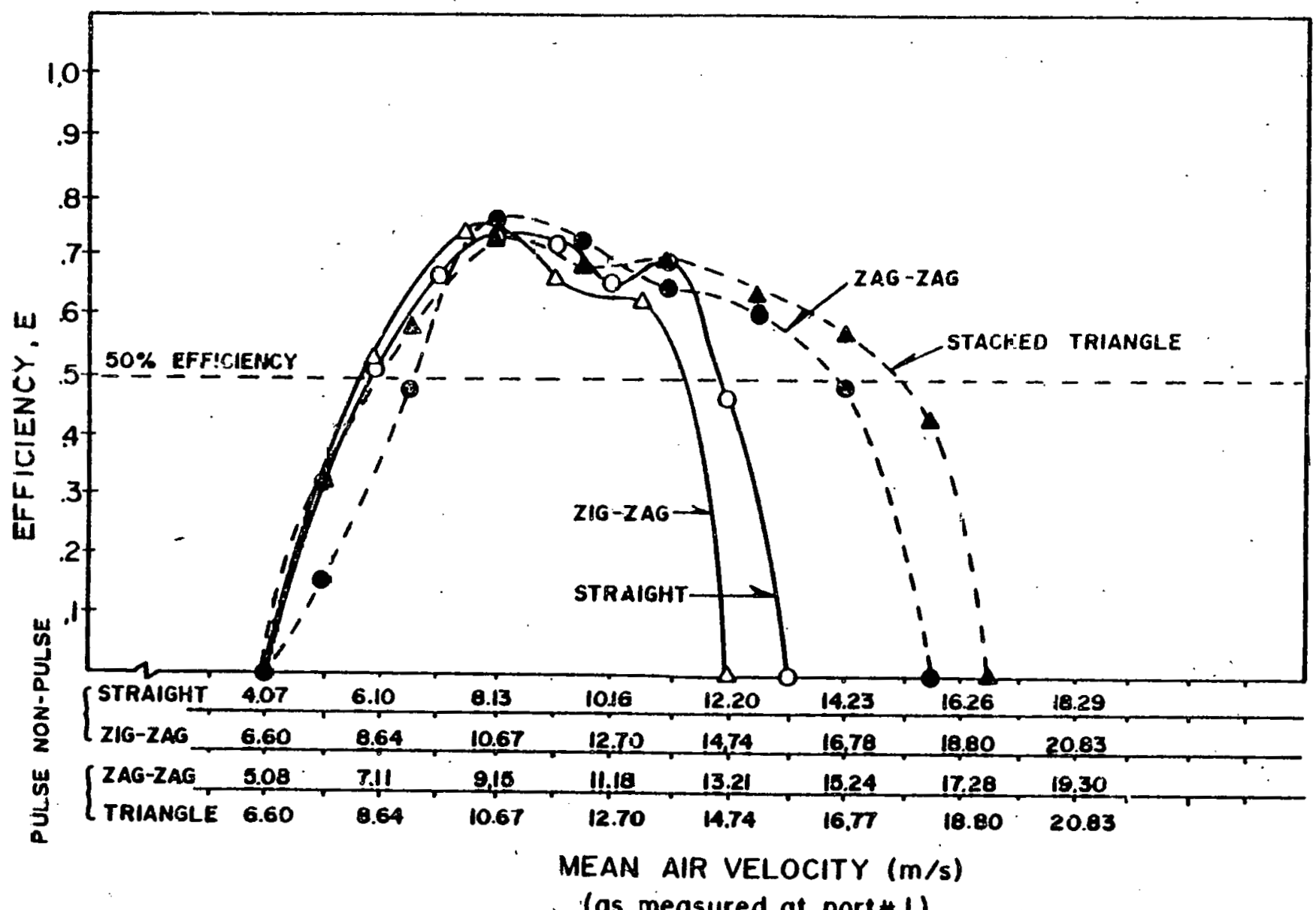

Exhibit 26. Separation Efficiency for Feed 2 


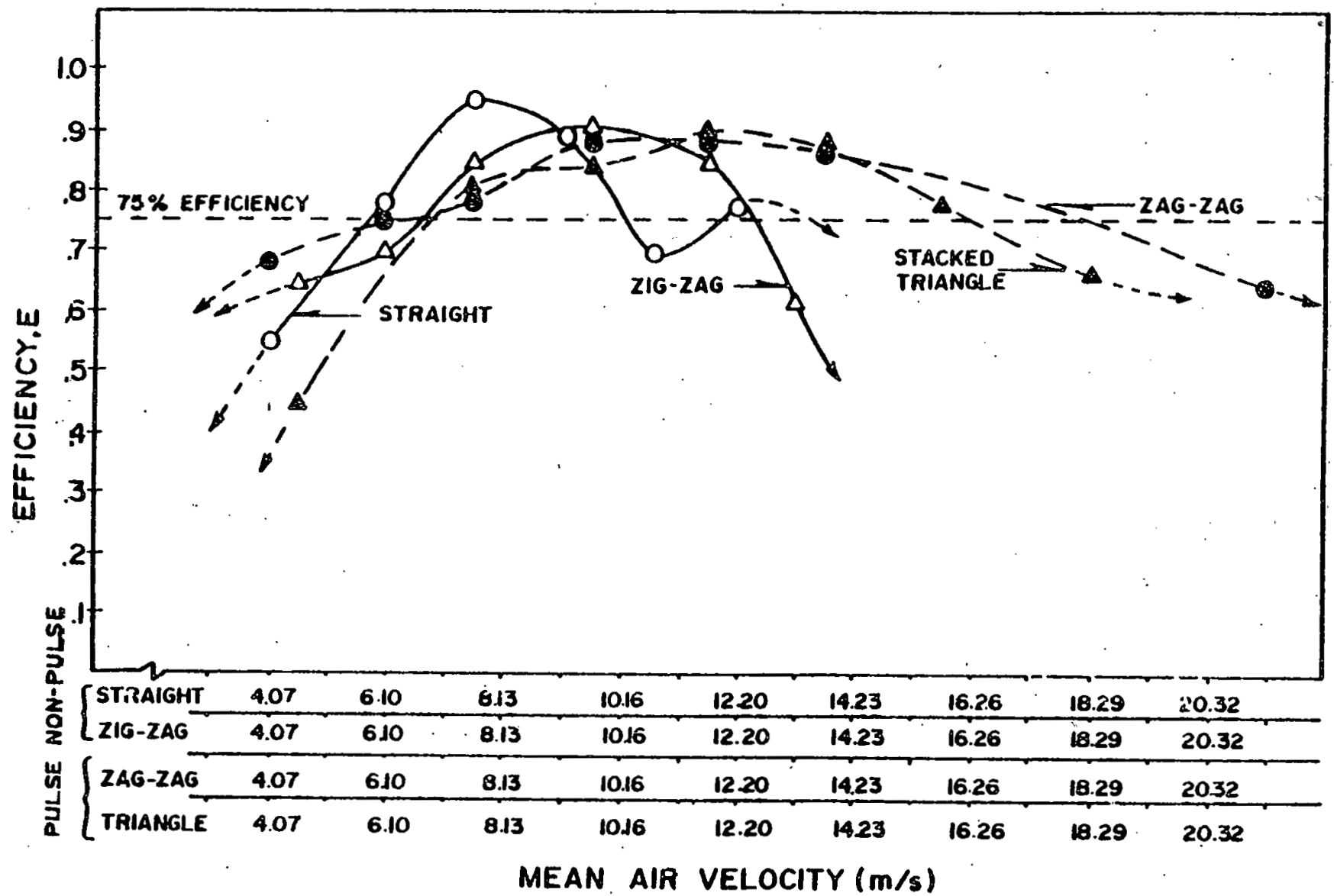

(as measured at pori \# I)

Exhibit 27. Separation Efficiency for Feed 3 
occur when using either of, the less homogeneous feeds. The velocity ranges differ greatly among the four configurations, as the "pulsing" classifiers operate over a $40 \%$ wider range than the "non-pulsing" classifiers do.

Experiments with Feed 2 gave a good indication of the separation capability of each classifier on dry, irregularly shaped particles of two different densities. No attempt will be made here to compare the separation data nf Feed 1 with the data of Feed 2, exccpt to say that the trend of efficiencies of the classifiers is similar. The "pulsing" classifiers exhibit higher peak efficiencies and wider ranges of operable velocities than do the "non-pulsing" classifiers, as can be seen in Exhibit 26.

Feed 3 was a more realistic simulation of MSW than either of the other two, althgugh it conldined neither the assortment of material nor the moisture content of real MSw. Separation data were expectedly more complex than that of Feeds 1 and 2 , and the efficiencies were calculated by grouping components into either "lights" or "heavies". This simplification is 'made with the assumption that the combustible, organic material is less dense than the inorganic, non-combustible material.

The large difference in the densities of paper $(.87$ $\mathrm{gm} / \mathrm{cubic} \mathrm{cm})$ and steel $(3.70 \mathrm{gm} / \mathrm{cubic} \mathrm{cm})$ caused there to be litlle varlation in their behavior as the air velocity in the throat was changed. Since very little paper was rejected, even at low velocities, and very little steel was extracted, 
even at high velocițies, neither minimum nor maximum velocities could be established. Thus, no distinct velocity range was determined, although there was an observable difference in the range over which classifiers attained greater than $75 \%$ efficiency. As was seen previously in Exhibit 27, pulsing yields a significant improvement over non-pulsing in the gross separation of Feed 3.

In a waste-to-energy production facility, MSW entering the airstream may obstruct or impede the air flow, causing a significant decrease in air velocity in the throat. The pulsing classifiers are more resistant to this type of change than the non-pulsing operating above a certain efficiency over a wider range of velocities, and would be of great economic benefit to the waste-to-energy industry.

The four configurations which were tested were assumed to be representative of pulsing and non-pulsing classifiers. This was verified by examining characteristic velocity profiles of each classifier. In the zag-zag and stacked Triangle Classifiers, the maximum velocity is much greater at the constricted throat sections than at the expansions. Note Exhibits 28 and 29. Here, the velocity decreases significantly toward either wall at the expanded section, while it is relatively constant throughout the width of constricted sections. Similar velocity profiles show that horizontal changes in velocity, i.e. pulsing actions are not evident in the straight and $\mathrm{Zig-zag}$ configurations. 


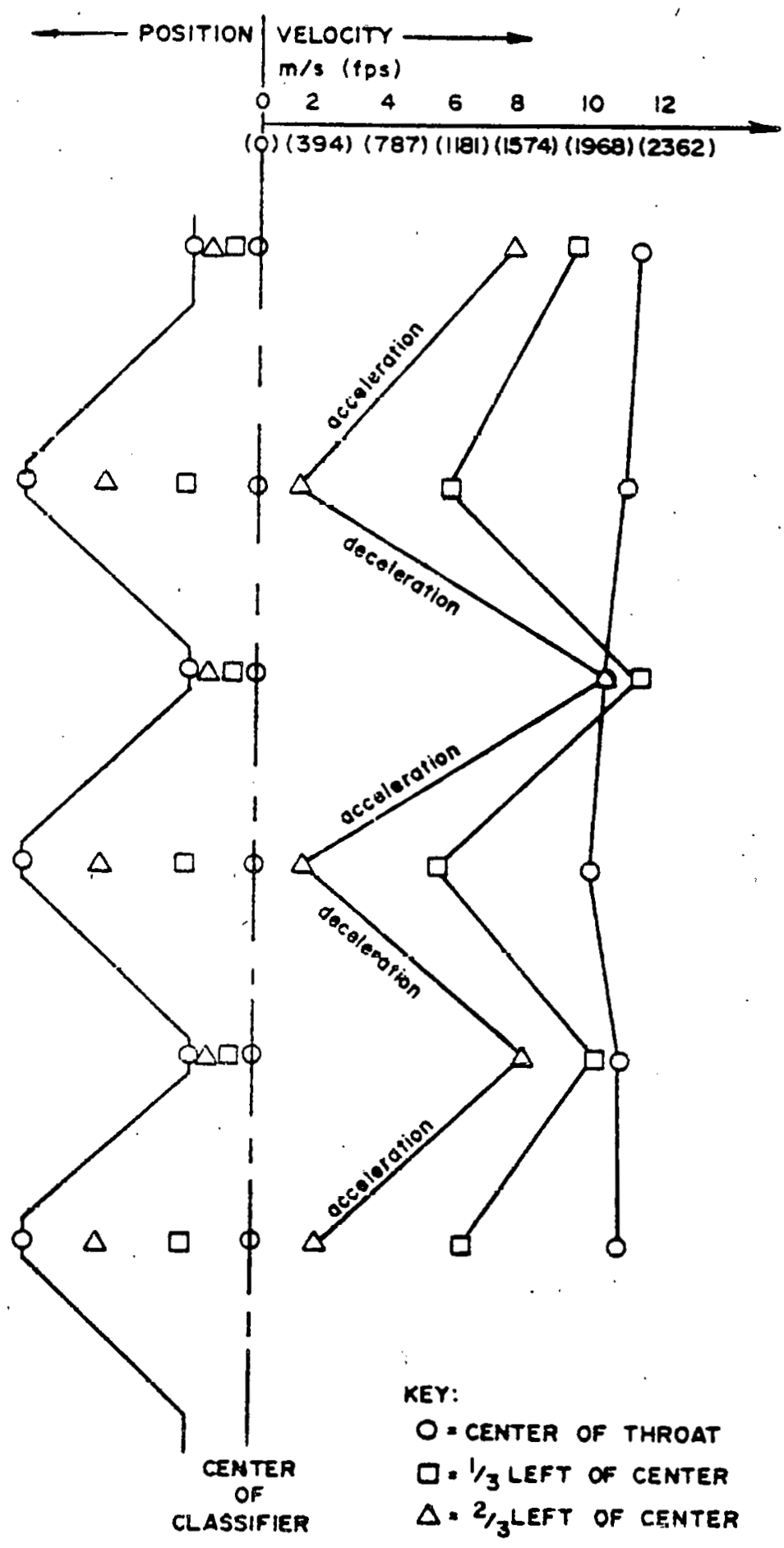

Exhibit 28. Zag-Zag Velocity Grid 


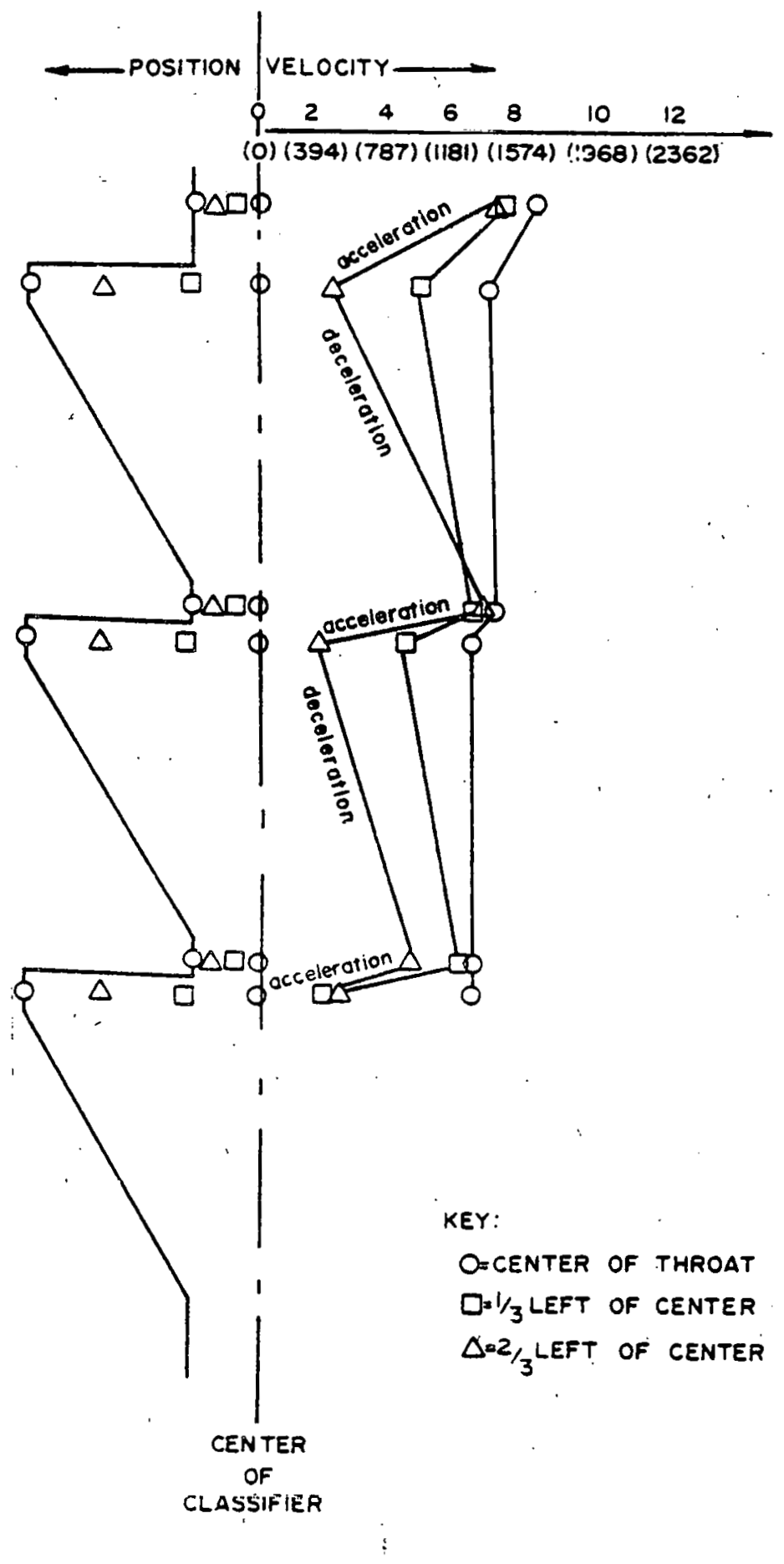

Fxhibit 29. Stacked Triangle Velocity Grid 
The classifiers examined in this research are what Stessel and Peirce [6] have termed passive pulsing air classifiers. As the velocity profiles in Exhibits 28 and 29 show, air velocity does change between wide and narrow points in the classifier throats; in other words, the air accelerates and decelerates between wide and narrow throat cross-sections. A particle passing through the throat naturally travels either up or down. In so doing, the particle experiences alternating zones of alr moving at high and low velocities. In other words, the particle experiences accelerating and decelerating air movement as a function of the particle's passage through the throat. The particle feels pulsing airflow whose pulse period is a function of the speed with which the particle passes successive constrictions and widening of the throat.

5. CONCIIISTONS

Several conclusions can.be drawn from the results of this research task:

1) Constrictions and expansions in the with of the classifier throat produce a pulsed air stream within the classifier, as indicated by the characteristic velocity profiles in Exhibit, 28 and 29. 
2) The pulsing classifiers appear to exhibit more complete separation of mixed particles than do the non-pulsing classifiers.

3) The pulsing classifiers appear to operate over a wider range of air speeds than do the non-pulsing classifiers.

4) It cannot be concluded that the Zag-Zag and Stacked Triangle classifiers, which have been developed in this research, represent the optimal configuration of pulsing classifiers. Studying these shapes has indicated, however, that there are beneficial effects of pulsing on particle separation.

5) By altering the shape of the walls, new configurations can be designed and tested. Two shapes suggested here for future research are the Pagoda and the Snowman, which are both shown in Exhibit 30. Another classifier with potentially greater separation capabilities than those which were tested is the stacked Cone. This shape is an expansion of the stacked Triangle into three dimensions, and is also shown in Exhibit 30 . 


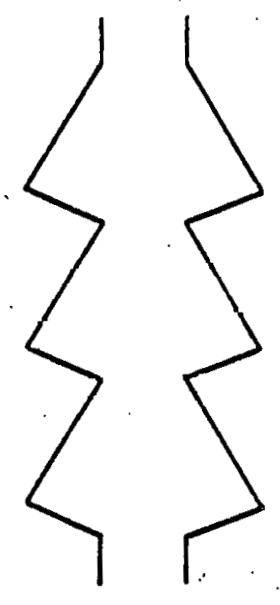

THE PAGODA

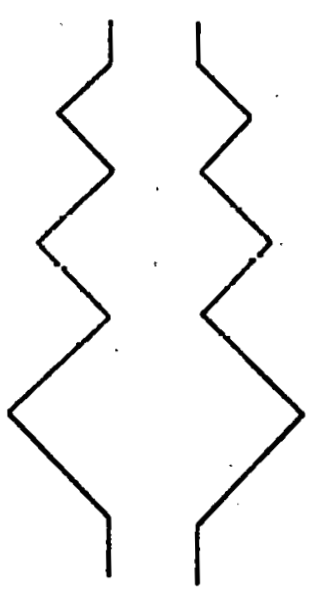

THE SNOWMAN

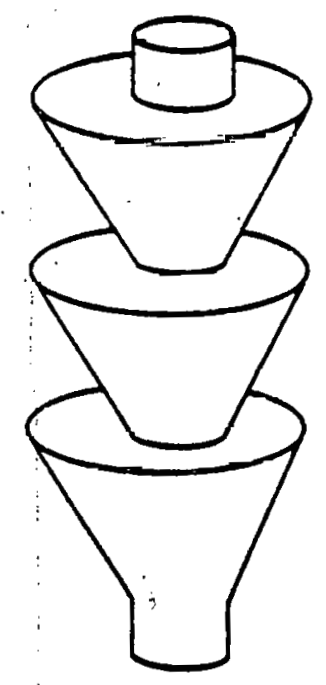

STACKED CONE

Exhibit 30. Potential Classifier Configurations 
The information gained in this research may have a significant impact on waste-to-energy engineering. At the present time, most facilities are operating at a financial deficit. There is a great need for a method of reducing the contamination of the extract, thereby increasing its energy content. Common problems in air classification could be overcome by a classifier which employs the theory of pulsing.

One problem often encountered is that air speed within the classifier throat is subject to change with variations in feed concentration or with mechanical instabilities. Unfortunately, these variations are not predictable, and even the most accurate controls cannot prevent them. Using a pulsing classifier instead of a non-pulsing one would increase the resistance of the system to velocity fluctuations, since it operates over a wider range of velocities.

Another benefit of pulsing classifiers is that their levels of performance, as defined in this paper, are higher than those of non-pulsing classifiers. It is possible that variations of the Stacked Triangle or Zag-Zag could achieve even higher performance levels than were obtained in this research, because the specific dimensions were chosen somewhat arbitrarily. Design parameters such as throat area, stage angle, stage height and number of stages should be studied further to determine their optimal values. 
REFERENCES

1. Bartlett, J., Vesilind, P. A.; "The Effect of Moisture on Air Classification Performance," Fundamental Aspects of Air Classifier Operation and Design. Final Report to D.O.E. Research Contract DE-AC02-79CS20544. Duke Environmental Center, Durhail, N.C., 1981 .

2. "Concrete and Mineral Aggregates," Annual Book of the American Society of Testing and Materials. ASTM: Philadelphia, Pa. 1979. pg. 438 .

3. Saul, C. S., Peirce, J.J.; Air Classification uf Glass Particles. Duke University: Center for Environmental Englneering, Durham, N.C., 1981.

4. Savage, Diaz, and Trezek, "Performance Characterization of Air Classlfiers in Resource Recovery Processing," Proceedings of 1980 National Waste Processing Conference. ASME: New York, 1980. pp. 339-349.

5. Senden, M.M.G., "Performance of Zigzag Air Classifiers at Low Particle Concentrations," Proceedings of 1980 National Waste Processing Conference. ASME: New York, 1980. pp. 351-359. 
6. Stessel, R. I., Peirce, J. J.; Pulsed Flow Air Classification. Duke University: Center for Environmental Engineering, Durham, N.C., 1982.

7. Taub, J. B., Peirce, J. J.; The Effect of Feed Composition on Air Classifier Separation

Performance. Duke University: Center for

Environmental Engineering, Durham, N..C., 1981.

8. Vesilind, P. A. and A. E. Rimer, Unit Operations in Resource Recovery. Prentice-Hall, Inc.: New Jersey, 1981. pg. 12 .

9. Wittenberg, N., Peirce, J. J.; The Effect's of Air Classifier Configuration on Separation Performance. Duke University: Center for Environmental Engineering, Durham, N.C., 1981.

10. Worrell, W. A.; Testing and Evaluation of Three Air Classifier Throat Designs. Duke University: Center for Environmental Engineering, Durham, N. C., 1977. 


\section{CHAP'TER V}

CONCLUSIONS

Conclusions are drawn from this research and organized below for the literature search, the theory development, and the laboratory tests. From the Literature survey, the following conclusions are drawn:

- Previous modeling efforts have been largely statistical.

- Such statistical models are of limited use to the design engineer working on variations of the zig-rag elassifiers for which the models were developed, but are of little or no use in considering different types of classifiers.

- Past experimental work has revolved around determinin efficiencies of existing classifiers and verifying or calibrating 'statistical models.

- Deterministic models of classifier performance are lacking in the literature. 
- No research is documented which addresses the behavior of particles under conditions critical to air classifiers: particles larger than aerosols in pulsing (rather than oscillating) air flow under a control body force (gravity) in direction of the flow.

Our investigations of the theory of air classification lead to the following conclusions:

- This pulsed-flow model is deterministic, and can guide the design of pulsed-flow air classifiers. Of particular importance is the design considerations of pulse frequency. amplitude and wave form.

- The theory behind pulsed flow air classification indicates that current designs for air classifiers cannot avoid poor separation of particles in a complex mixture because the classifiers do not cause prolonged or repeated periods of acceleration. 
- Pulsed-flow air classification theoretically separates particles by retarding particle approach to terminal velocity and/or forcing repeated retreats and renewed approaches.

From laboratory analysis of passive pulsed-flow air classification, it is apparent that:

- Constrictions and expansions in the width of the classifier throat produce a pulsed air stream within the classifier, as indicated by the characteristic velocity profiles in Exhibit 11 and 12.

- The pulsing rlassifiers permit more complete separation of mixed particles than do the non-pulsing classifiers.

- The pulsing classifiers operate more efficiently over a wider range of air velocities than do tho non-pulsing classifiers. 
- The Zag-Zag and stacked Triangle classifiers, do not necessarily represent the optimal configuration of pulsing classifiers. Studying these shapes has indicated, however, that there are beneficial effects of pulsing on particle separation. The pulse wave form, duration and magnitude must be studied further. 


\section{THIS PAGE}

WAS INTENTIONALLY

LEFT BLANK 
APPENDIX I NOTATION 


\section{NOTATION}

The following symbols are used in this report:

$$
\begin{aligned}
& A=\text { area/top stage } \\
& a=\text { acceleration } \\
& B=\text { bottom stage } \\
& \text { C m eoncenlialiun } \\
& c_{0}=\text { drag coefficient } \\
& d=\text { diameter of sphere } \\
& D=\text { diameter of sohere } \\
& E=\text { efficiency } \\
& F=\text { force } \\
& g \text { = acceleration of gravity } \\
& I=\text { amplification factor } \\
& k=\text { constant } \\
& \mathrm{m}=\text { mass } \\
& p=\text { pressure } \\
& x_{e}=\text { mass of lights extracted } \\
& x_{0}=\text { total.mass of lights injected } \\
& Y_{e}=\text { mass ot heavies rejected } \\
& \mathrm{Y}_{0}=\text { total mass of heavies injected } \\
& P_{\text {subscript }}=\text { probability } \\
& S=\text { Senden's efficiency }
\end{aligned}
$$




$$
\begin{aligned}
\mathrm{v}_{\mathrm{D}} & =\text { particle velocity } \\
\mathrm{v}_{\mathrm{A}} & =\text { air velocity } \\
\mathrm{x} & =\text { lights } \\
\mathrm{y} & =\text { hervies } \\
\mathrm{N} & =\text { period } \\
& =\text { density }
\end{aligned}
$$

subscripts

$$
\begin{aligned}
& A=\text { air } \\
& B=\text { buoyancy } \\
& D=\text { drag } \\
& f=\text { falling } \\
& F=\text { fluia } \\
& E=\text { gravity } \\
& i=\text { exiting top } \\
& j=\text { exiting bottom/random stage } \\
& 0=\text { feed } \\
& d=\text { single-stage } \\
& r=\text { rising } \\
& R=\text { cumulative } \\
& s=\text { sphere } \\
& t=\text { terminal }
\end{aligned}
$$


THIS PAGE

WAS INTENTIONALLY

LEFT BLANK 
137 


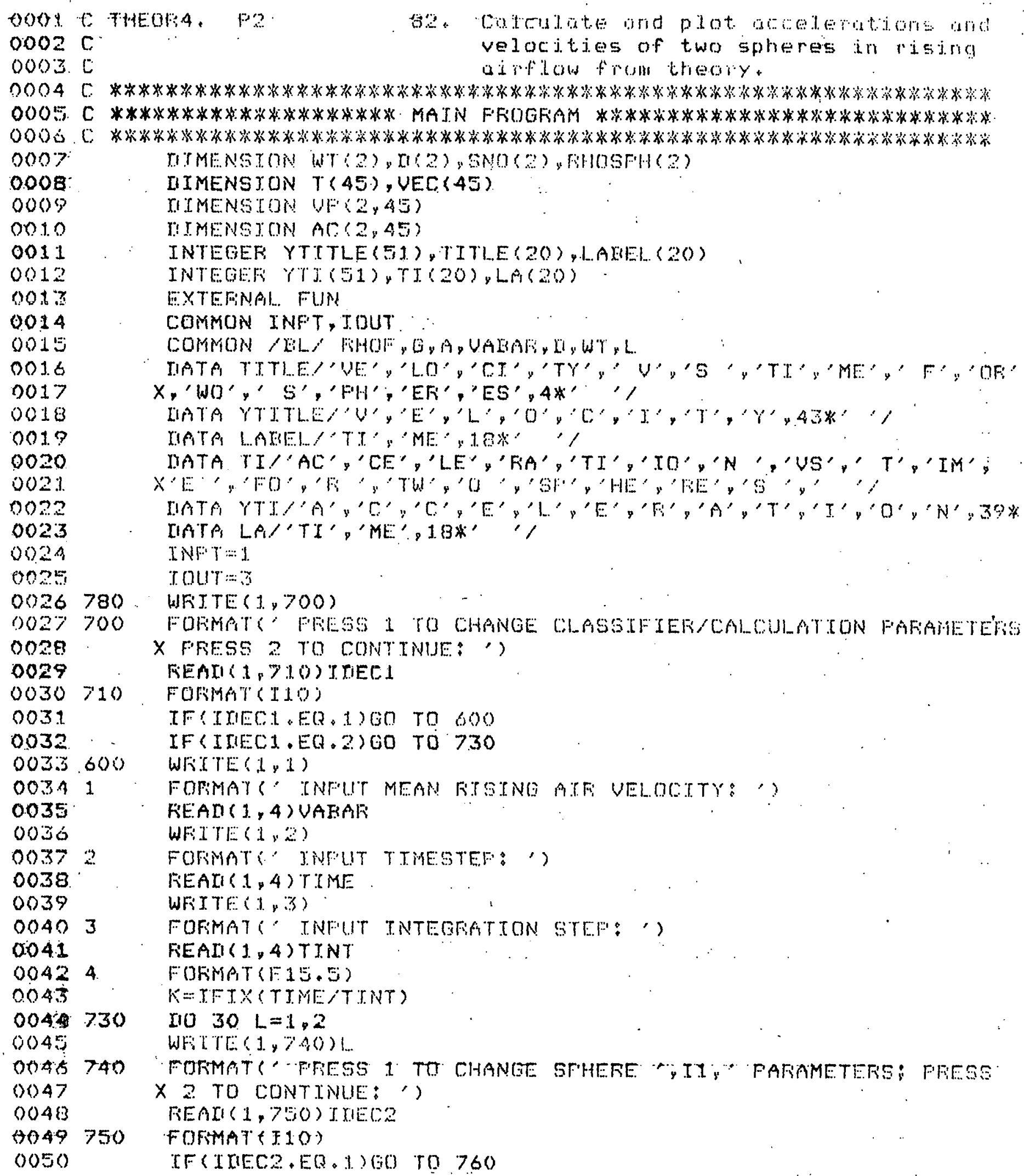




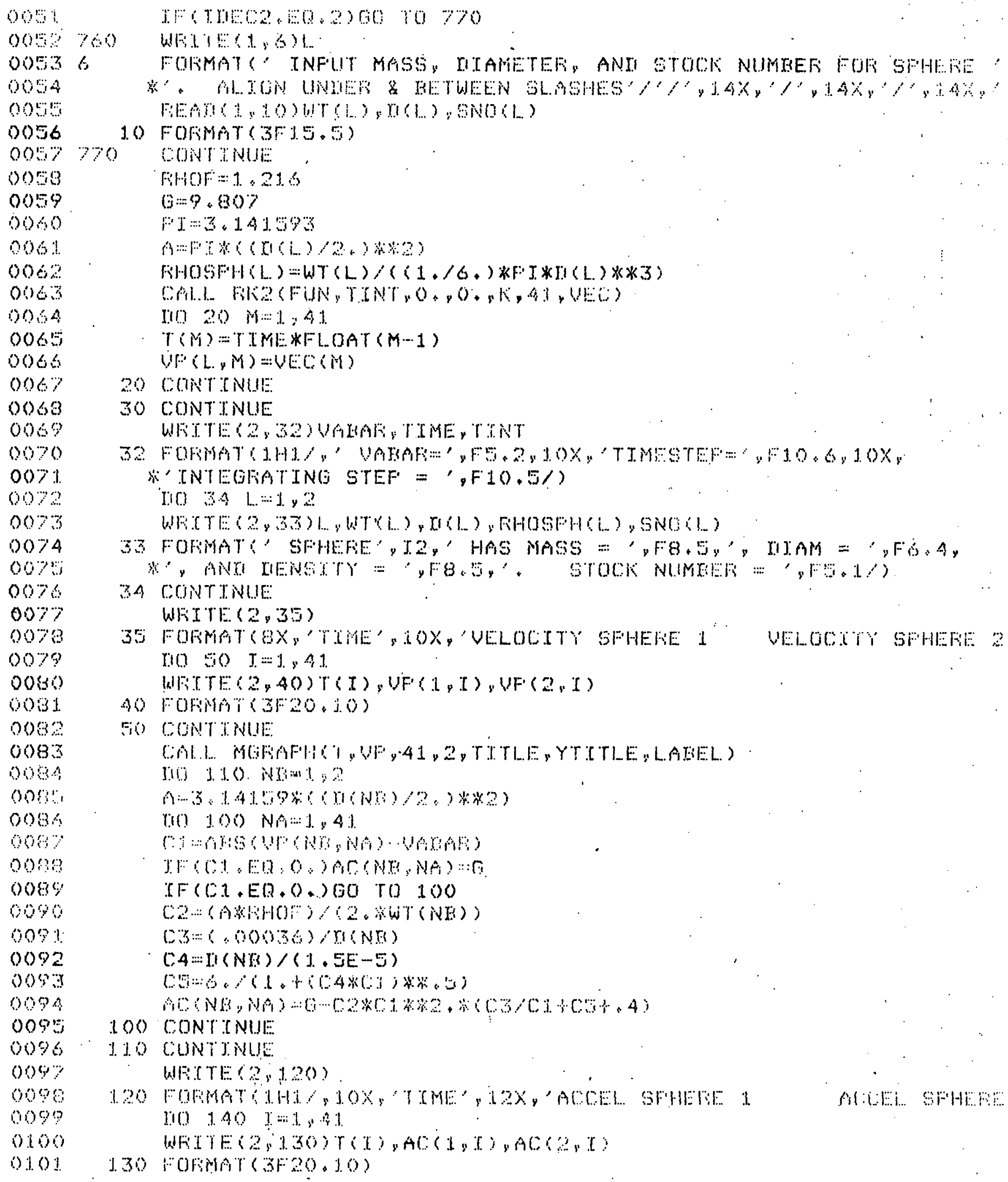




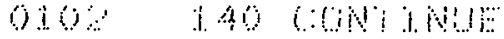

$010 \%$

0.104200

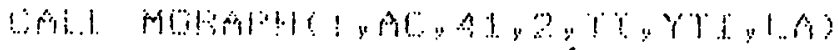

() 100300

latefile $(1,300)$

010.6

$0.10 \%$

3.0

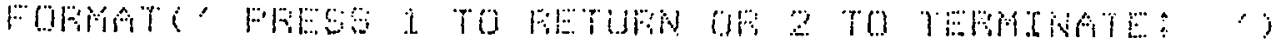

0.09

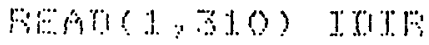

0109

o. J. 0

Oti i

o. 1.2

o) 13

o. 1. $A$

o.1.

01.4

$011 \%$

01.10

$011 \%$

0.20

0121

0122

()) $2 \%$

0.124

() $12 \div$

0126

0) $12 \%$

0. 28

0125

0130

0131

o) $3 \%$

01.32

0.134

0130

$0 ! 3 \%$

0) 37

FOBMAT:TE)

T.

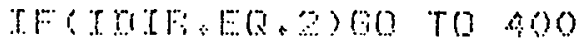

$400 \quad 80 \%$

$00 \quad 10290$

C

c

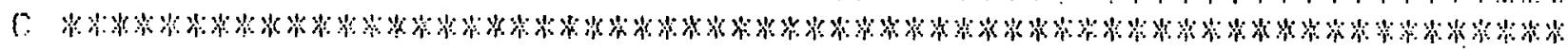

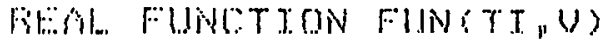

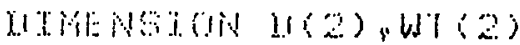

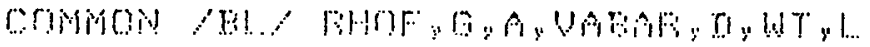

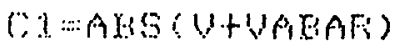

i.

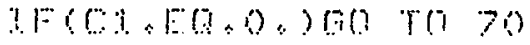

$(C)(A * F+H O F) /(2, * W T(1))$

$(3)(00000)(1)(1 .$.

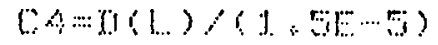

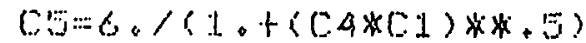

FUN

70 CONT RME:

FETURAT

ENI

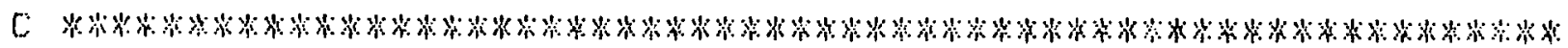

C

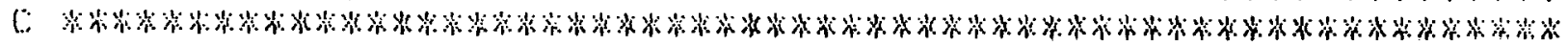

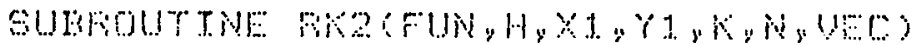

ITTENSTON UEC $(41)$

He:

$Y \cdots Y .1$

$x:=\times 1$

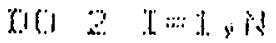

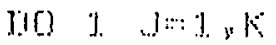

0139

0140

0. 141

$0.12 \%$

0143

0.44

0140

0146

$014 \%$

Y I $=H A F$ UN $(X, Y)$

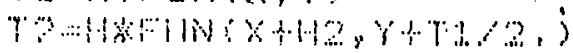

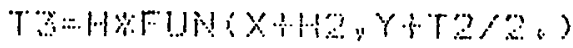

$T A=H$ KFUN $(X+H, Y+T 3)$

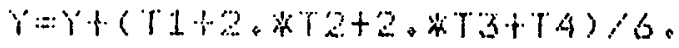

$x: x+\cdots+\cdots$

1 CONTINIJE

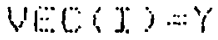

0.48

0149

0150

5 andignta

BETIST

ENon

(). 1.1

0112

6

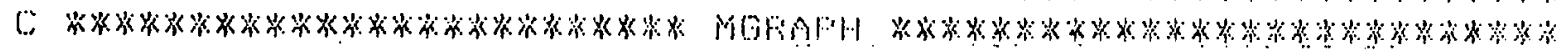


6.

0)

0) $1: 3$

() 156

Ois?

0) 53

0.159

0) 160

o.t'1

b. 32

0.63

0) 64

0 í:

0) 168

0) $16 \%$

0160

$016 \%$

0170

i) 31

0172

$017 \%$

$01 \% 4$

0.17

0176

0) $17 \%$

$01 \%$

$0.17 \%$

01.30

0.131

Q1.32

0.98

$018 \mathrm{~A}$

0.185

01.6

$010 \%$

0. 180

0189

0) 190

0191

$01 \%$

0193

0194

$015 \%$

0.196

0197

0198

$019 \%$

) 200

0201

0202

$0 \%$

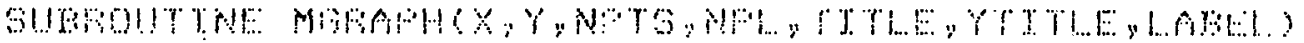

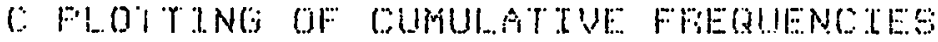

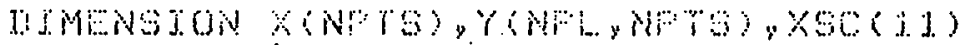

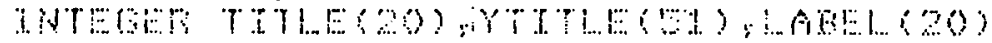

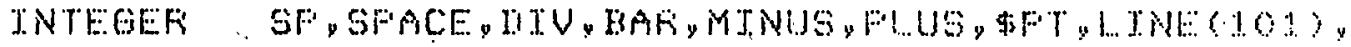

- Givi:g)

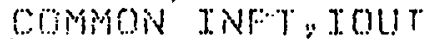

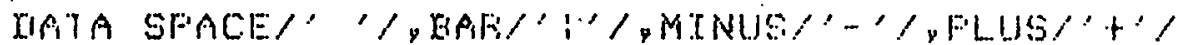

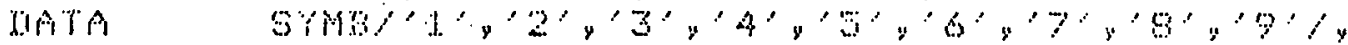

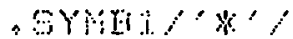

$X M A x=x(1)$

XitiN :: Xil

$Y M B \times 1=Y(1,1)$

YMLNA := Y $(1,1)$

Vio 10. I $=1$, y

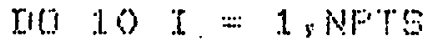

XMAX $=A M A X](X[I), X M A X)$

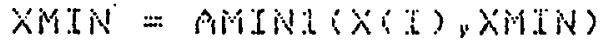

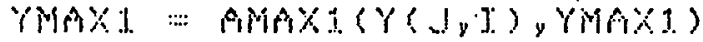

YMINL = ARIENI(YLJVI),YMLAUL)

1.0 CORTENUE:

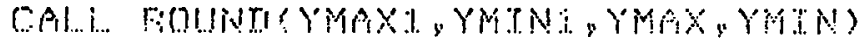

WFITE (2,1.20) (TITLE(]J) y.I J. 20)

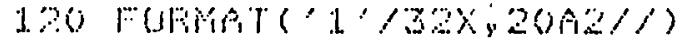

XE $=$ XMAX -. XNITN

$Y H:=$ YMAX - YMIN

FYS $=0.0$

तथ

$10070 \mathrm{I} 3=1,11$

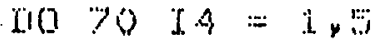

$S F=$ SFACE

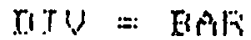

JYT : $=$ XT - 1

TF (TA ANE , 1 ) OO TO 30

SF $=$ MTNUS

IIU :.: FLLUS

$30 \because=0$

I0 40 [5 $[5=1 ; 11$

$\dddot{B}=\because 2+1$

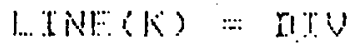

IF (IG :EA, JI) 00 TO 40

III 41 it $6=1,9$

K $=k+i$

4. LINE(KK) = SF

40 contrinul:

TYTE :-:

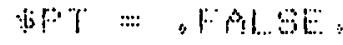

TH (TA , NE: 1 ) 60 TO 50

WFT $=$. PFUE.

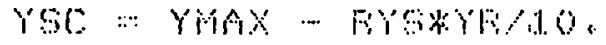


1904

020

0206

$020 \%$

0209

$020 \%$

$02 \mathrm{~d} 0$

021

0212

0213

0214

0215

016

0217

0218

0' $\mathrm{i} 9$

0.200

0221

02

0223

0) 224

0225

0226

0) 227

0220

0229

0230

021

ora

0.233

023

$02 \geq 5$

0236

$02 \%$

0236

0239

0240

024

$024:$

0243

O2.4

0245

0246

6947

0248

0249

02100

0)?

ores

0

0 a

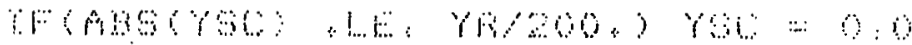

bus fires t 1.0

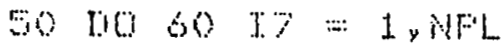

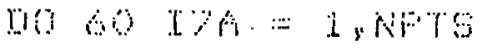

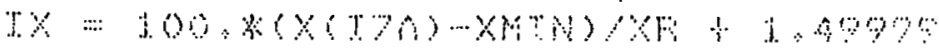

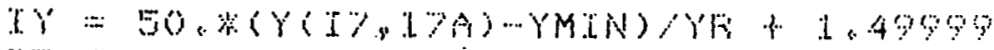

JF (XY : ME: IYT)

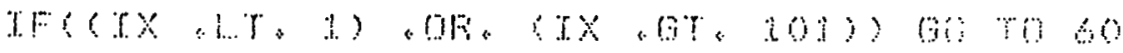

TF (NFL,EG J) LTNE $(J X)=$ SYMUI

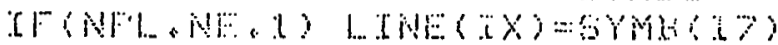

60 Com? Tive:

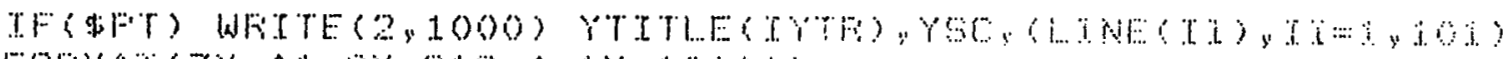

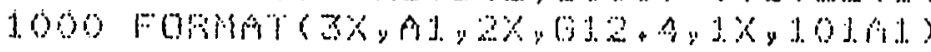

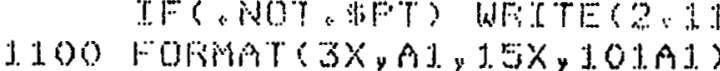

TH(T.

yo contritu:

Q0 $\mathrm{F} \times \mathrm{s}: \cdots, 0$

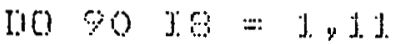

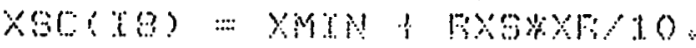

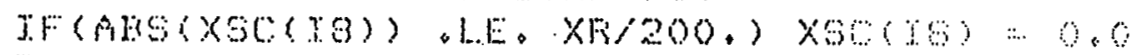

$901 \times 3=1 \times 3+1: 0$

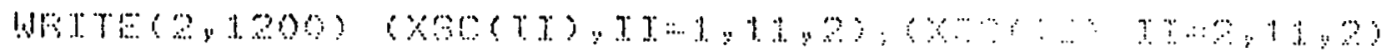

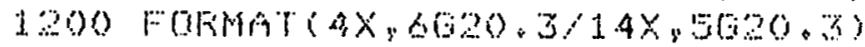

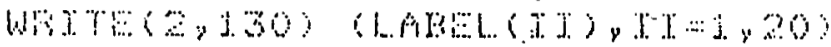

130 Frowet $630 \times 2002 \%$

FETUFi

ENI

C

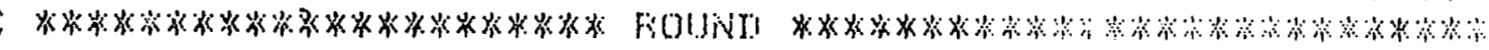

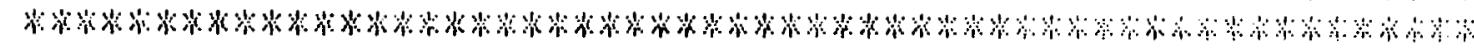

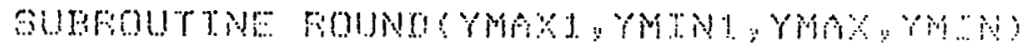

TIMENGION GEOMU $\mathrm{L} 2)$

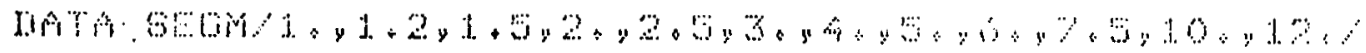

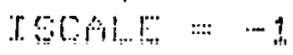

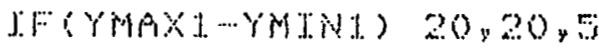

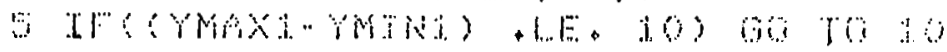

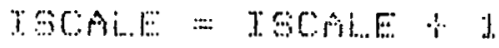

YMAXI := YMAXI,10.

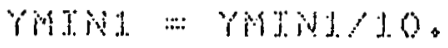

(a) TO

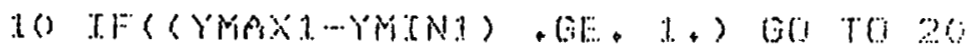

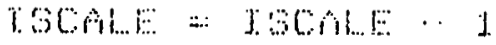

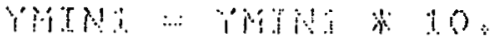

TMAxi

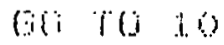

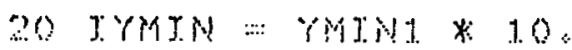

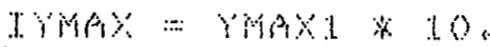

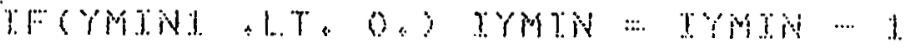

IF (YMAXI , OT, O, IYMAX - IYMAX \&

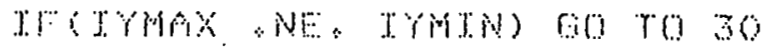




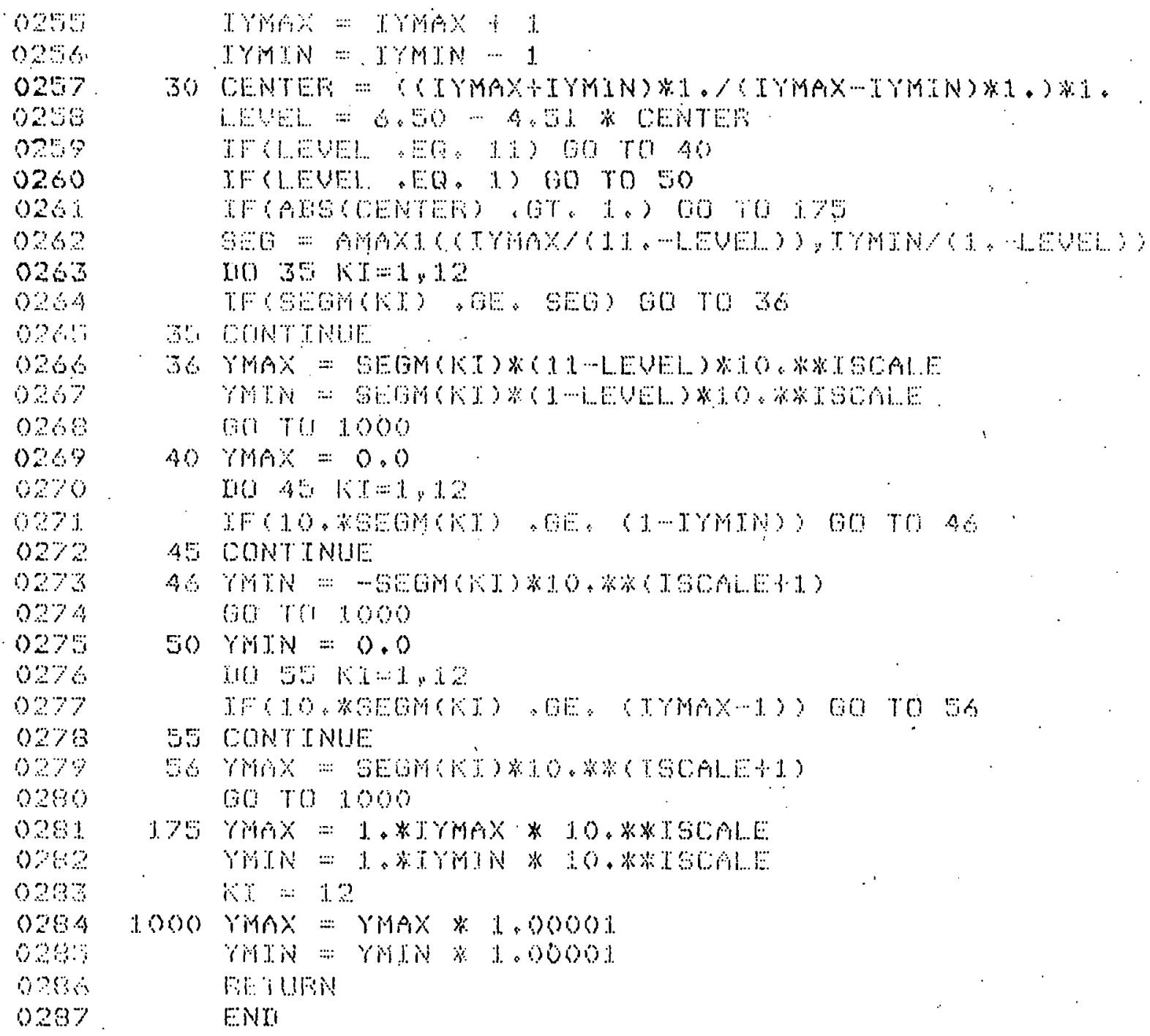

